\title{
In-Situ Creep Testing Capability Development for Advanced Test Reactor
}

B. G. Kim

J. L. Rempe

D. L. Knudson

K. G. Condie

B. H. Sencer

August 2010

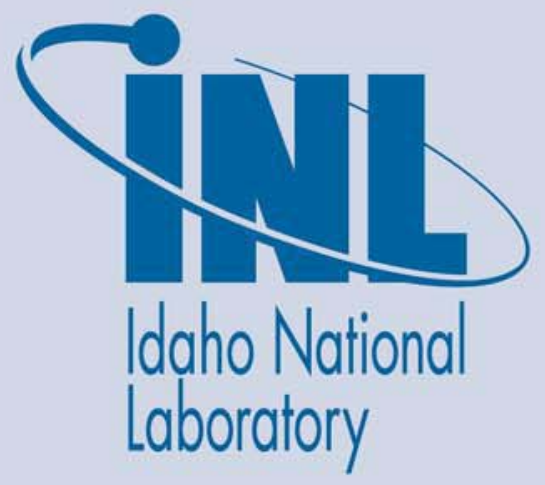

The INL is a U.S. Department of Energy National Laboratory operated by Battelle Energy Alliance 


\section{DISCLAIMER}

This information was prepared as an account of work sponsored by an agency of the U.S. Government. Neither the U.S. Government nor any agency thereof, nor any of their employees, makes any warranty, express or implied, or assumes any legal liability or responsibility for the accuracy, completeness, or usefulness of any information, apparatus, product, or process disclosed, or represents that its use would not infringe privately owned rights. References herein to any specific commercial product, process, or service by trade name, trademark, manufacturer, or otherwise, does not necessarily constitute or imply its endorsement, recommendation, or favoring by the U.S. Government or any agency thereof. The views and opinions of authors expressed herein do not necessarily state or reflect those of the U.S. Government or any agency thereof. 
INL/EXT-10-17779

\section{In Situ Creep Testing Capability Development for the Advanced Test Reactor}

B. G. Kim, J. L. Rempe, D. L. Knudson, K. G. Condie and B. H. Sencer

August 2010

Idaho National Laboratory

Idaho Falls, Idaho 83415

Prepared for the

U.S. Department of Energy

Office of Nuclear Energy

Under DOE Idaho Operations Office

Contract DE-AC07-05ID14517 



\section{CONTENTS}

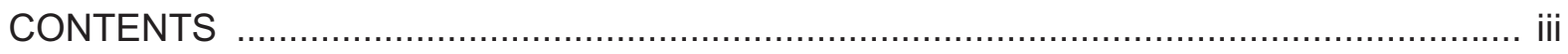

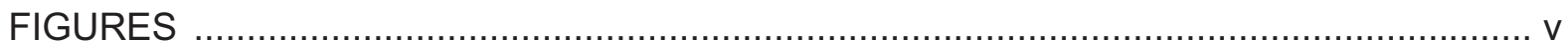

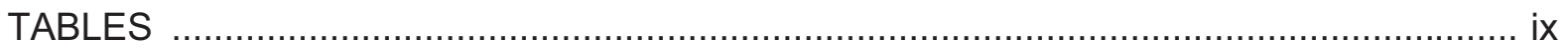

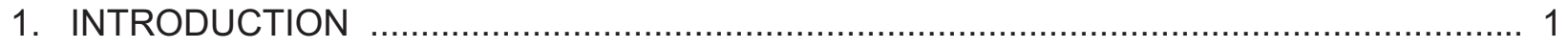

1.1. Objective of Creep Test Rig Development Activities ............................................ 2

1.2. Overall Objective of Autoclave Testing Effort ................................................. 2

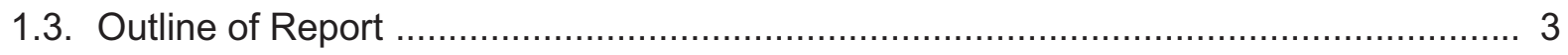

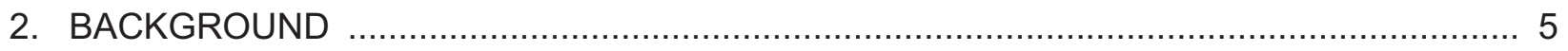

2.1. Belgium (In-Pile Tensile Testing in BR2) …............................................... 5

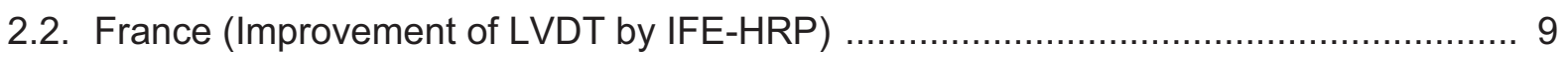

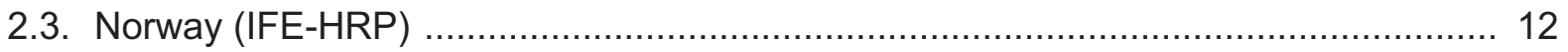

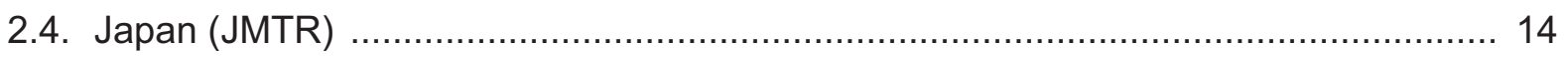

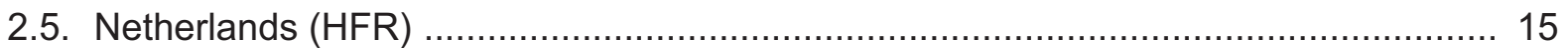

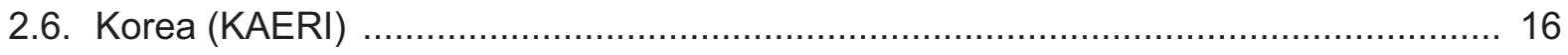

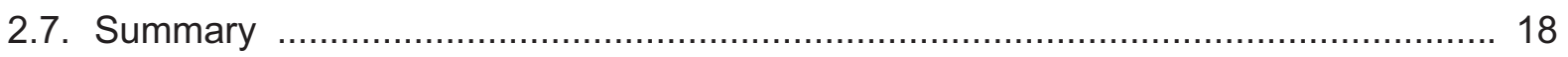

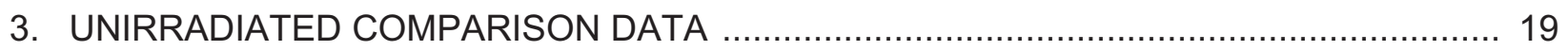

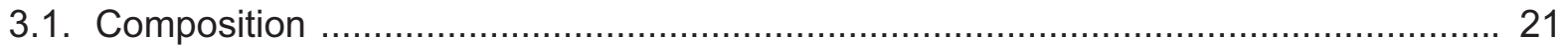

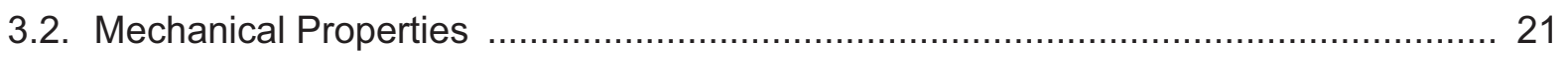

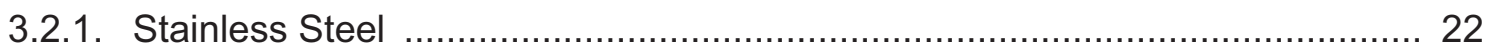

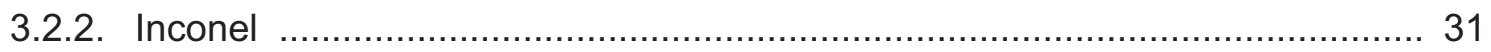

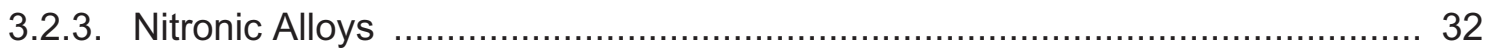

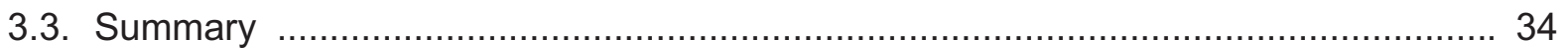

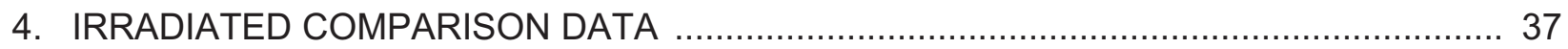

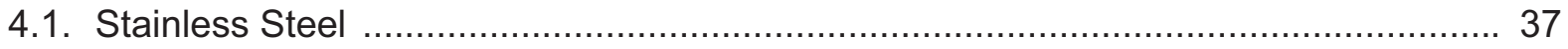

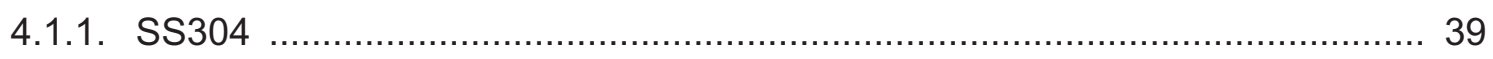

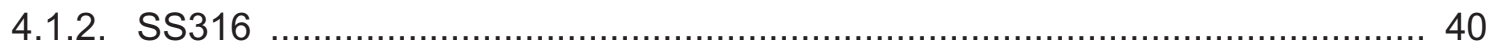

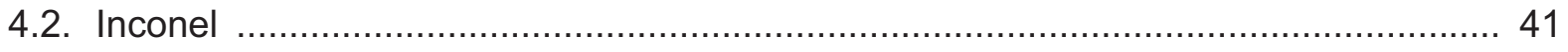

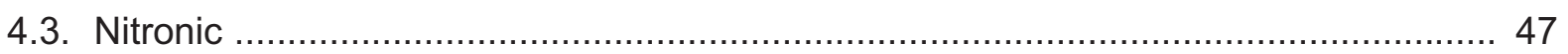

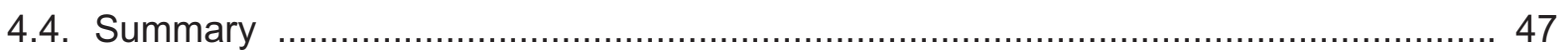

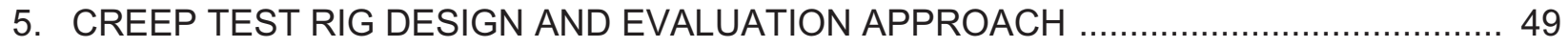

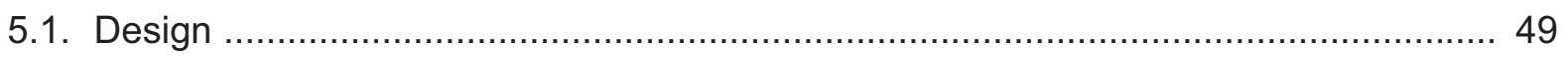

5.2. ABAQUS Evaluations for Gamma Heating Effects ....................................... 52

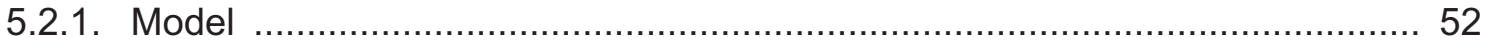

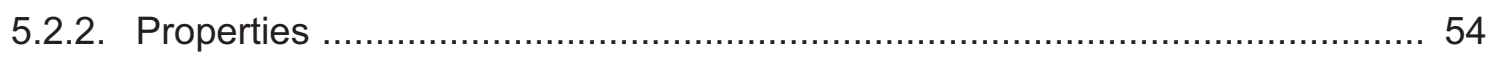




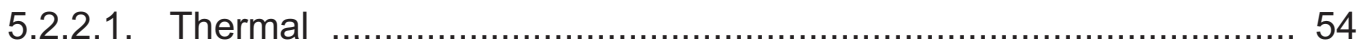

5.2.2.2. Gamma Heating …................................................... 56

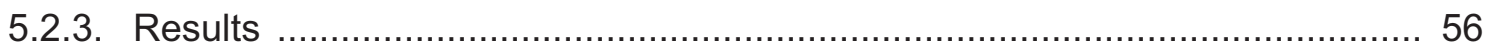

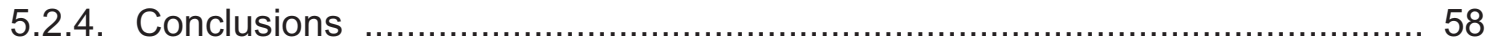

5.3. Autoclave and Associated Equipment ....................................................... 59

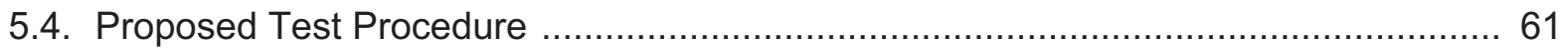

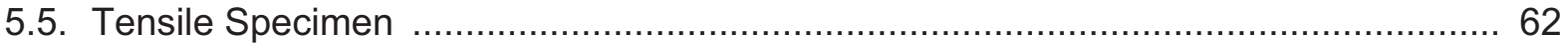

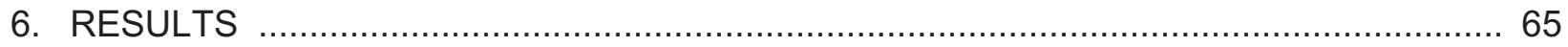

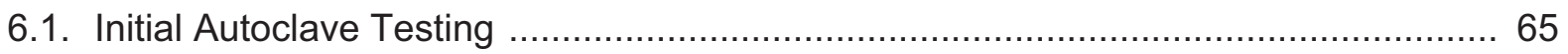

7. SUMMARY AND RECOMMENDATIONS FOR ATR PWR LOOP TESTS ..................... 69

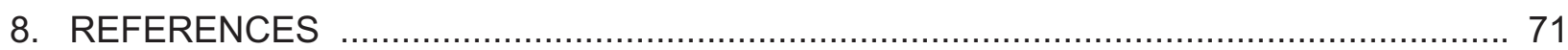




\section{FIGURES}

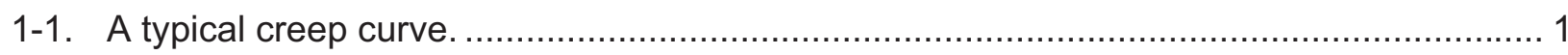

2-1. Schematic of tensile test module: (1) gas line, (2) pneumatic loading unit, (3) firm specimen fixing point, (4) specimen, (5) movable specimen fixing point, (6) LVDT plunger and (7) LVDT holder.

2-2. Actual tensile test rig for BR-2 irradiations: (a) simplified layout and operational features including necessary instrumentation; and (b) final assembly of test module prior to installation in the test rig. 7

2-3. High temperature calibration device of the pneumatic loading unit................................ 8

2-4. Bellows stiffness and friction fall of the pneumatic loading unit as a

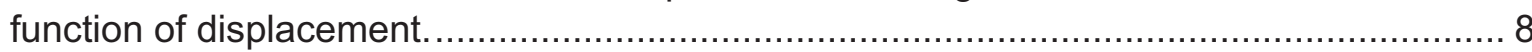

2-5. The measured and calculated loads of the bellows.................................................. 9

2-6. Principle of LVDT (a: primary coil; b: secondary coils; c: magnetically

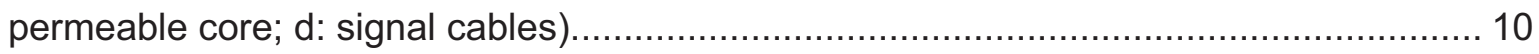

2-7. Wiring schematic for LVDTs using the five-wire method........................................... 11

2-8. Proposed sensor for detecting elongation and diameter changes in OSIRIS testing.

2-9. Illustration of instrumented tensile specimen used in stress relaxation study; instrumentation includes bellows that allows online variation applied load (stress), temperature control through gas lines and monitoring of specimen elongation by means of LVDT.

2-10. Example of online changes in stress that are made as specimen elongation on order 2-6 $\mathrm{mm}$ recorded by means of LVDT.

2-11. Elongation data recorded for CW 316 SS and CW $316 \mathrm{LN}$

2-12. Schematic diagram of irradiation creep capsule (94M-2A) under a high thermal neutron flux condition in JMTR.

2-13. (a) Effect of neutron irradiation on creep curves and (b) Effect of neutron irradiation on the steady-state creep rate of type of type 304 stainless steel.

2-14. Comparison of creep curves of in-pile (94M-2A [high thermal flux] and 94M-3A [thermal shielded]), post-irradiation (93M-33A, 93M-37A and

$94 \mathrm{M}-1 \mathrm{~A})$ tests and unirradiated material.

2-15. Conceptual design and selected components of HANARO irradiation creep capsule. ..... 17

3-1. An outline of PWR components and materials. (Image courtesy of R. Staehle. ${ }^{19}$ )........... 19

3-2. An outline of BWR components and materials. (Image courtesy of R. Staehle. ${ }^{19}$ )........... 20

3-3. Typical stress-strain curves for Types 301 and 304 stainless steel. ............................. 25

3-4. Stress-strain diagrams for type 304 stainless steel as a function of temperature. ............ 25

3-5. Temperature-dependent SS304 yield strength and tensile strength data. ${ }^{33}, 35,36,38 \ldots \ldots .26$

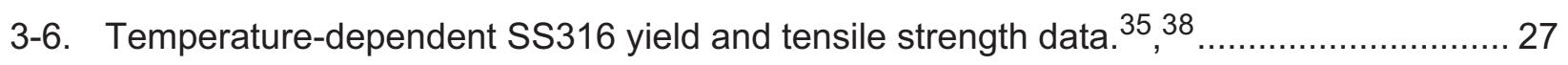

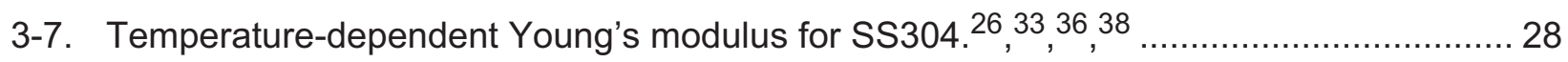

3-8. Temperature-dependent engineering stress - strain curves for (a) annealed 
316LN, (b) annealed 316, (c) annealed 304, and (d) 20\% cold-worked 316LN. ${ }^{38}, 39$

3-9. Temperature-dependent yield and ultimate tensile strength for stainless steels............. 30

3-10. Temperature-dependent SS304 stress-strain data and the corresponding bilinear fit. ..... 30

3-11. Temperature-dependent engineering stress-strain curves for 304 stainless steel........... 31

3-12. Mechanical properties of (a) Inconel 600, (b) Inconel 718 and (c) Inconel X-750........... 32

3-13. Inconel 600 ultimate strength-INL test results compared with Special Metals data. ${ }^{33}$...... 33

3-14. Young's Modulus of Inconel 600, 718 and X-750 as a function of temperature ................ 33

3-15. Yield strength, tensile strength and elongation of Nitronic 50 as a function of temperature. 34

3-16. Young's Modulus of Nitronic 50 as a function of temperature..................................... 34

4-1. The length changes of specimen of AMCR-0033 annealed at $400^{\circ} \mathrm{C}$ are plotted versus the neutron dose.

4-2. Measured DD/Do versus dose for the unstressed capsules (P-19, P-21), the capsules with a hoop stress of $69 \mathrm{MPa}(\mathrm{P}-32, \mathrm{P}-39, \mathrm{P}-49)$, and the capsules with a hoop stress of $188 \mathrm{MPa}(\mathrm{P}-38, \mathrm{P}-48)$....

4-3. Measured DD/Do versus dose for the unstressed capsules (P-19, $\mathrm{P}-21)$, the capsules with a hoop stress of $69 \mathrm{MPa}$ (P-32, P-39, P-49), and the capsules with a hoop stress of $188 \mathrm{MPa}(\mathrm{P}-38, \mathrm{P}-48)$ in the low dose region............................. 41

4-4. Engineering stress-strain curves for irradiated austenitic stainless steels.

4-5. Calculated stress dependence of irradiation creep strain of SS316 at 2 dpa for $60{ }^{\circ} \mathrm{C}$ and $300{ }^{\circ} \mathrm{C}$.

4-6. Engineering stress-strain curves of precipitation-hardened Inconel 718 (PH IN718) and solution-annealed Inconel 718 (SA IN718) at various doses.....

4-7. True stress-true strain curves of precipitation-hardened Inconel 718 (PH IN718) and Solution-annealed Inconel 718 (SA IN718).

4-8. Yield stress versus irradiation temperature, Ti, for Alloy 718 in the solution treated condition, irradiated $\sim 20 \mathrm{dpa}$ and tested at three different temperatures.

4-9. Creep test tube geometry 46

4-10. Irradiation rig showing the location of the specimens and dosimeters. ........................ 46

4-11. Creep strain as a function of neutron fluence ..................................................... 47

4-12. Creep strain as a function of applied stress and neutron dose. ................................ 48

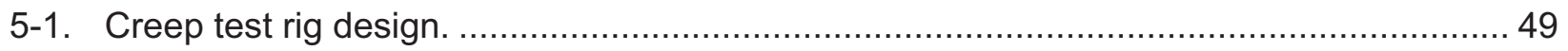

$5-2$. Schematic of test rig positioned in autoclave for testing ....................................... 50

5-3. Photo of creep test rig assembly, tensile specimen and autoclave fixturing. ..................50

5-4. Test rig inserted into fixture with positioning stand-offs used in the autoclave.................51

5-5. Abaqus model of a radial cross-section through key components of the

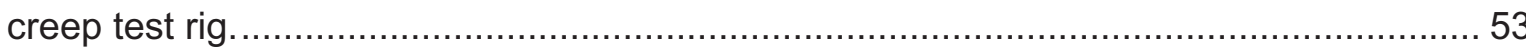

5-6. Inconel 600 and iron gamma heat rates (as projected for Cycle 143B). ...................... 57

5-7. Maximum LVDT coil temperature as a function of position relative to the core midplane. 
5-8. Temperature contours (in K) for key components of the creep test rig irradiated $76.7 \mathrm{~cm}$ above the ATR core midplane during Cycle 143B (with a projected center lobe power of $27.6 \mathrm{MW}$ )

5-9. Temperature contours (in K) for the LVDT coil irradiated $76.7 \mathrm{~cm}$ above the ATR core midplane during Cycle 143B (with a projected center lobe power of $27.6 \mathrm{MW}$ ).

5-10. Autoclave and supporting equipment layout.

5-11. Estimated stress for candidate specimen sizes assuming 2250 psi test pressure. 63

6-1. Creep test rig results for a $2 \mathrm{~mm}$ diameter / $28 \mathrm{~mm}$ long SS304 specimen. 66

6-2. Load frame results for a $2 \mathrm{~mm}$ diameter / $28 \mathrm{~mm}$ long SS304 specimens. 67 
INL/EXT-10-17779 


\section{TABLES}

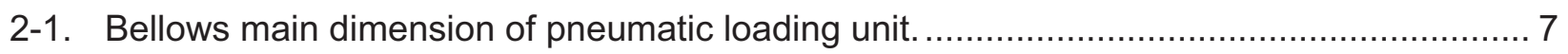

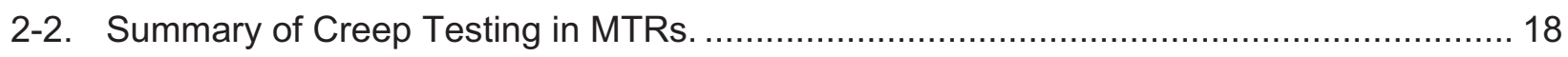

3-1. Typical chemical composition of stainless steel 304 and 316 (in wt\%) ....................... 21

3-2. Typical chemical composition of Inconel 600, 718 and X-750 (in wt\%). ${ }^{22} \ldots \ldots \ldots \ldots \ldots \ldots \ldots . . . . . . . . . . .22$

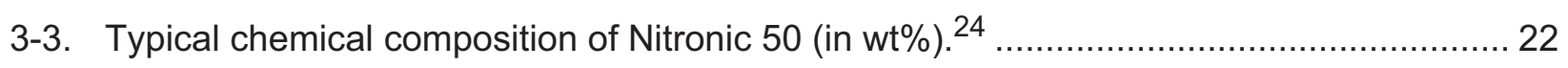

3-4. Typical room temperature $\left(20\right.$ to $\left.25^{\circ} \mathrm{C}\right)$ properties of SS, Inconel and Nitronic............... 23

3-5. Summary of stainless steel data reviewed from the literature..................................... 24

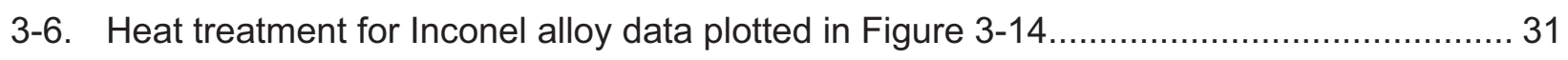

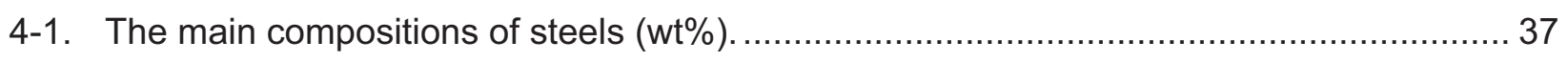

$5-1$. Summary description of components in creep test rig....................................... 51

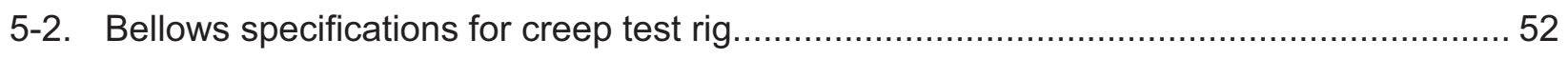

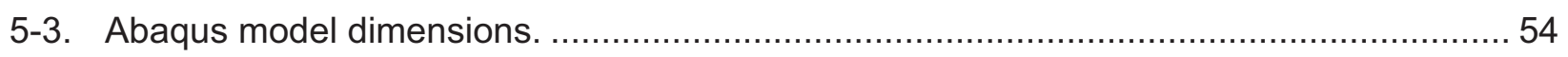

5-4. Thermal conductivies used in modeling key components of the creep test rig. ...............55

5-5. Conductance values used in modeling key components of the creep test rig..................56

5-6. Radiation properties used in creep test rig He/Ar gaps......................................... 56

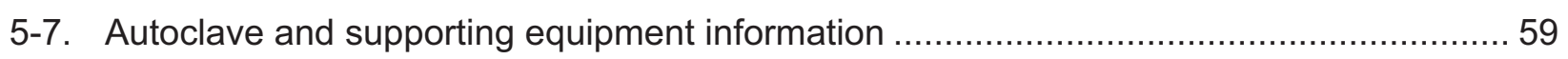

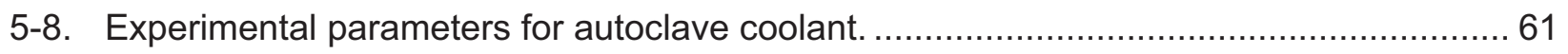


INL/EXT-10-17779 


\section{INTRODUCTION}

Creep is the slow, time-dependent strain that occurs in a material under a constant stress (or load) at high temperature. High temperature is a relative term, dependent on the materials being evaluated. A typical creep curve is shown in Figure 1-1. In a creep test, a constant load is applied to a tensile specimen maintained at a constant temperature. Strain is then measured over a period of time. The slope of the curve, identified in the figure below, is the strain rate of the test during Stage II or the creep rate of the material. Primary creep, Stage I, is a period of decreasing creep rate due to work hardening of the material. Primary creep is a period of primarily transient creep. During this period, deformation takes place and the resistance to creep increases until Stage II, Secondary creep. Stage II creep is a period with a roughly constant creep rate. Stage II is referred to as steady-state creep because a balance is achieved between the work hardening and annealing (thermal softening) processes. Tertiary creep, Stage III, occurs when there is a reduction in cross sectional area due to necking or effective reduction in area due to internal void formation; that is, the creep rate increases due to necking of the specimen and the associated increase in local stress.

In terms of dislocation theory, dislocations are generated continuously in the primary stage of creep. With increasing time, more and more dislocations are present. These dislocations increasingly interfere with each other's movement, thus causing the creep rate to decrease. In the secondary stage, a situation arises where the number of dislocations being generated is exactly equal to the number of dislocations being removed by annealing. This dynamic equilibrium causes the metal to creep at a constant rate. Eventually, however, the creep rate increases; and the specimen fails due to localized necking of the specimen (or component), void and micro crack formation at the grain boundaries, and various metallurgical effects such as coarsening of precipitates. When in service, an engineering component should never enter the tertiary stage of creep. It is therefore the secondary creep rate, which is of prime importance as a design criterion. Components, which are subject to creep, spend most of their lives in the secondary stage, so it follows that the metals or alloys chosen for such components should have as small a secondary creep rate as possible. In general, it is the secondary creep rate, which determines the life of a given component.

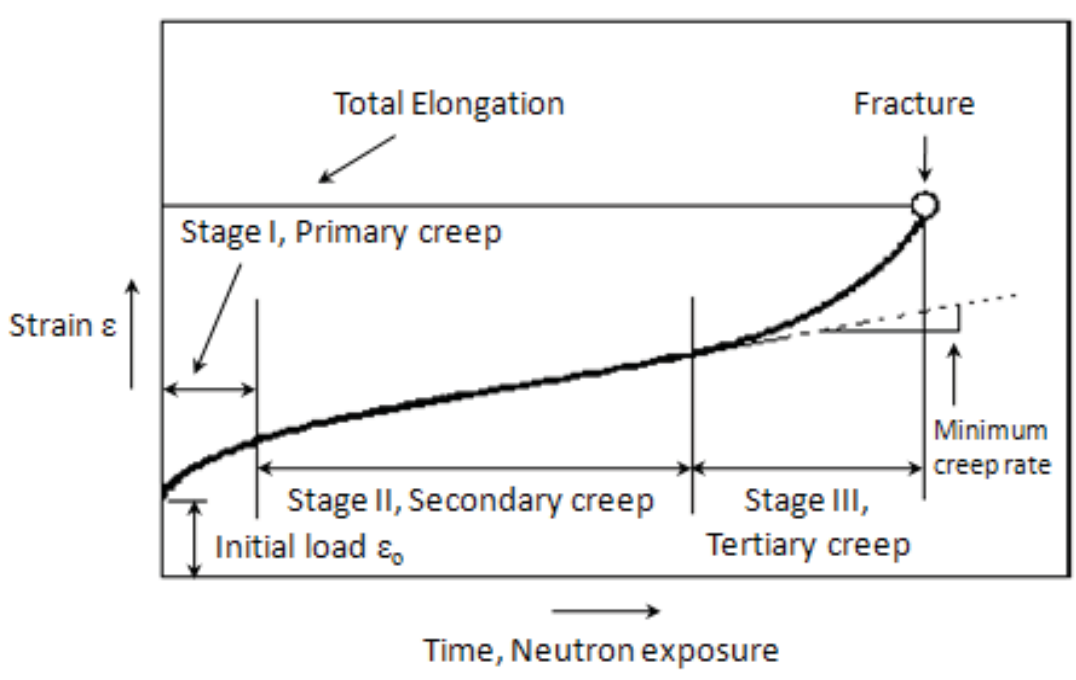

Figure 1-1. A typical creep curve. 
Irradiation creep is the additional strain that occurs as a result of the combined effect of irradiation and stress in materials. The strain occurring in the absence of irradiation is generally called thermal creep. Performance of fuel, cladding tubes, reactor pressure vessel, and other in-core components of nuclear power reactors can be affected by dimensional changes associated withcreep. Hence, it becomes necessary to determine the amount of creep expected to be suffered by a component during its lifetime in a reactor. This will enable the designer to assess the useful life of the component in the reactor and design suitable components after taking irradiation creep into consideration.

Often, radiation-induced creep is measured using a 'cook and look' approach where samples are irradiated in-situ for a period of time, removed from the reactor, measured, and then returned to the reactor. Repetition of this process can be expensive and time-consuming. Furthermore, it has the potential to disturb the phenomena of interest. Hence, it is desirable to obtain in-situ measurements of sample creep. This report documents the status of efforts by the Idaho National Laboratory (INL) to develop an in-situ creep testing capability for the Advanced Test Reactor (ATR). In particular, this document focuses on efforts to evaluate a prototype test rig in an autoclave at INL's High Temperature Test Laboratory (HTTL). In addition, comparison data are obtained for evaluating results from these autoclave tests.

\subsection{Objective of Creep Test Rig Development Activities}

As part of the ATR National Scientific User Facility (NSUF), efforts were initiated to develop an instrumented creep testing capability for specimens irradiated in Light Water Reactor (LWR) coolant conditions at the ATR. The test rig was developed such that samples will be subjected to similar loads as test rigs at the Halden Boiling Water Reactor (HBWR), e.g., applied loads ranging from 92 to $350 \mathrm{MPa}$ at temperatures between 290 and $370{ }^{\circ} \mathrm{C}$ up to at least 2 dpa. Efforts during FY08 and 09 focussed on finalizing a prototype test rig design and preparing equipment for autoclave testing of specimens in this prototype test

rig during FY10. ${ }^{1}$ Results from these autoclave tests will be used to develop a final design that will be inserted into an ATR PWR loop during FY11.

\subsection{Overall Objective of Autoclave Testing Effort}

As noted above, FY10 creep test rig development efforts are focussed on testing a prototype at INL's HTTL. The objectives of prototype testing include:

- Creep test rig checkout and verification that it can withstand PWR coolant conditions.

- Verification that signal processing equipment operates properly.

- Calibration of the creep test rig using samples with known creep behavior.

- Provide insights to finalize the design for creep test rig evaluations in an ATR PWR loop.

As noted within this document, the third step requires developing an understanding of the behavior of the creep test rig performance. Multiple autoclave tests were completed with different sample geometries and test materials to develop this understanding. Although it is recognized that irradiation-enhancement will make this calibration more difficult, a plan has been developed to allow similar calibration activities for in-pile testing of this setup. 


\subsection{Outline of Report}

As noted above, this report documents efforts to evaluate a prototype test rig in an autoclave at INL's HTTL. Section 2 of this report summarizes other efforts to develop in-pile creep testing capabilities at Materials and Test Reactors (MTRs). Section 3 provides an overview of creep and tensile data for unirradiate materials of interest for in-pile creep testing. These data were used to assess the performance of the new test rig. Section 4 provides an overview of available data for irradiated materials that will be used for comparison with data obtained from specimens in the ATR. Section 5 describes the design of the creep test rig and the HTTL autoclave test setup. Results from an ABAQUS thermal analysis to evaluate the impact of gamma heating in the ATR are also presented in this section. Section 6 presents data obtained from autoclave tests. Section 7 summarizes conclusions and recommendations from this effort. References cited in this document are listed in Section 8. 
INL/EXT-10-17779 


\section{BACKGROUND}

Generally, the effects of irradiation on material mechanical properties, are evaluated by completing irradiation tests in MTRs (Material Test Reactors) followed by PIE (Post Irradiation Examination). During the last 50 years, a large number of these tests have been performed to analyze the degradation of mechanical properties as a function of fluence (or dpa; displacement per atom) and temperature. Then, these results are used to assess the safety and lifetime of materials used in structural components of operating nuclear power plants. Recently, it is increasingly emphasized that the research on neutron irradiation effects of materials is necessary in order to assess the integrity and lifetime extension of operating Nuclear Power Plants (NPPs) and to develop fuels and materials supporting advanced reactor systems. During irradiation tests of materials in MTRs, it is desirable to measure characteristic changes in a variety of ways, including remote sensing and in situ observations. Of these measurements, the effort is currently progressing to measure dimensional changes (elongation) of materials during in-pile creep tests in MTRs. This section summarizes key international in-pile creep testing efforts and results in MTRs.

There are two types of creep tests completed in MTRs. The first are instrumented tests with online monitoring and controlling of test conditions and real-time detection of creep rate. The second are noninstrumented tests with specimen evaluations completed outside the reactor and test parameters derived from reactor operating conditions. In instrumented experiments, parameters, such as specimen temperature, the load exerted on the specimen, and specimen elongation, are monitored and/or controlled using suitable sensors (extensometers, LVDTs, bellows, optical transducers, thermocouples, small heaters, etc.) that are positioned in close proximity to the specimen under investigation. Instrument selection should consider effects of radiation inside the reactor on their performance. Instrumented experiments are complicated to design and expensive. Very few instrumented experiments can be carried at a time due to limited test positions and space available in MTRs. Non-instrumented experiments are comparatively simple in design, enable larger numbers of specimens to be tested at a time, and less expensive to manufacture. However, irradiation creep using non-instrumented devices is measured using a 'cook and look' approach where samples are irradiated in-situ for a period of time, removed from the reactor, measured outside the reactor, and then returned to the reactor. Repetition of this process can be expensive, time-consuming, and has the potential to disturb the phenomena of interest. Creep tests with in-situ measurement of specimen elongation by instrumentations under irradiation are able to offer more detailed information of creep behavior of material. Therefore, instrumented experiments offer control over experimental variables and improved accuracy of data than possible in non-instrumented experiments.

\subsection{Belgium (In-Pile Tensile Testing in BR2)}

As part of the European Fusion Development Agreement (EFDA), in-reactor uniaxial tensile tests at a constant strain rate were performed in the BR2 reactor at Mol, Belgium. ${ }^{2-3}$ The purpose of this work was to design, construct and calibrate a tensile loading module for instrumented tensile tests in the BR2. This tensile loading module, as shown in Figure 2-1, was developed by the VTT Technical Research Center of Finland, and the actual test rig with this module was developed as shown in Figure 2-2 by Mol for irradiations in the BR-2. The materials used in this test were thin $(0.3 \mathrm{~mm})$ sheets of oxygen free high conductivity (OFHC) copper containing 10,3<1 ppm, and $<1 \mathrm{ppm}$, respectively, of $\mathrm{Ag}, \mathrm{Si}, \mathrm{Fe}$ and $\mathrm{Mg}$, and $\mathrm{CuCrZr}$ alloy because these materials are expected to be exposed to thermal and mechanical loads in ITER (International Thermonuclear Experimental Reactor). This work has shown that it is technically feasible to carry out well-defined, controlled dynamic in-reactor tensile tests, making it possible to investigate the intrinsic 
role of applied stress and displacement damage acting concurrently in determining the global deformation behavior of the material under dynamic irradiation conditions.

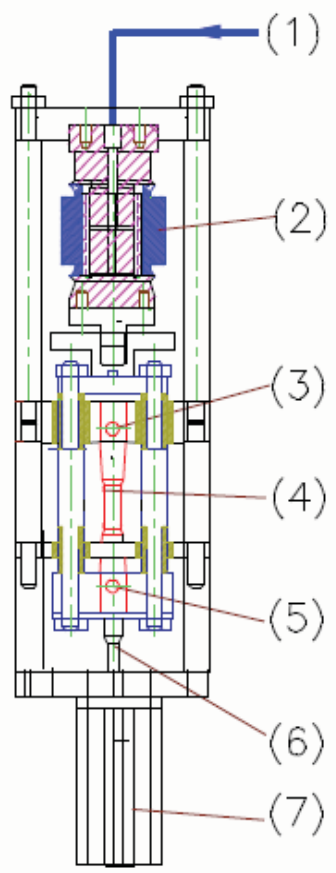

Figure 2-1. Schematic of tensile test module: (1) gas line, (2) pneumatic loading unit, (3) firm specimen fixing point, (4) specimen, (5) movable specimen fixing point, (6) LVDT plunger and (7) LVDT holder.

The load generated by the pneumatic loading unit with the metallic bellows is calculated from the pressure difference experienced by the bellows. The stiffness and effective cross section of the bellows impacts the load produced by the specimen. However, the "stiffness" of the pneumatic loading unit differs from the stiffness of the bellows. Hence, as shown in Figure 2-3, VTT developed a calibration unit to correlate the applied gas pressure in the bellows with the actual load acting on the tensile specimen. A two step calibration procedure was implemented. In the first step, the characteristic stiffness of the bellows together with friction forces of the moving parts of the module were determined. As shown in Figure 2-4, the pressure loss (arising from the metal bellows' stiffness and internal parts) and the friction fall of the pneumatic loading unit can be determined over its working range. In the second step, the load induced on the tensile specimen by the applied gas was measured directly by a load cell. As shown in Figure 2-5, the interaction of pressure and load was determined by performing constant displacement rate tests with demonstration specimens. Selection of the demonstration specimen depends on the working range of the real test specimens to be used. Key parameters for the bellows used in the pneumatic loading unit are shown in Table 2-1. 

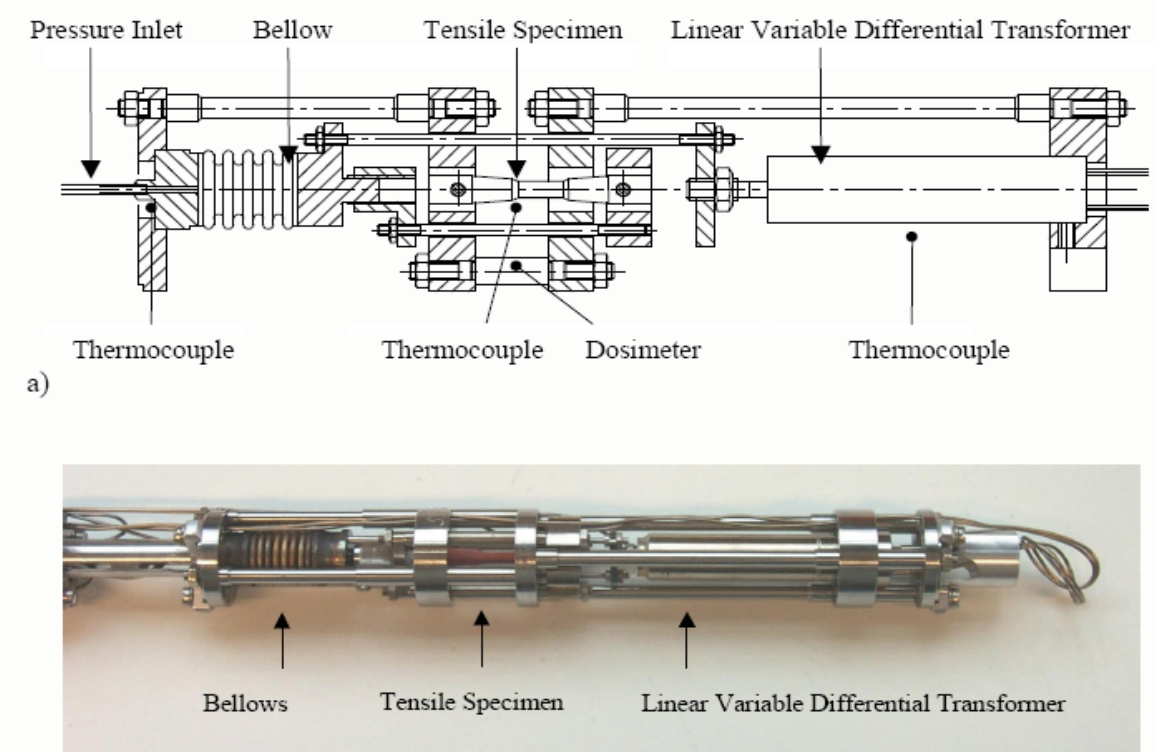

b)

Figure 2-2. Actual tensile test rig for BR-2 irradiations: (a) simplified layout and operational features including necessary instrumentation; and (b) final assembly of test module prior to installation in the test rig.

Table 2-1. Bellows main dimension of pneumatic loading unit.

\begin{tabular}{|c|c|}
\hline Bellows specification & Value \\
\hline Internal diameter & $12.5 \mathrm{~mm}$ \\
External diameter & $19.0 \mathrm{~mm}$ \\
Elastic deformation per convolution (axial) & $+/-0.15 \mathrm{~mm} / \mathrm{conv}$ \\
Spring rate per convolution & $813 \mathrm{~N} / \mathrm{mm} /$ conv \\
Effective bellows cross section & $189 \mathrm{~mm}{ }^{2}$ \\
Number of convolution & 7 \\
Axial movement for whole bellows & $+/-1.05 \mathrm{~mm}$ \\
Maximum pressure & $15 \mathrm{MPa}$ \\
\hline
\end{tabular}

The inside pressure of the bellows, its stiffness (i.e., spring rate), and the friction fall of the pneumatic loading unit are needed to calculate the force acting on the test specimen. The force induced by the pneumatic loading unit can be calculated from the following formula: 


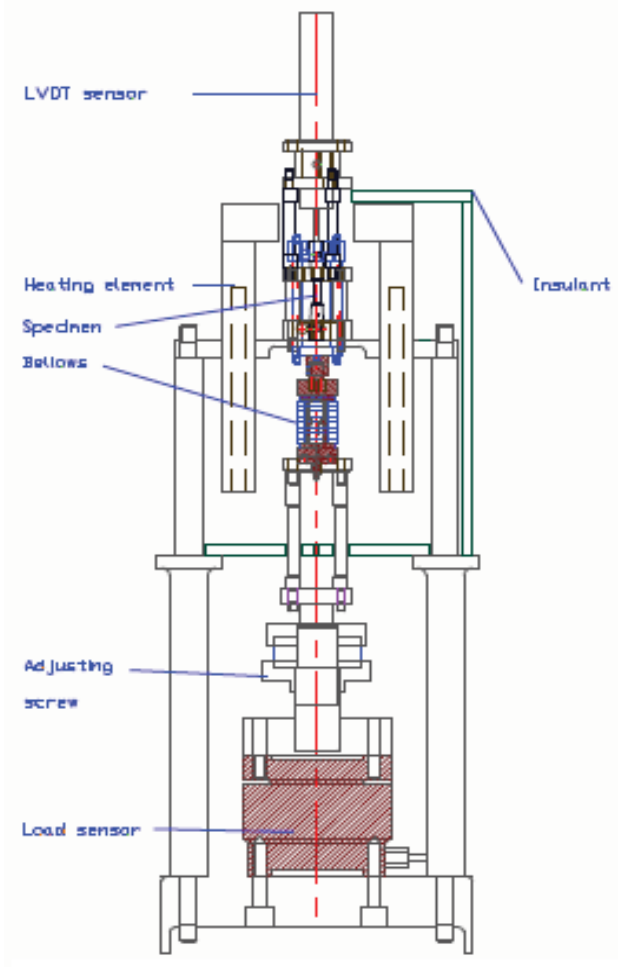

Figure 2-3. High temperature calibration device of the pneumatic loading unit.

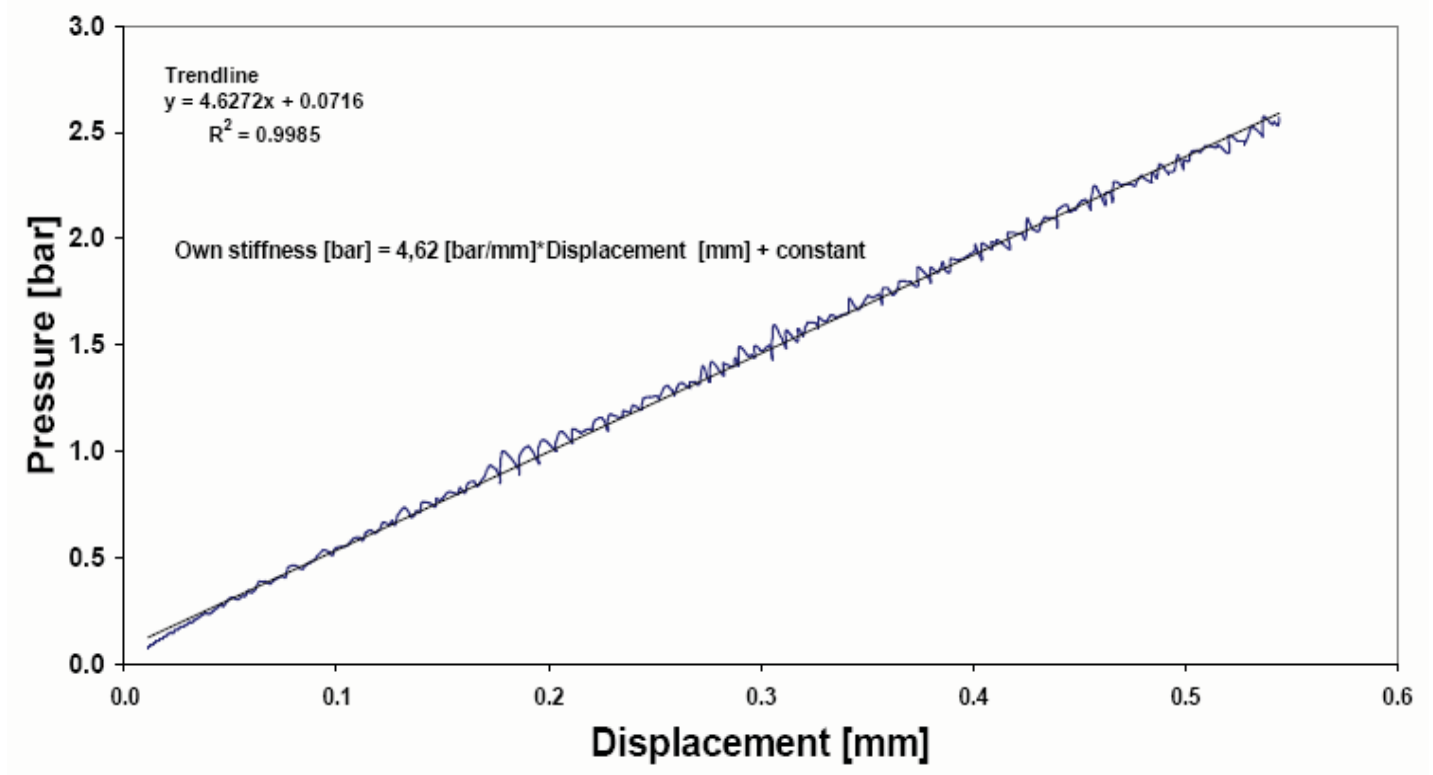

Figure 2-4. Bellows stiffness and friction fall of the pneumatic loading unit as a function of displacement. 


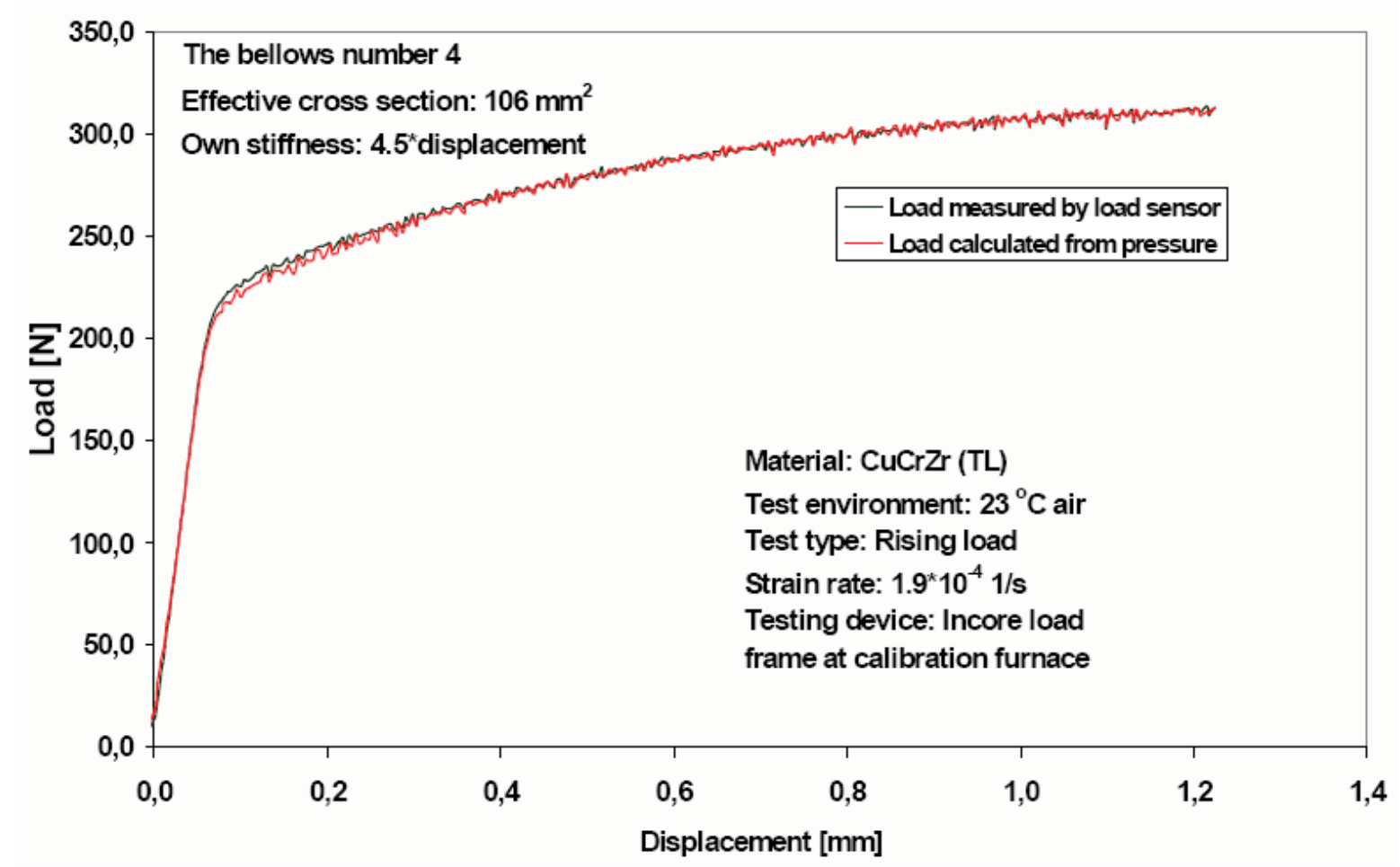

Figure 2-5. The measured and calculated loads of the bellows.

$$
\begin{aligned}
& F=p A_{\text {eff }}-F_{\mu}-F_{s} \\
& F_{s}=c_{\delta} \delta_{b} n_{w} \\
& \text { where } \\
& F \quad=\text { load }[\mathrm{N}] \\
& F_{s} \quad=\text { load required to expand the bellows }[\mathrm{N}] \\
& F_{\mu} \quad=\text { friction fall }[\mathrm{N}] \\
& p \quad=\text { pressure }[\mathrm{MPa}] \\
& A_{e f f} \quad=\text { bellows effective cross section }\left[\mathrm{m}^{2}\right] \\
& \mathrm{c}_{\delta} \quad=\text { axial spring rate for the bellows }[\mathrm{N} / \mathrm{mm}] \\
& \delta_{b} \quad=\text { required axial movement for the whole bellows }[\mathrm{mm}] \\
& n_{w} \quad=\text { number of convolutions. }
\end{aligned}
$$

\subsection{France (Improvement of LVDT by IFE-HRP)}

It is well known that Linear Variable Differential Transformers (LVDTs) are usually applied to measure the position of a magnetically permeable core (attached to a specimen due to the signals that it induces 
in the primary and secondary coils surrounding the core. The Institute for Energy Technology/Halden Reactor Project (IFE/HRP) has developed a wide range of specialized sensors, equipment and techniques to perform in-core measurements during irradiation tests in the HBWR (Halden Boiling Water Reactor). IFE/HRP in-core sensors for fuel and material performance can detect fuel temperature, fission gas release, fuel swelling/densification, cladding creep, corrosion/crud buildup, and crack-growth rates. ${ }^{4-8}$ Many of HRP's in-core instrumentation relies upon LVDTs. The LVDT is a versatile instrument used to transform a mechanical movement into an electrical signal. The primary coil is activated by a $400 \mathrm{~Hz}$ constant-current generator and the position of the magnetically-permeable core in relation to the coils affects the balance of the signal from the secondary coils. Thus, any mechanical movement changes the position of the magnetically-permeable core; and the corresponding signal can be measured. The LVDTs are designed to operate under PWR conditions $\left(350{ }^{\circ} \mathrm{C}\right.$ and 150 bar), but they can also be operated for shorter periods up to 500 ${ }^{\circ} \mathrm{C}$. Figure 2-6 shows the principle design of an LVDT.

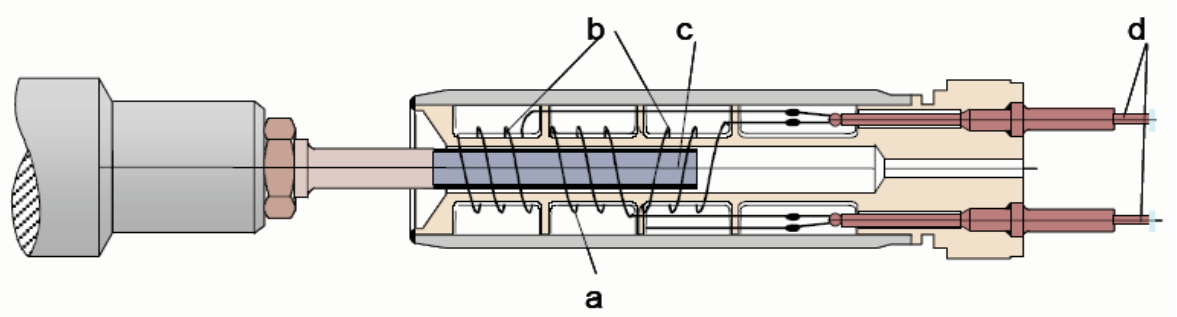

Figure 2-6. Principle of LVDT (a: primary coil; b: secondary coils; c: magnetically permeable core; d: signal cables).

As summarized in Reference 1, CEA (Commissariat à l'Énergy Atomique) has used LVDTs fabricated by the IFE/HRP in the OSIRIS reactor with accuracies of $\pm 4 \mu \mathrm{m}$ and displacements up to $\pm 15 \mathrm{~mm}$ (total range) and $\pm 6 \mathrm{~mm}$ (linear range) since 2005. CEA, in collaboration with IFE/HRP, has recently started an effort to improve the performance of LVDTs. During 2007, CEA performed a series of out-of-pile tests to characterize and try to improve the performance of these LVDTs and diameter gauges based on LVDT sensors. Tests were conducted at room temperature and at higher temperatures (up to $380{ }^{\circ} \mathrm{C}$ ) in inert gas, water, and sodium potassium conditions. As part of this effort, CEA proposed several improvements to LVDT designs currently manufactured by IFE/HRP. First, to extend their measurement range, CEA has requested that a polynomial equation be used to characterize the signal of LVDTs procured from IFE/HRP. Second, CEA requested that IFE/HRP develop a 'fifth wire' or "self compensating electronics setup." Figure 2-7 illustrates the wiring used for such a setup (compared to the standard 4-wire setup that only uses the wires labeled 1, 2, 3, and 4). ${ }^{1,9}$ In this configuration, wire 3 and 4 are Type $\mathrm{K}$ "B" thermocouple wires and wire 5 is a Type $\mathrm{K}$ " $\mathrm{A}$ " thermocouple wire. In a 4-wire configuration, only the voltage difference between the two secondary coils is measured. In particular, the ratio of signals from the secondary are used to quantify elongation rather than the combined secondary signal. As long as the LVDT is at a uniform temperature, the signal should be more accurate (because it is no longer susceptible to Curie temperature effects if all components are simultaneously subjected to the same temperature).

In the MELODIE and MUSCIA tests, it is planned to evaluate the performance of these improved designs in the OSIRIS reactor during 2010. As shown in Figure 2-8, ${ }^{1}$ the MELODIE tests will provide real-time elongation and diameter change data from an in-core irradiation of a PWR fuel cladding tube $(90 \mathrm{~mm})$ at $350{ }^{\circ} \mathrm{C}$. The test capsule includes controlled mechanical loading ranging from 60 to $180 \mathrm{MPa}$ (with stress steps) and variable bi-axial stress ratio: ranging from 0 (hoop stress) to infinity (axial stress). 


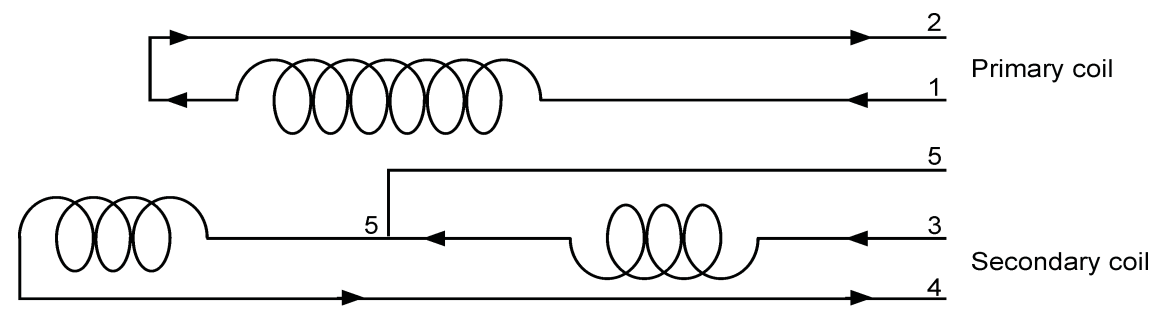

Figure 2-7. Wiring schematic for LVDTs using the five-wire method.
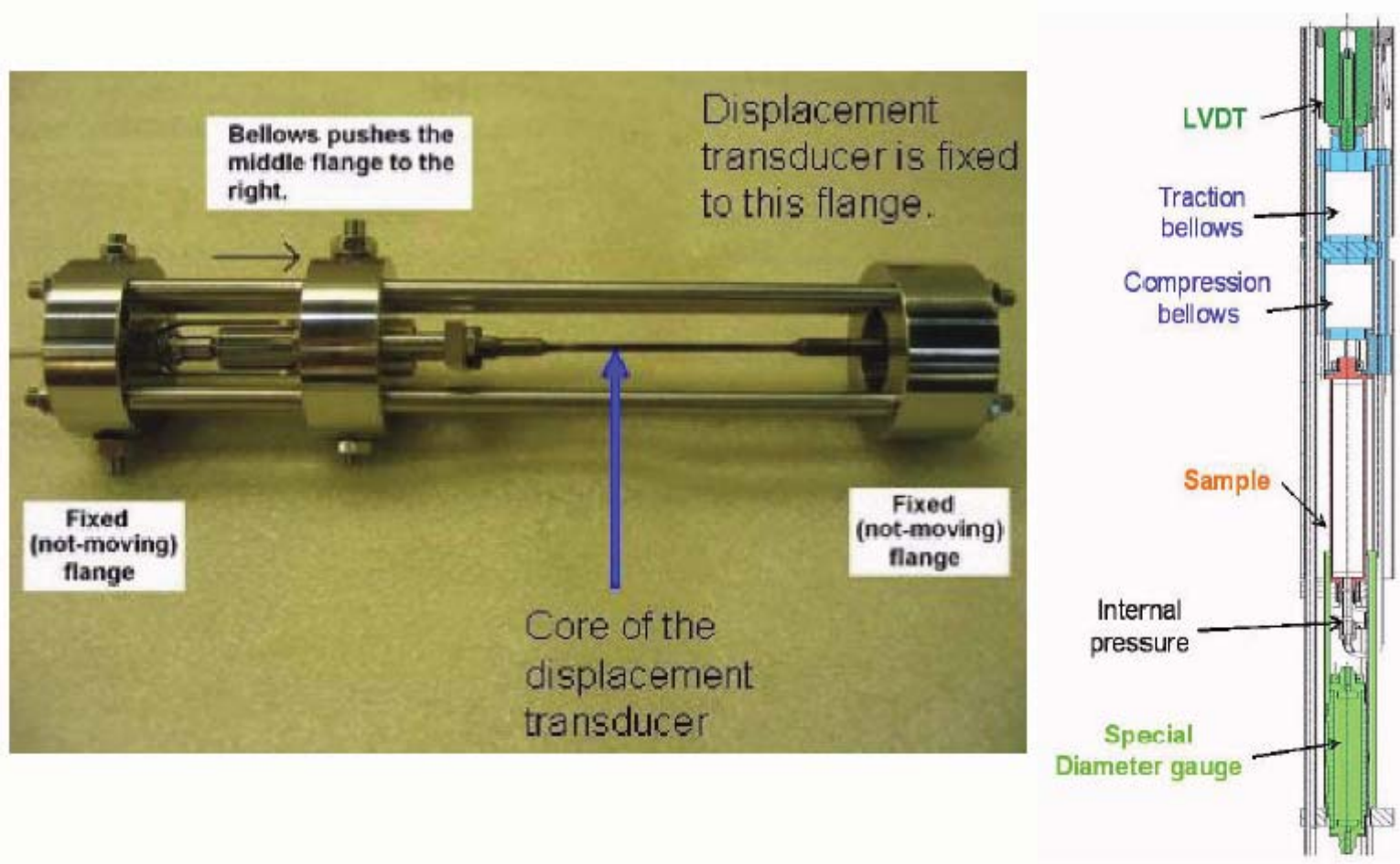

Figure 2-8. Proposed sensor for detecting elongation and diameter changes in OSIRIS testing.

As described in References 5 and 9, even if these sensors (LVDTs) are now reliable and accurate, their use can be limited because of their size and mass, which can imply high gamma heating that may affect the thermal homogeneity of the sample. In addition, their integration and installation is not always straightforward in small sized and narrow experiments. On the contrary, resistive strain gauges can be adapted to the geometry of irradiation devices in a more flexible way; however they often require in-situ re-calibration systems due to the drift of the signal induced by material changes under radiation. Their bonding to a variety of surfaces in harsh nuclear environments also calls for very specific know-how and their limited sensitivity does not necessarily allow reaching the required measurement specifications. Therefore, in order to obtain in-situ data during irradiation test, it is necessary to confirm stain gauges' degradation or drift induced by neutron radiation and to establish a re-calibration process of them. 


\subsection{Norway (IFE-HRP)}

Various types of IFE-HRP's instrumentation, which are primarily based on the LVDT measuring principle, are described in References 4 and 5. An overview of in-core corrosion monitoring techniques, including instruments for measuring crack growth, crack initiation, irradiation creep, in-core water conductivity, fuel cladding thickness and electrochemical impedance spectroscopy is presented in Reference 10. In the creep tests, the test materials are small tensile specimens $(2.5 \mathrm{~mm}$ diameter and a gauge length of $\sim 50 \mathrm{~mm}$ ) prepared from unirradiated, solution annealed 304 and cold worked 316 stainless steels. The specimens are subject to constant displacement conditions during irradiation in an inert environment to fluences of $\sim 0.25,1$ and $1.4 \times 10^{21} \mathrm{n} \mathrm{cm}^{-2}(>1 \mathrm{MeV})$. Load (stress) is applied to the specimens via bellows that are compressed by means of gas pressure that is introduced into the chamber housing the bellows (Figure 2-9). Constant displacement of the tensile specimens is maintained by monitoring sample elongation by means of LVDTs and adjusting (reducing) the applied load (stress) on the specimens online, by decreasing the pressure in the bellows housing units. In addition to the bellows gas lines, the test units are also equipped with gas lines that enable the specimen temperature to be varied in the range from 240 to $400{ }^{\circ} \mathrm{C}$, by altering the composition of helium argon gas mixture surrounding the specimens. An example of the load reductions made on a $316 \mathrm{~N}$ stainless steel lot specimen when length changes on the order of $2 \mathrm{~mm}$ are detected by the LVDT is shown in Figure 2-10. Another example is shown in Figure 2-11 ${ }^{11}$. Reference 1 also summarizes IFE-HRP instrumentation activities using LVDTs.

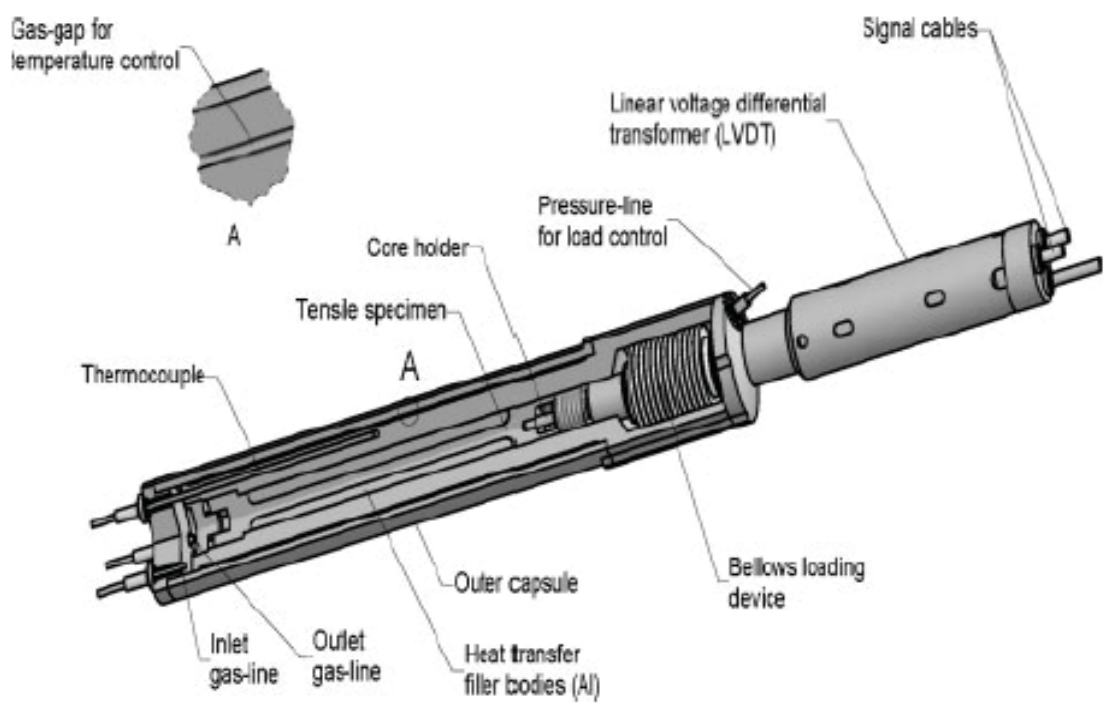

Figure 2-9. Illustration of instrumented tensile specimen used in stress relaxation study; instrumentation includes bellows that allows online variation applied load (stress), temperature control through gas lines and monitoring of specimen elongation by means of LVDT.

The standard Halden LVDTs can withstand Boiling Water Reactor (BWR) and Pressurized Water Reactor (PWR) conditions. However, for operation in liquid metal (NaK), as used in fast reactors, or for operation under super-critical water conditions, the maximum pressure can be up 250 bar and the required operating temperature can be as high as $600{ }^{\circ} \mathrm{C}$, which is above the maximum-recommended temperature 


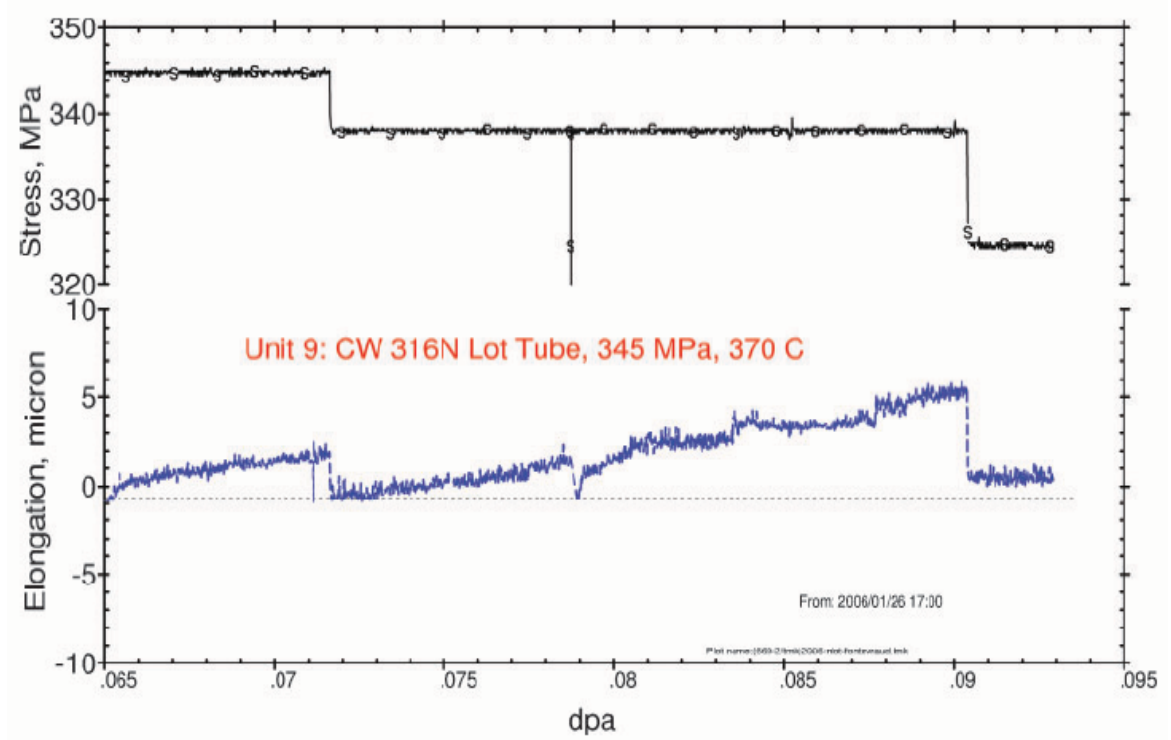

Figure 2-10. Example of online changes in stress that are made as specimen elongation on order 2-6 $\mu \mathrm{m}$ recorded by means of LVDT.

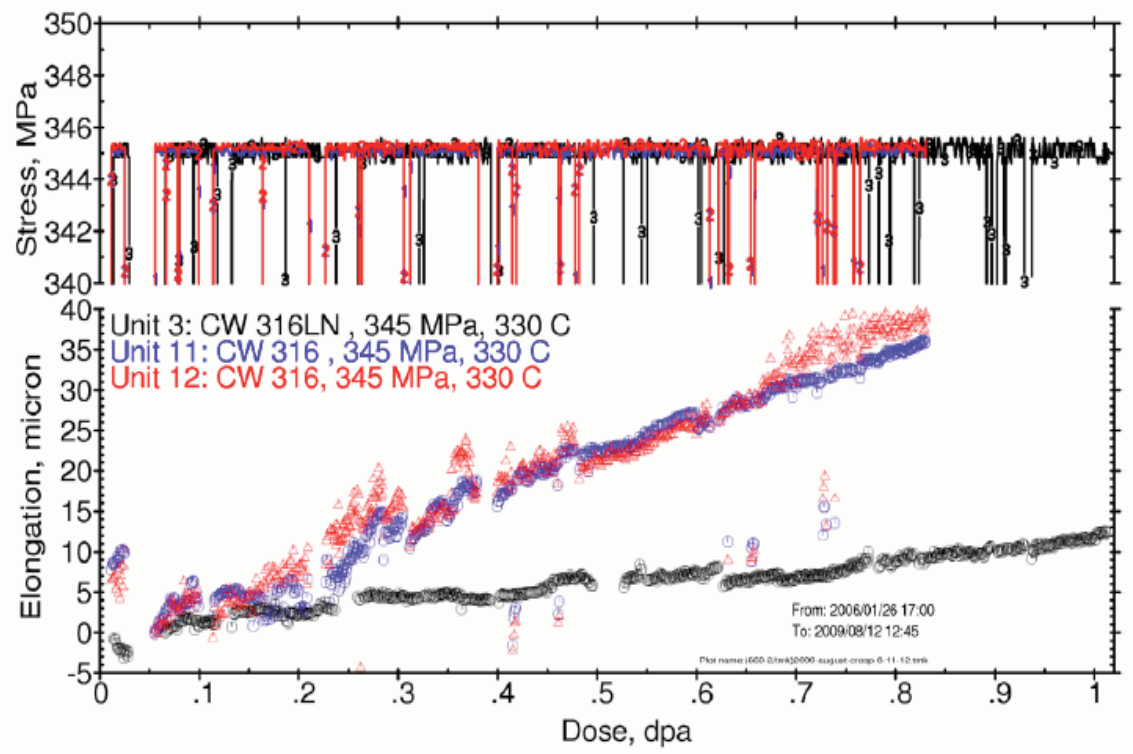

Figure 2-11. Elongation data recorded for CW $316 \mathrm{SS}$ and CW $316 \mathrm{LN}$.

for the IFE/HRP LVDTs. In addition, international research into Gen-IV reactors has led to the High Performance Light Water Reactor (HPLWR) concept, which will operate at $\sim 250$ bar and $\sim 500{ }^{\circ} \mathrm{C}$. Therefore, high temperature (up to $600^{\circ} \mathrm{C}$ )/high pressure LVDT's are now under development and testing by IFE/HRP. ${ }^{4,5}$ 
The IFE/HRP LVDT maximum recommended temperature is based on the Curie point of nickel. The wire used for the coils of the instruments consists of a copper conductor with nickel cladding. As the temperature passes through the Curie point of nickel $\left(356-358{ }^{\circ} \mathrm{C}\right)$, there is a noticeable change in the output signal and a change in the instrument sensitivity. Tests by INL found that standard Halden LVDT operate at temperatures above $500{ }^{\circ} \mathrm{C}$ for a limited time (up to approximately 700 hours) prior to signal degradation. ${ }^{12}$ To avoid the issue of the Curie point, IFE/HRP is now testing other coil wire materials. Standard LVDTs have two-wire mineral insulated $\left(\mathrm{Al}_{2} \mathrm{O}_{3}\right)$ cables with an Inconel 600 sheath. In these developmental LVDTs, the wires are either anodized aluminium or ceramic insulated silver alloy wire. Different wire materials are being tested for these LVDT's. Successful operation of these LVDTs has now been demonstrated by IFE/HRP at $600{ }^{\circ} \mathrm{C}$ and 250 bar. $^{11}$

\subsection{Japan (JMTR)}

A study on in-pile/post-irradiation creep under different neutron spectra has been performed using uniaxial tensile specimens in the Japan Materials Testing Reactor (JMTR), Japan. The objective of this creep experiment was to contribute to the understanding of the neutron spectral effect on creep behavior. For this purpose, in-pile creep capsules with uni-axial creep specimens for irradiating under different neutron spectra were developed for JMTR testing. Figure $2-12^{13}$ shows a schematic diagram of one of the creep irradiation capsules (94M-2A). Different levels of stress can be applied to two creep specimens using bellows pressurized by helium gas. The elongation of each creep specimen was measured using an LVDT. The temperature of the specimen was measured using a thermocouple on the gauge length portion of the specimen, and controlled at $550{ }^{\circ} \mathrm{C}$ using the electric heater installed in the capsule. The temperatures of the specimens were to be controlled at $550 \pm 1{ }^{\circ} \mathrm{C}$, and at $550 \pm 3{ }^{\circ} \mathrm{C}$, even in cases where large temperature fluctuations were produced by irradiation of other capsules. Out-of-core creep tests of both unirradiated and irradiated material were performed at $550^{\circ} \mathrm{C}$. Irradiation temperatures of specimens for post-irradiation creep ranged between 485 and $556^{\circ} \mathrm{C}$. In-pile creep tests with high thermal neutron flux were performed at $550{ }^{\circ} \mathrm{C}$ using stress levels of 245 and $284 \mathrm{MPa}$. Under the thermal neutron shield condition, the in-pile creep test of the lower specimen was performed at $550{ }^{\circ} \mathrm{C}$ and $245 \mathrm{MPa}$ because the temperature of the upper specimen could not reach $550^{\circ} \mathrm{C}$. Detailed irradiation conditions in JMTR are summarized in Reference 13.

A comparison of creep curves obtained by in-pile creep under different neutron spectra, post-irradiation creep and creep of the unirradiated material is shown in Figure 2-13(a). The creep curve after normal irradiation is shown as a typical example of a post-irradiation creep curve. Although the in-pile creep deformation under a thermal neutron shield condition is only a little larger than that of the unirradiated material, the tertiary creep stage starts earlier under this condition. The early stage of in-pile creep deformation under a high thermal neutron flux condition is larger than observed for other cases. Figure 2-13(b) also compares the steady-state creep rates. The steady-state creep rate of post-irradiation creep increases in comparison with that of the unirradiated material although it has a large scatter band. The steady-state creep rate of in-pile creep under a thermal neutron shield condition is slightly larger than that of the unirradiated material. In contrast, the in-pile steady-state creep rate for the high thermal neutron flux condition is a factor above 10 higher than the unirradiated one and lies at the upper band of the post-irradiation creep. All creep curves of post-irradiation tests at $550{ }^{\circ} \mathrm{C}$ and $245 \mathrm{MPa}$ are shown in Figure 2-14 together with curves for in-pile tests and unirradiated material. The creep curves of post-irradiation tests vary significantly even for specimens irradiated in the same capsule, e.g., three specimens of 93M-37A and two specimens of $94 \mathrm{M}-1 \mathrm{~A}$. For this reason, the creep rate of post-irradiation tests also has widely scattered values. 


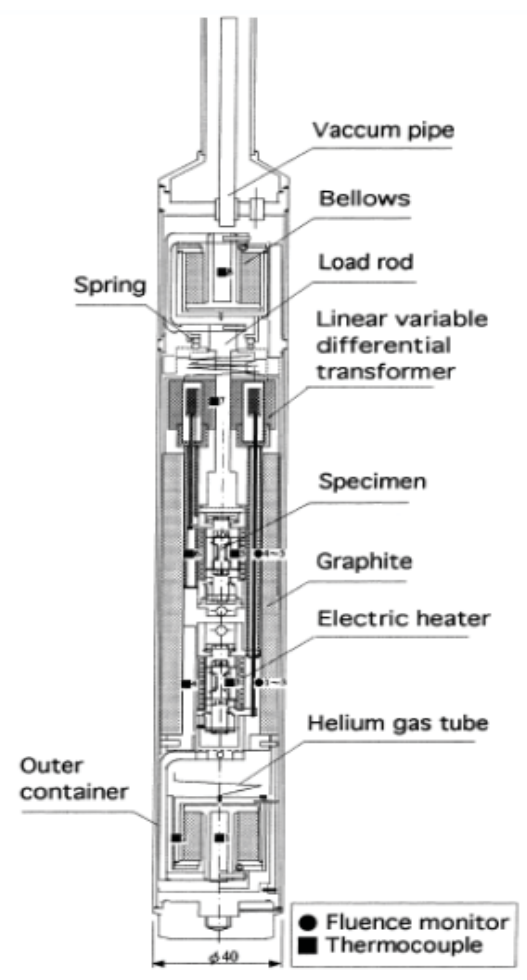

Figure 2-12. Schematic diagram of irradiation creep capsule (94M-2A) under a high thermal neutron flux condition in JMTR.

The results from the irradiation test in JMTR are described in the Reference 13. In-pile creep properties at $550{ }^{\circ} \mathrm{C}$ appear to depend on the neutron spectrum, but a spectral effect on post-irradiation creep properties is not exhibited. The steady-state creep rate of in-pile creep under a thermal neutron shield condition is slightly larger than observed for the unirradiated material. The steady-state in-pile creep rate under a high thermal neutron flux condition and post-irradiation creep increases in comparison with that of the unirradiated material. It is suspected that the cause of the accelerated creep deformation and fracture observed in irradiation creep tests may be related to enhancement of thermal creep in terms of freely migrating defects $\left(\mathrm{FMD}^{14}\right)$ formed under a high thermal neutron flux in addition to increased helium embrittlement.

\subsection{Netherlands (HFR)}

Irradiation creep elongation has been investigated in the High Flux Reactor (HFR) at Petten using two types of irradiation creep facilities for uniaxial stresses. ${ }^{15}$ In the Trieste facility, 49 specimens can be irradiated simultaneously at various stresses and temperatures. Then, creep elongations are measured out-ofpile at ambient temperatures in a hot cell using a photoelectric incremental linear measuring system. The typical neutron flux density in the Trieste irradiation position in the HFR is $2 \times 10^{18} \mathrm{~m}^{-2} \mathrm{~s}^{-1}$ corresponding to a displacement rate of $1.7 \times 10^{-7} \mathrm{dpa} \mathrm{s}^{-1}$ for AMCR alloys (AMCR-0033, -7758, and -7763) and US stainless steels (CE-316, US-316 and US-PCA). In order to check whether the $\varepsilon$-phase, which is formed in the manganese-containing steels during cooling, disturbs creep elongations measurements, Crisp, a second type of irradiation creep facility was developed. In this facility, the in-situ creep elongation of three specimens can be measured during irradiation. 


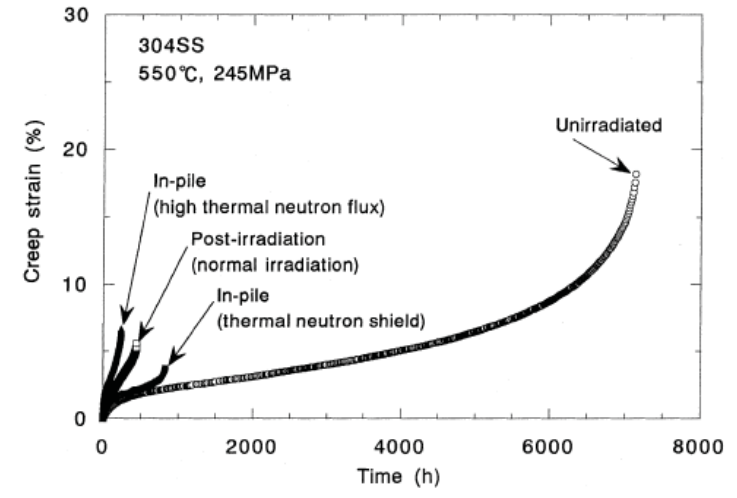

(a)

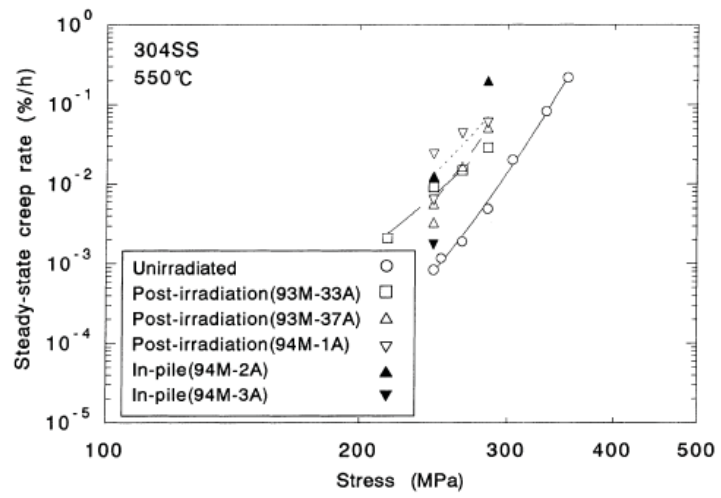

(b)

Figure 2-13. (a) Effect of neutron irradiation on creep curves and (b) Effect of neutron irradiation on the steady-state creep rate of type of type 304 stainless steel.

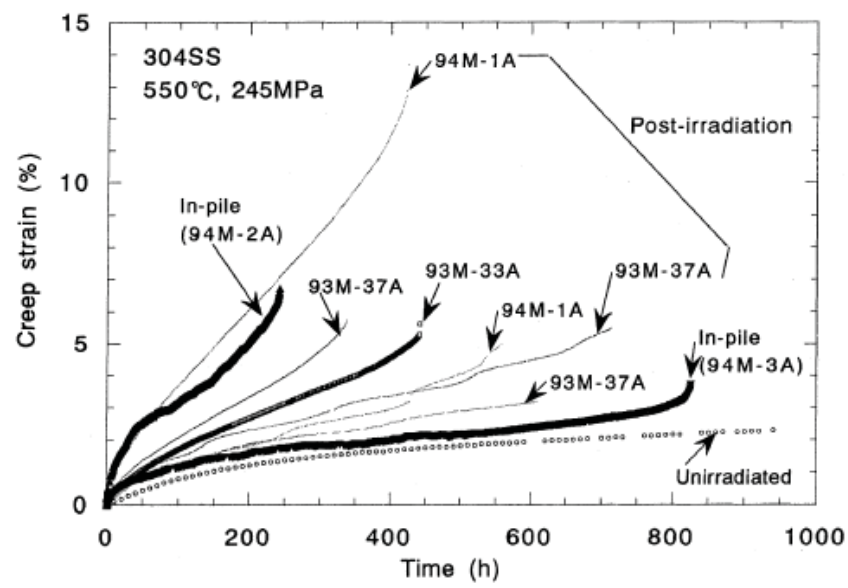

Figure 2-14. Comparison of creep curves of in-pile (94M-2A [high thermal flux] and 94M-3A [thermal shielded]), post-irradiation (93M-33A, 93M-37A and 94M-1A) tests and unirradiated material.

\subsection{Korea (KAERI)}

KAERI has developed specialized capsules for creep and fatigue testing. ${ }^{16-18}$ These capsules often include thermocouples, fluence monitors, and heaters. In these capsules, stresses on specimens can be loaded using bellows that are internally pressurized with He gas. The temperatures of the specimen can be controlled by varying gap sizes among the internal parts of capsules and using small electric heaters installed in the capsule. Temperatures are measured using thermocouples near the specimen. Real-time changes in specimen length changes are measured using LVDTs.

Figure 2-15 shows the conceptual design and selected components prior to assembling an irradiation creep capsule for testing in HANARO. This conceptual design is similar to the in-pile uniaxial tensile test- 
ing performed in the BR2 reactor shown in Figure 2-1, but creep tests in HANARO are performed with specimens in an inert atmosphere. The HANARO creep test capsule contains four tensile specimens. The first HANARO creep test investigated four stainless steel $316 \mathrm{~L}$ tensile specimens that were $1.8 \mathrm{~mm}$ in diameter and $30 \mathrm{~mm}$ in gauge length. Test objectives included confirming the design of the creep capsule and to compare the performance of IFE-HRP's LVDT and commercial LVDTs. This creep test, which was completed in July 2006, was performed with specimens subjected to temperatures of up to $600{ }^{\circ} \mathrm{C}$ and stresses as high as $253 \mathrm{MPa}$ for 23 full power days (the 45th cycle) of HANARO operation.

During this creep test, the temperatures and the displacements were measured real-time for the four specimens. The temperatures of the specimens varied from 367 to $555^{\circ} \mathrm{C}$ when subjected to 1 bar (internal pressure in the capsule) of He gas at a HANARO power of $30 \mathrm{MW}$. These temperatures depended on the specimen position in the HANARO irradiation position. During the irradiation test, the temperatures of the specimens were measured at $600 \pm 5^{\circ} \mathrm{C}$ by controlling He gas pressure and heater power. Data indicated that LVDT temperatures remained below $300{ }^{\circ} \mathrm{C}$ during this irradiation test. As noted above, two kinds of LVDTs were used to measured the displacements of specimens in this capsule. There were one IFE/HRP LVDTs and three commercial vendor LVDTs. The displacement of the specimen measured with the IFE/HRP's LVDT was measured without any failures. Results were within the range of displacements estimated in out-pile performance test, but specimen property data were not compared with literature data to assess accuracy of estimated loads applied by the test rig. Displacements from the commercial LVDTs were not detected due to failures that occurred at the beginning of the test. Due to budget limitiations, the program was terminated. However, it is hoped that the program will be restarted in the future.

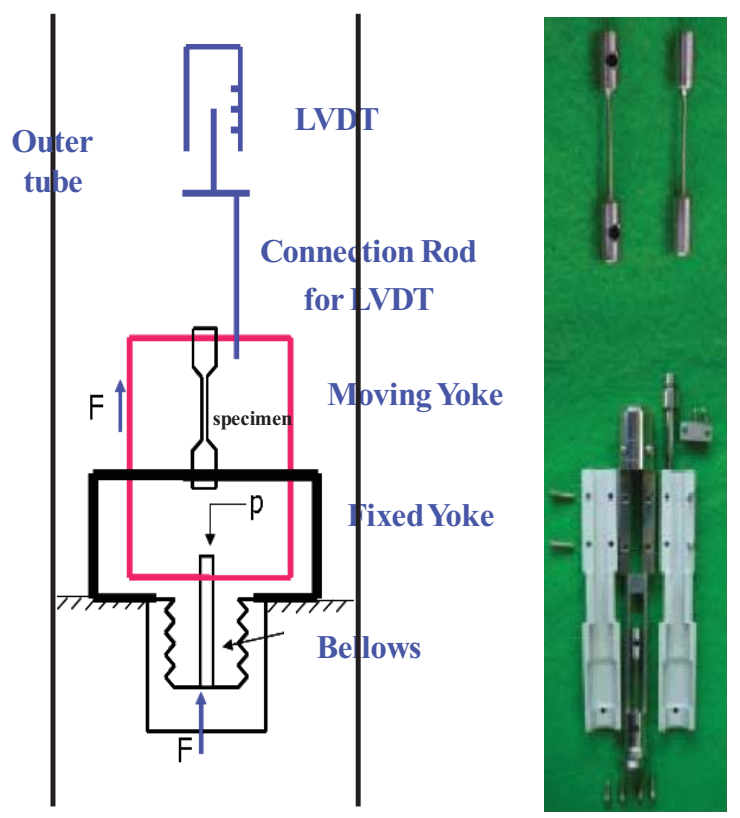

Figure 2-15. Conceptual design and selected components of HANARO irradiation creep capsule. 


\subsection{Summary}

Table 2-2 summarizes the information reviewed in this section. As indicated in this table, several international research organizations are already conducting in-pile creep tests that can provide real-time data for detecting specimen elongation and controlling loads applied to the specimens. As discussed in Section 5, the proposed INL setup will be conducted with specimens in contact with coolant at PWR pressures and temperatures. Hence, the INL setup will be the second organization to pursue testing specimens in contact with coolant. The first INL test rig is not as advanced as the test rig evaluated at the BR-2. Although the system will be able to provide real-time data with respect to specimen elongation, it does not include the capability to control the load to the specimen. Nevertheless, it is a significant first step. If ATR testing of the first INL creep rig is successful, it is anticipated that follow-on INL efforts will include the capability to provide real-time data with respect to elongation and the capability to monitor and control the load applied to the specimen.

Table 2-2. Summary of Creep Testing in MTRs.

\begin{tabular}{|c|c|c|c|c|c|}
\hline Country/Reactor & Test Conditions & $\begin{array}{l}\text { Real Time } \\
\text { Load } \\
\text { Control }\end{array}$ & Method & $\begin{array}{l}\text { Real Time } \\
\text { Elongation } \\
\text { Detection }\end{array}$ & Method \\
\hline Belgium /BR-2 & $\begin{array}{l}\text { stagnant reactor } \\
\text { coolant (about } \\
\left.90^{\circ} \mathrm{C}\right)\end{array}$ & Yes & $\begin{array}{l}\text { internally- } \\
\text { pressurized } \\
\text { bellows }\end{array}$ & Yes & $\begin{array}{l}\text { monitored } \\
\text { LDVT }\end{array}$ \\
\hline France / OSIRIS ${ }^{\mathrm{a}}$ & $\begin{array}{l}\text { Inert gas, water, } \\
\text { and } \mathrm{NaK} \text { (from } \\
\text { room temperature } \\
\text { up to } 380^{\circ} \mathrm{C} \text { ) }\end{array}$ & Yes & $\begin{array}{l}\text { internally- } \\
\text { pressurized } \\
\text { bellows }\end{array}$ & Yes & $\begin{array}{c}\text { monitored } \\
\text { LDVT; external } \\
\text { diameter } \\
\text { gauges also } \\
\text { used }\end{array}$ \\
\hline Norway/ HBWR & $\begin{array}{c}\text { Inert gas } \\
\left(240-400^{\circ} \mathrm{C}\right)\end{array}$ & Yes & $\begin{array}{l}\text { internally } \\
\text { pressurized } \\
\text { bellows }\end{array}$ & $\begin{array}{l}\text { Yes (External } \\
\text { diameter } \\
\text { gauges also } \\
\text { used) }\end{array}$ & $\begin{array}{c}\text { monitored } \\
\text { LVDT (under } \\
\text { developing for } \\
600^{\circ} \mathrm{C} \text { and } 250 \\
\text { bar) }\end{array}$ \\
\hline Japan /JMTR & $\begin{array}{l}\text { Inert gas } \\
\left(550^{\circ} \mathrm{C}\right)\end{array}$ & Yes & $\begin{array}{l}\text { internally } \\
\text { pressurized } \\
\text { bellows }\end{array}$ & Yes & $\begin{array}{l}\text { monitored } \\
\text { LVDT }\end{array}$ \\
\hline Netherlands /HFR & $\begin{array}{l}\text { Inert gas and } \mathrm{NaK} \\
\quad\left(300-600^{\circ} \mathrm{C}\right)\end{array}$ & Yes & $\begin{array}{l}\text { self-contained } \\
\text { spring washer } \\
\text { system }\end{array}$ & $\begin{array}{l}\text { Yes (semi- } \\
\text { continuous) }\end{array}$ & $\begin{array}{l}\text { monitored } \\
\text { LVDT }\end{array}$ \\
\hline Korea /HANARO & $\begin{array}{l}\text { Inert gas (up to } \\
600{ }^{\circ} \mathrm{C} \text { ) }\end{array}$ & Yes & $\begin{array}{l}\text { internally- } \\
\text { pressurized } \\
\text { bellows }\end{array}$ & Yes & $\begin{array}{l}\text { monitored } \\
\text { LDVT }\end{array}$ \\
\hline
\end{tabular}

a. In upcoming tests. Previous tests rely on out-of-pile measurements with strain gauges. 


\section{UNIRRADIATED COMPARISON DATA}

Irradiation creep is an important concern for nuclear reactor structures and materials. In particular, the study of irradiation creep is essential for core structures and RPVs (Reactor Pressure Vessels) of light water reactors (LWRs) operating in the US in light of efforts to extend their life time. Currently, the oldest operating reactors are 40 years old; and most US reactor licenses will be extended to 60 years. Recently, Allen and Busby ${ }^{19}$ reported on radiation damage concerns for extended LWR service. As shown in Figures 3-1 and 3-2, most components of PWRs and BWRs are located in very harsh environments. These materials include low alloy steel, carbon steel, stainless steel, Inconel, etc. This section provides comparison data for materials of interest to industry to be used for in-pile creep testing. Primarily, comparison data are provided for SS304, SS316, Inconel 600, Inconel 718, Inconel X-750 and XM-19 (Nitronic 50). Note that Nitronic has not yet been incorporated into operating LWRs. However, as discussed in this section, its superior properties make it of interest.

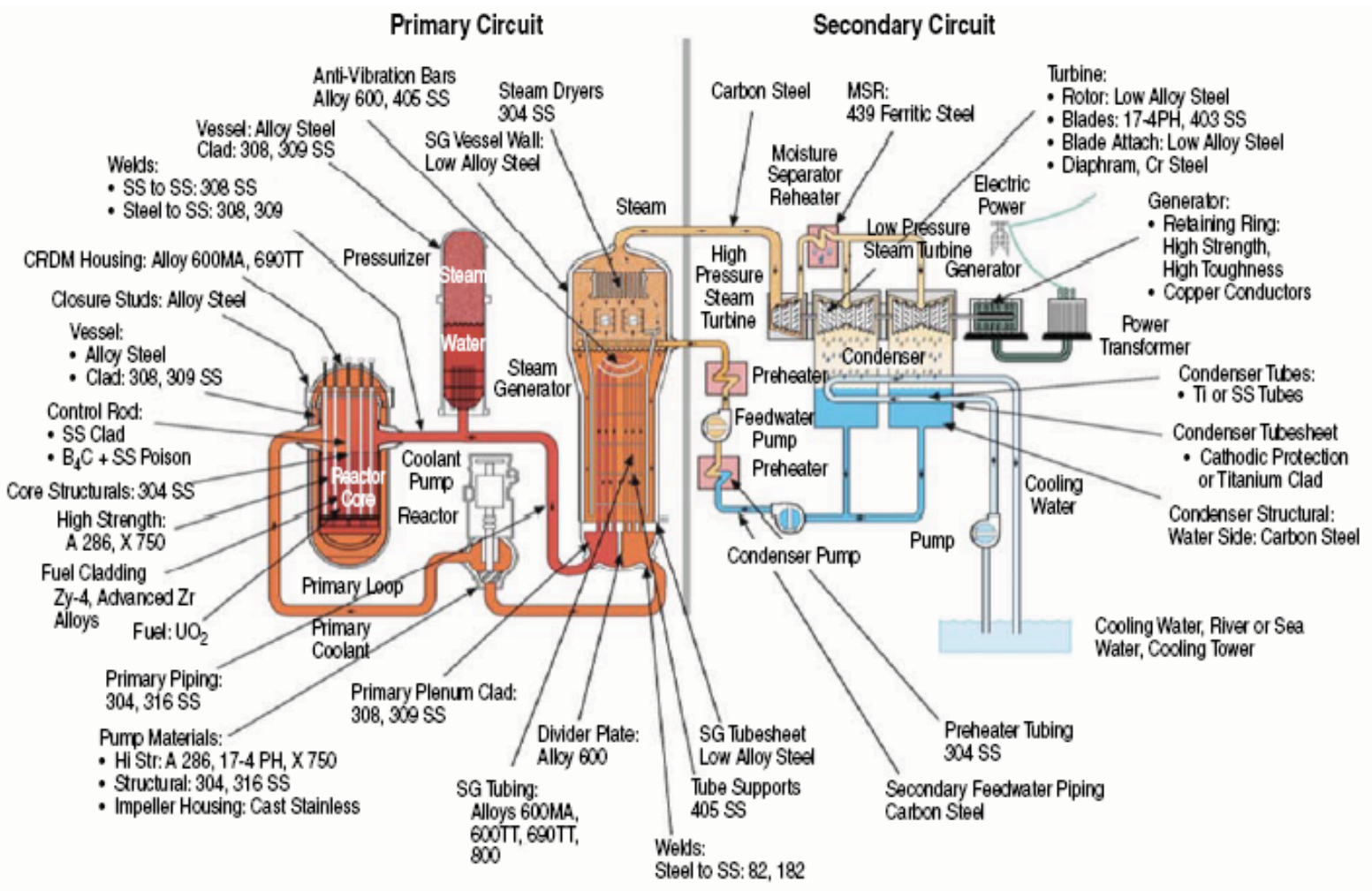

Figure 3-1. An outline of PWR components and materials. (Image courtesy of R. Staehle. ${ }^{19}$ )

Stainless steel: ${ }^{20}$ Stainless steel 300 series refers to austenitic stainless steels containing chromium and nickel. The stainless steels in the austenitic group have different compositions and properties, but many common characteristics. These stainless steels can be hardened by cold working, but not by heat treatment. In the annealed condition, all are essentially nonmagnetic, although some may become slightly magnetic by cold working. They have excellent corrosion resistance, unusually good formability, and increase in strength as a result of cold work. Type 304 (sometimes referred to as $18-8$ stainless) is the most widely used alloy of the austenitic group. It has a nominal composition of $18 \%$ chromium and $8 \%$ nickel. 


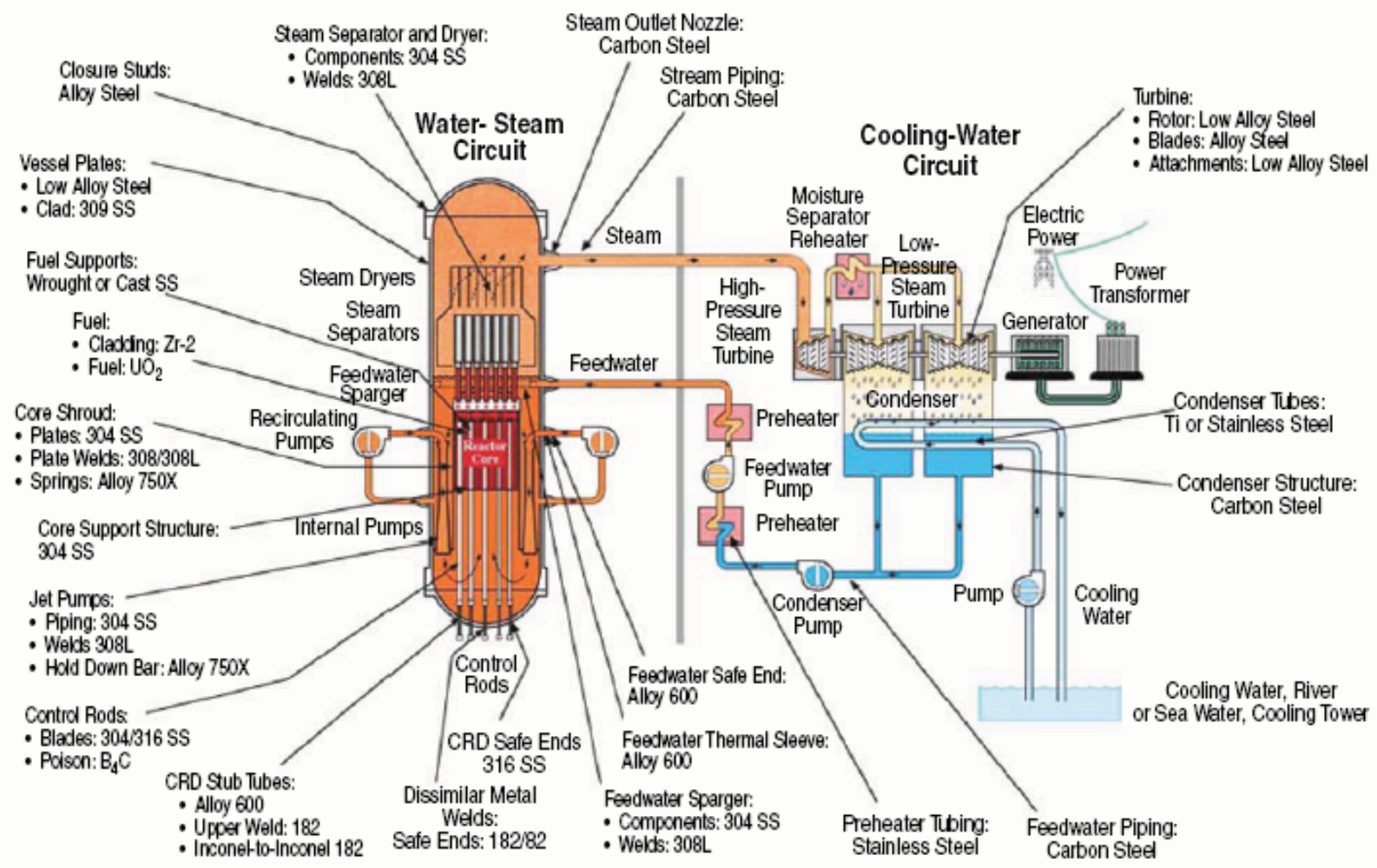

Figure 3-2. An outline of BWR components and materials. (Image courtesy of R. Staehle. ${ }^{19}$ )

Inconel: ${ }^{21}$ Inconel 600 is a nickel-chromium alloy with good oxidation resistance at high temperatures and resistance to chloride-ion stress-corrosion cracking, corrosion by high-purity water, and caustic corrosion. It is used for furnace components, in chemical and food processing, in nuclear reactors, and for sparking electrodes. Inconel 718 is a precipitation-hardenable nickel-chromium alloy also containing significant amounts of iron, niobium, and molybdenum along with lesser amounts of aluminum and titanium. It combines corrosion resistance and high strength with outstanding weldability including resistance to post-weld cracking. The alloy has excellent creep-rupture strength for temperatures up to $700{ }^{\circ} \mathrm{C}$. It is used in gas turbines, rocket motors, spacecraft, nuclear reactors, pumps, and tooling. Inconel X-750 is a nickel-chromium alloy similar to Inconel 600 , but it has been precipitate-hardened by adding aluminum and titanium. It has good resistance to corrosion and oxidation along with high tensile and creep-rupture properties for temperatures up to $700{ }^{\circ} \mathrm{C}$. Its excellent relaxation resistance is useful for high temperature springs and bolts. This material is often used in gas turbines, rocket engines, nuclear reactors, pressure vessels, tooling, and aircraft structures.

Nitronic 50: ${ }^{22}$ Nitronic 50 (XM-19) provides a combination of corrosion resistance and strength not found in any other commercial material available in its price range. This austenitic stainless steel has corrosion resistance greater than that provided by $316,316 \mathrm{~L}, 317$ and $317 \mathrm{~L}$ plus approximately twice the yield strength at room temperature. In addition, it has very good mechanical properties at both elevated and subzero temperatures. Unlike many austenitic stainless steels, Nitronic 50 does not become magnetic when cold worked or cooled to sub-zero temperatures. It is an effective alloy for the petroleum, petrochemical, chemical, fertilizer, nuclear fuel recycling, pulp and paper, textile, food processing and marine industries. Components using the combination of excellent corrosion resistance and high strength currently include 
pumps, valves and fittings, fasteners, cables, chains, screens and wire cloth, marine hardware, boat and pump shafting, heater exchanger parts, springs and photographic equipment. The chemical composition and some available mechanical and thermal (coefficient of expansion) properties of these materials are described in this section.

For each of these materials, the chemical composition is first identified. Then, available mechanical properties at room and elevated temperatures for unirradiated materials is provided. If available, irradiated data are provided. Although data for irradiated materials aren't currently needed for comparison with results from autoclave testing at INL's HTTL, they are of interest for comparison with data obtained in future evaluations.

\subsection{Composition}

The chemical compositions of stainless steel 304 and 316, Inconel 600, 718, X-750, and Nitronic 50 are listed in Tables 3-1, 3-2, and 3-3, respectively. ${ }^{20-25}$

Table 3-1. Typical chemical composition of stainless steel 304 and 316 (in wt\%).

\begin{tabular}{|c|c|c|c|c|c|}
\hline Element & SS 304 $^{\mathbf{a}}$ & SS 304L $^{\mathbf{a}}$ & SS 304H $^{\mathbf{b}}$ & SS 316 $^{\mathbf{a}}$ & SS316L $^{\mathbf{a}}$ \\
\hline $\mathrm{Cr}$ & $18-20$ & $18-20$ & $18-20$ & $16-18$ & $16-18$ \\
$\mathrm{Ni}$ & $8-10.5$ & $8-12$ & $8-10.5$ & $10-14$ & $10-14$ \\
$\mathrm{Fe}$ & Balance & Balance & Balance & Balance & Balance \\
$\mathrm{C}$ & 0.08 & 0.03 & $0.04-0.10$ & 0.08 & 0.03 \\
$\mathrm{Mn}$ & 2.0 & 2.0 & 2.0 & 2.0 & 2.0 \\
$\mathrm{Si}$ & 0.75 & 0.75 & 0.75 & 0.75 & 0.75 \\
$\mathrm{P}$ & 0.045 & 0.045 & 0.045 & 0.045 & 0.045 \\
$\mathrm{~S}$ & 0.03 & 0.03 & 0.03 & 0.03 & 0.03 \\
$\mathrm{~N}$ & 0.1 & 0.1 & 0.1 & 0.1 & 0.1 \\
$\mathrm{Mo}$ & - & - & - & $2.0-3.0$ & $2.0-3.0$ \\
\hline
\end{tabular}

a. See Reference 21 .

b. See Reference 22 .

\subsection{Mechanical Properties}

Room temperature material properties (tensile strength, yield strength, and Young's Modulus of stainless steel (304 and 316), Inconel $(600,718, \mathrm{X}-750)$, and Nitronic 50 are summarized in Table 3-4. ${ }^{21-25}$ Temperature-dependent structural properties for each material of interest are also summarized in this section. Specifically, the yield strength, Young's Modulus, and ultimate strength are provided for SS304, SS316, Inconel 600, Inconel 718, and Nitronic 50. 
Table 3-2. Typical chemical composition of Inconel 600, 718 and X-750 (in wt\%). ${ }^{22}$

\begin{tabular}{|c|c|c|c|c|c|c|c|}
\hline Element & $\begin{array}{c}\text { Inconel } \\
\mathbf{6 0 0}\end{array}$ & $\begin{array}{c}\text { Inconel } \\
\mathbf{7 1 8}\end{array}$ & $\begin{array}{c}\text { Inconel } \\
\mathbf{X - 7 5 0}\end{array}$ & Element & $\begin{array}{c}\text { Inconel } \\
\mathbf{6 0 0}\end{array}$ & $\begin{array}{c}\text { Inconel } \\
\mathbf{7 1 8}\end{array}$ & $\begin{array}{c}\text { Inconel } \\
\mathbf{X - 7 5 0}\end{array}$ \\
\hline $\mathrm{Ni}$ & 72.0 & $50.0-55.0$ & 70.0 min. & $\mathrm{Al}$ & - & $0.20-0.80$ & - \\
$\mathrm{Cr}$ & $14.0-17.0$ & $17.0-21.0$ & $14.0-17.0$ & $\mathrm{Ti}$ & - & $0.65-1.15$ & $2.25-2.75$ \\
$\mathrm{Fe}$ & $6.0-10.0$ & Balance & $5.0-9.0$ & $\mathrm{Si}$ & 0.5 & 0.35 max. & 0.5 max. \\
$\mathrm{Nb}$ & - & $4.75-5.50$ & - & $\mathrm{C}$ & 0.15 & 0.80 max. & - \\
$\mathrm{Mo}$ & - & $2.8-3.3$ & - & $\mathrm{S}$ & 0.015 & 0.015 max. & 0.01 \\
$\mathrm{Co}$ & - & $1.0 \max$. & $1.0 \max$. & $\mathrm{P}$ & - & 0.015 max. & - \\
$\mathrm{Mn}$ & 1.0 & $0.35 \max$. & - & $\mathrm{B}$ & - & 0.006 max. & - \\
$\mathrm{Cu}$ & 0.5 & $0.30 \max$. & $0.5 \max$. & & & & \\
\hline
\end{tabular}

Table 3-3. Typical chemical composition of Nitronic 50 (in wt\%). ${ }^{24}$

\begin{tabular}{|c|c|c|c|c|c|}
\hline Element & Min & Max & Element & Min & Max \\
\hline $\mathrm{Fe}$ & Balance & Balance & $\mathrm{N}$ & 0.24 & 0.3 \\
$\mathrm{C}$ & 0.03 & 0.05 & $\mathrm{Ti}$ & - & 0.02 \\
$\mathrm{Mn}$ & 4.0 & 5.5 & $\mathrm{Al}$ & - & 0.02 \\
$\mathrm{P}$ & - & 0.04 & $\mathrm{~B}$ & 0.0008 & 0.0025 \\
$\mathrm{~S}$ & - & 0.015 & $\mathrm{Cb}$ & 0.12 & 0.2 \\
$\mathrm{Si}$ & 0.2 & 0.6 & $\mathrm{Ta}$ & - & 0.1 \\
$\mathrm{Cr}$ & 20.5 & 22.0 & $\mathrm{Sn}$ & - & 0.03 \\
$\mathrm{Ni}$ & 11.75 & 13.0 & $\mathrm{~V}$ & 0.10 & 0.3 \\
$\mathrm{Mo}$ & 2.0 & 2.5 & $\mathrm{~W}$ & - & 0.15 \\
$\mathrm{Cu}$ & 0 & 0.75 & & & \\
\hline
\end{tabular}

\subsubsection{Stainless Steel}

Austenitic stainless steels of the 300 series generally have good resistance to irradiation embrittlement. They show no significant shift of ductile to brittle transition temperature by irradiation at low temperatures (below $400{ }^{\circ} \mathrm{C}$ ), although they show low resistance to irradiation swelling and creep above about $400{ }^{\circ} \mathrm{C} .{ }^{27}$ These steels have been not only widely used in conventional nuclear power plants, where operation temperatures are limited below $400{ }^{\circ} \mathrm{C}$, but are also selected for advanced reactor components such as the first wall and shield of ITER ${ }^{28}$ and the container vessel for the liquid metal target of the spallation neutron source $^{27-30}$. 
Table 3-4. Typical room temperature $\left(20\right.$ to $\left.25^{\circ} \mathrm{C}\right)$ properties of SS, Inconel and Nitronic.

\begin{tabular}{|c|c|c|c|c|c|}
\hline Material & TS MPa (min.) & $\begin{array}{c}\text { YS MPa (min.) } \\
\text { (0.2\% offset) }\end{array}$ & $\begin{array}{c}\text { Young's Modulus } \\
\text { (GPa) }\end{array}$ & Remarks & Ref. \\
\hline SS 304 & 515 & 205 & 193 & annealed plate & 21,25 \\
SS 304L & 170 & 193 & annealed plate & 21,25 \\
SS 304H & 485 & 205 & 193 & annealed plate & 21,25 \\
SS 316 & 515 & 205 & 193 & annealed plate & 21,25 \\
SS 316L & 515 & 170 & 193 & annealed plate & 21,25 \\
Inconel 600 & 485 & 310 & 200 & & 22 \\
Inconel 718 & $\sim 1380$ & $\sim 1100$ & 208 & & 22,23 \\
Inconel X-750 & 1250 & 870 & 214 & & 22,23 \\
Nitronic & $827 \sim 862$ & $414 \sim 448$ & 199 & annealed & 24,31 \\
Nitronic 50 & 690 & 380 & & & \\
\hline
\end{tabular}

a. Mechanical properties shown are for the commonly available forms. Properties of other forms of the grade may vary.

b. Annealed $1121^{\circ} \mathrm{C}+$ water quench, annealed $1066^{\circ} \mathrm{C}+$ water quench.

Results from a literature review of available data are summarized in Table 3-5. As indicated in this table, figures and tables in this section compare results for Young's modulus, yield strength and tensile strength for SS304 because this material was selected for initial testing in the INL-developed creep test rig. Also, selected data are presented for SS316. Table 3-5 also summarizes the fabrication processes and heat treatments applied to specimen data presented in this section. Where possible, comparison figures and tables in this section note whether the material has been annealed or cold-worked. As discussed in Section 6, specimen data from the test rig are compared with data obtained from a load frame on an identical specimen. However, initial comparison data available to INL were limited to results from room temperature tests. Hence, comparison data provided INL useful information for assessing creep test rig performance. Typical stress-strain curves for Types 301 and 304 stainless steel at room temperature are shown in Figure 3-3. ${ }^{31}$ Figure 3-4 ${ }^{32}$ compares SS304 room temperature and elevated temperature stress strain curves.

As shown in Figure 3-3, certain meta-stable types of austenitic stainless steel, such as type 301 can develop higher strengths and hardnesses than type 304 for a given amount of cold work (although the heattreatment and cold-work for specimens used to obtain these curves isn't specified in Reference 31). In meta-stable austenitic stainless steels, deformation triggers transformation of austenitic to martensite. The effect of this transformation on strength is illustrated in Figure 3-3, which compares the stress-strain curve for type 304 with that for type 301. The parabolic shape of the curve for type 304 indicates that strain hardening occurs throughout the duration of the application of stress, but that the amount of strain hardening for a given increment of stress decreases as stress increases. On the other hand, the stress-strain relationship for type 301 indicates an accelerated rate of strain hardening after an initial increment of 10 to $15 \%$ plastic strain. This accelerated strain hardening is a direct result of deformation induced transformation to martensite. ${ }^{31}$

Elevated/low temperature stress-strain diagrams are similar in appearance to those obtained at room temperature (see Figure 3-4). Relative to ambient temperature, materials become stronger, but less ductile, as temperature decreases. ${ }^{34}$ Although simple, stable alloys exhibit increased ductility with rising tempera- 
Table 3-5. Summary of stainless steel data reviewed from the literature.

\begin{tabular}{|c|c|c|c|c|c|c|c|c|c|}
\hline Source & Materials & $\begin{array}{c}\text { Cold- } \\
\text { worked }\end{array}$ & $\begin{array}{c}\text { Hot } \\
\text { worked }\end{array}$ & Annealed & $\begin{array}{l}\text { Temp. } \\
\text { Range }\end{array}$ & YM (GPa) & YS (MPa) & US (MPa) & Reference \\
\hline \multirow{5}{*}{$\begin{array}{c}\text { Touloukian, } \\
\text { et al. }\end{array}$} & SS 304 & & & o & RT & 193 & 205 & 515 & 21,25 \\
\hline & SS304L & & & o & RT & 193 & 170 & 485 & 21,25 \\
\hline & SS304H & & & o & $\mathrm{RT}$ & 193 & 205 & 515 & 21,25 \\
\hline & SS 316 & & & o & RT & 193 & 205 & 515 & 21,25 \\
\hline & SS316L & & & o & RT & 193 & 170 & 485 & 21,25 \\
\hline $\begin{array}{c}\text { Engineering } \\
\text { ToolBox }\end{array}$ & $\begin{array}{l}\text { SS 304, 310, } \\
316,321,347\end{array}$ & & & o & $\begin{array}{l}\text { RT- } \\
650^{\circ} \mathrm{C}\end{array}$ & $\begin{array}{c}\text { (See Figure } \\
3-7 \text { ) }\end{array}$ & & & 26 \\
\hline \multirow{12}{*}{$\begin{array}{c}\text { Metal } \\
\text { Handbook } \\
\text { Vol. } 3\end{array}$} & \multirow[t]{2}{*}{ SS 304} & & o & o & RT & & 205 & 515 & \multirow[t]{2}{*}{31} \\
\hline & & o & & o & $\mathrm{RT}$ & & 310 & 620 & \\
\hline & \multirow[t]{2}{*}{$304 \mathrm{~L}$} & & $\mathrm{o}$ & o & RT & & 170 & 480 & \multirow[t]{2}{*}{31} \\
\hline & & o & & o & RT & & 310 & 620 & \\
\hline & $304 N$ & & & o & RT & & 240 & 550 & 31 \\
\hline & $304 \mathrm{LN}$ & & & o & RT & & 205 & 515 & 31 \\
\hline & \multirow[t]{2}{*}{316} & & o & o & RT & & 205 & 515 & \multirow[t]{2}{*}{31} \\
\hline & & o & & o & RT & & 310 & 620 & \\
\hline & \multirow[t]{2}{*}{$316 \mathrm{~L}$} & & o & o & RT & & 170 & 480 & \multirow[t]{2}{*}{31} \\
\hline & & o & & o & RT & & 310 & 620 & \\
\hline & $316 \mathrm{LN}$ & & & o & RT & & 205 & 515 & 31 \\
\hline & $316 \mathrm{~N}$ & & & o & RT & & 240 & 550 & 31 \\
\hline Rempe et al. & 304 & & & $\begin{array}{l}\text { annealed } \\
\text { at } 1050^{\circ} \mathrm{C} \\
\text { for } 1 \mathrm{hr} \text {, } \\
\text { forced- air } \\
\text { cooled }\end{array}$ & $\begin{array}{c}\mathrm{RT} \\
704^{\circ} \mathrm{C} \\
777^{\circ} \mathrm{C}\end{array}$ & $\begin{array}{c}195 \\
138 \\
130 \\
\text { (See Figure } \\
3-7 \text { ) }\end{array}$ & $\begin{array}{c}252 \\
98 \\
93 \\
\text { (See Figure } \\
3-5 \text { ) }\end{array}$ & $\begin{array}{c}642 \\
285 \\
197 \\
\text { (See Figure } \\
3-5)\end{array}$ & 33 \\
\hline ASME Code & $\begin{array}{c}304,304 \mathrm{H}, \\
304 \mathrm{~L}, 304 \mathrm{LN}, \\
316,316 \mathrm{LN}, \\
316 \mathrm{~N}\end{array}$ & & & & $\begin{array}{l}\text { RT- } \\
540^{\circ} \mathrm{C}\end{array}$ & & $\begin{array}{l}\text { (See Figures } \\
3-5 \text { and 3-6) }\end{array}$ & $\begin{array}{l}\text { (See Figures } \\
3-5 \text { and 3-6) }\end{array}$ & 35 \\
\hline Cheng et al. & SS304 & & $\begin{array}{c}\text { solution } \\
\text { heat } \\
\text { treatment } \\
\text { at } \\
1150^{\circ} \mathrm{C} \\
\text { for } 1 \mathrm{hr}\end{array}$ & & $\begin{array}{c}\mathrm{RT} \\
200^{\circ} \mathrm{C} \\
400^{\circ} \mathrm{C}\end{array}$ & $\begin{array}{c}233 \\
212 \\
194 \\
\text { (See Figure } \\
3-7 \text { ) }\end{array}$ & $\begin{array}{c}338 \\
200 \\
144 \\
\text { (See Figure } \\
3-5 \text { ) }\end{array}$ & & 36 \\
\hline Byun et al., & $\begin{array}{c}\mathrm{SS} 304,316 \\
316 \mathrm{LN}\end{array}$ & & & $\begin{array}{l}\text { annealed } \\
\text { at } 1050^{\circ} \mathrm{C} \\
\text { for } 30 \\
\text { min. after } \\
\text { machining }\end{array}$ & $\begin{array}{c}\mathrm{RT} \\
200^{\circ} \mathrm{C} \\
400^{\circ} \mathrm{C}\end{array}$ & $\begin{array}{c}185 \\
176 \\
173 \\
\text { (See Figure } \\
3-7 \text { ) }\end{array}$ & $\begin{array}{c}200 \\
120 \\
100 \\
\text { (See Figures } \\
\text { 3-5 and 3-6) }\end{array}$ & $\begin{array}{c}600 \\
450 \\
400 \\
\text { (See Figures } \\
\text { 3-5 and 3-6) }\end{array}$ & 38 \\
\hline
\end{tabular}




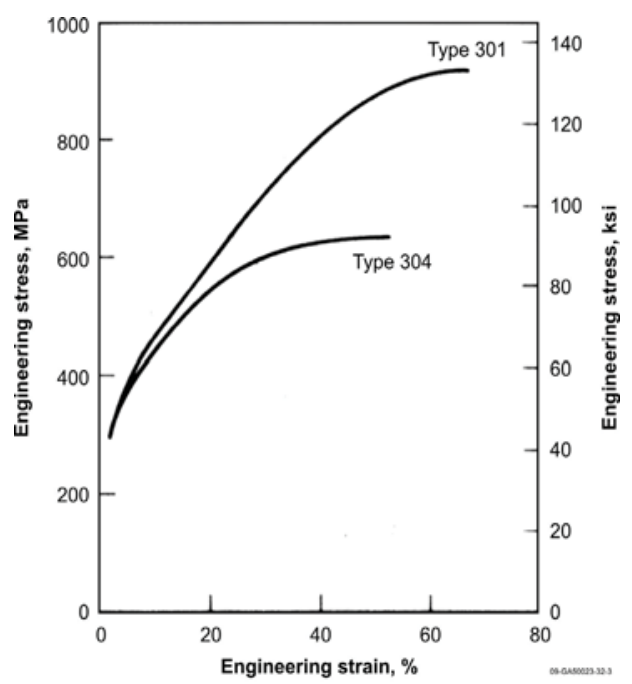

Figure 3-3. Typical stress-strain curves for Types 301 and 304 stainless steel.
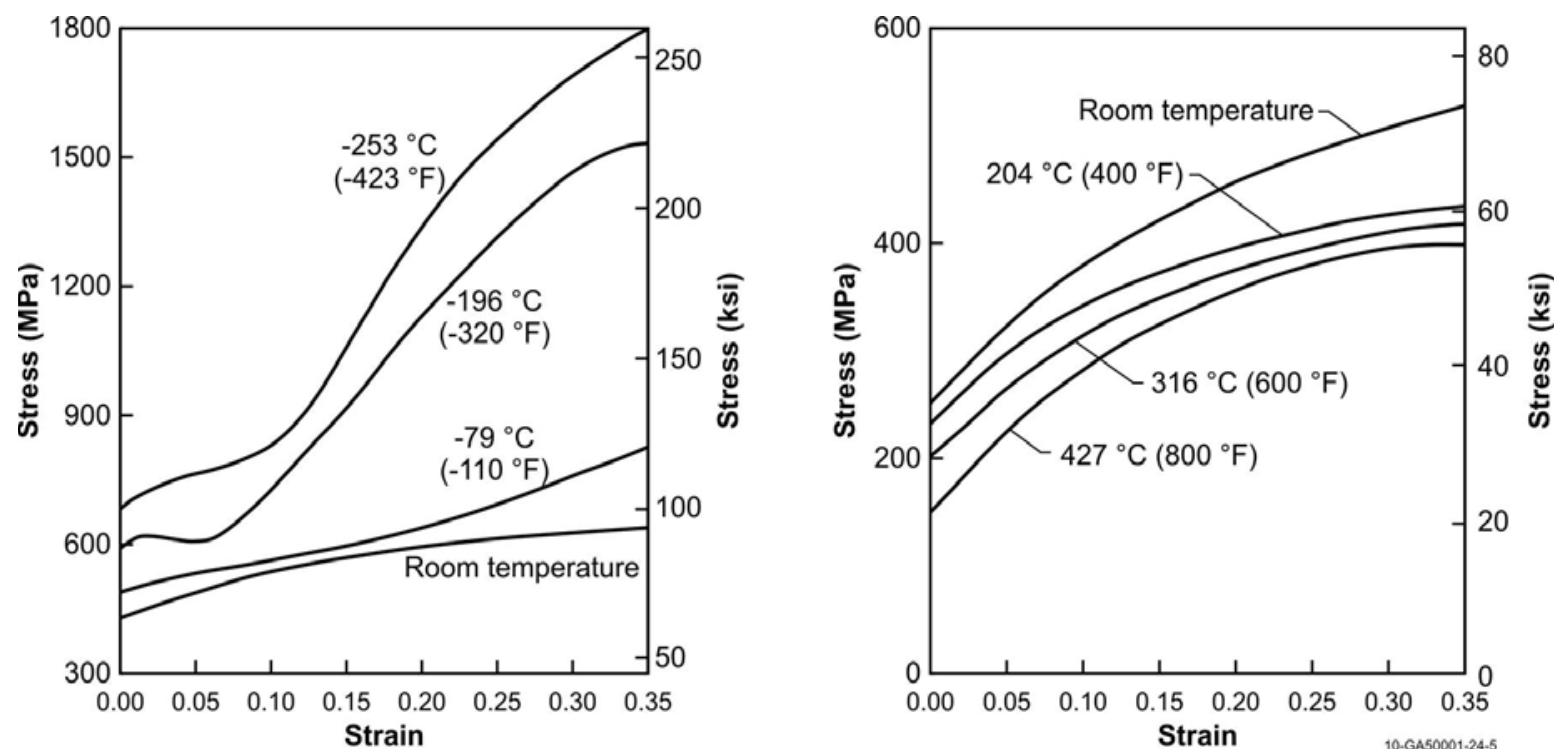

Figure 3-4. Stress-strain diagrams for type 304 stainless steel as a function of temperature.

tures, the temperature-ductility behavior for most engineering materials varies greatly. Such discontinuities in ductility with increasing temperature usually can be traced to metallurgical instabilities - carbide precipitation, for example - that affect the failure mode. ${ }^{34}$

Figure 3-5 compares SS304 yield strength and tensile strength data from References 33, 35, 36 and 38. In addition, this figure includes Reference 36 data for specimens that were formed into hot-rolled bars and annealed at $1150{ }^{\circ} \mathrm{C}$ for 1 hour, and then machined into round and solid bar specimens for uniaxial test and tubular specimens for multi-axial tests. Reference 35 values are minimum values recommended by the ASME code for various product forms and/or manufacturing histories (e.g., cold-working, hot working, annealing, etc.). In Figure 3-5, the strengths for SS304 are averaged from Reference 35. INL data pub- 
lished in Reference 33 were obtained from specimens fabricated into round bars that were annealed for 1 hour at $1323 \mathrm{~K}$ and forced-air cooled prior to testing.
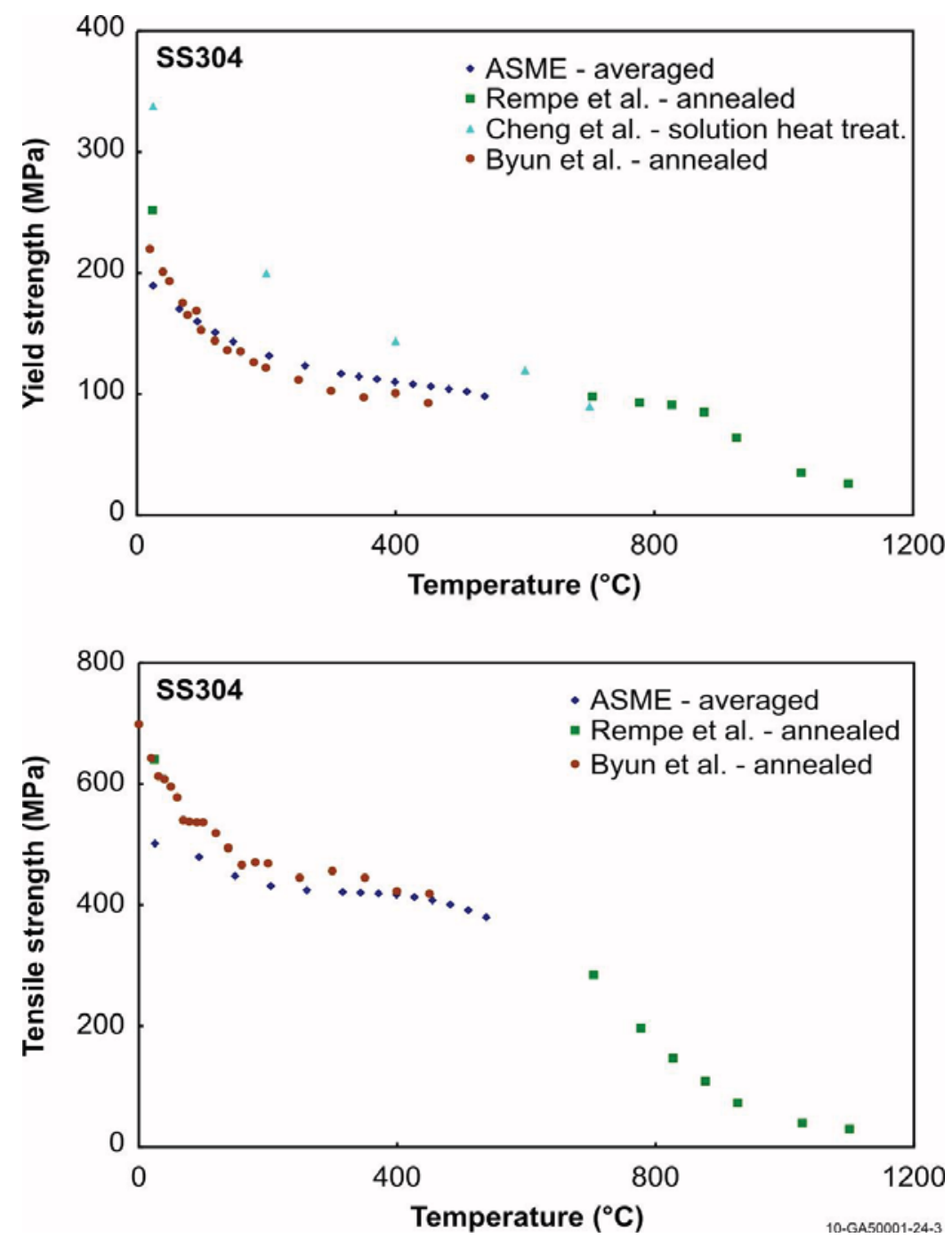

Figure 3-5. Temperature-dependent SS304 yield strength and tensile strength data. ${ }^{33,35,36,38}$

Figure 3-6 shows SS316 yield strength and tensile strength data from References 35 and 38. Reference 35 values are also minimum values recommended by the ASME code for SS316 various product forms and/or manufacturing histories (e.g., cold-working, hot working, annealing, etc.). The strengths for SS316 are also averaged from Reference 35. Byun et al.'s data shown in Reference 38 were obtained from specimens annealed at $1050{ }^{\circ} \mathrm{C}$ for $30 \mathrm{~min}$. after machining, $20 \%$ cold-rolled from a 1 -mm thick sheet. As shown in this figure, the resultant yield strengths and tensile strengths differ significantly. These differences are primarily attributed to difference in specimen fabrication history. However, all curves clearly exhibit a decrease in strength at higher temperatures. Figure 3-6 also compares minimum SS304 yield strength data published in Reference 35 and 38. Again, large differences in these curves are attributed to differences in specimen fabrication history. 

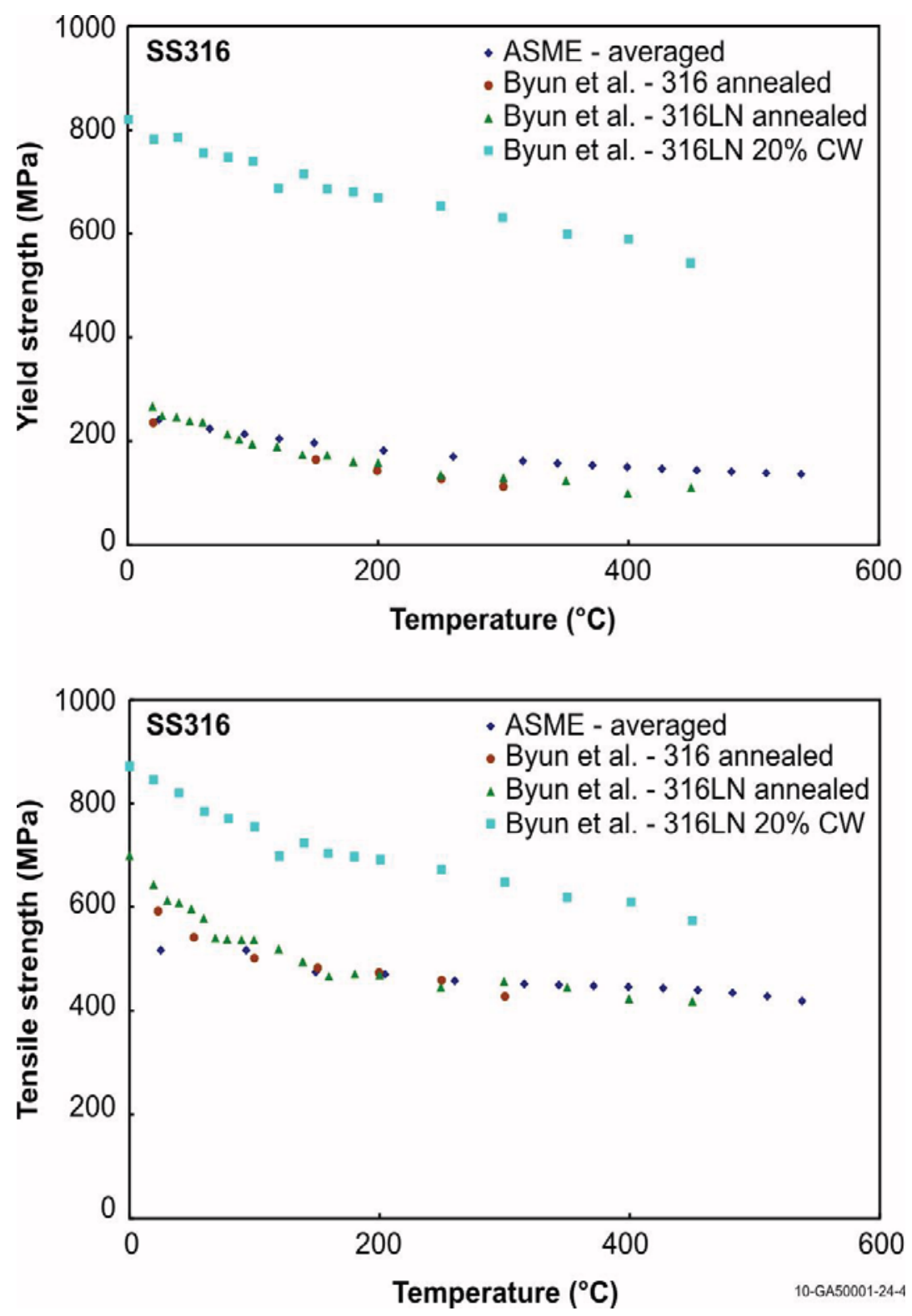

Figure 3-6. Temperature-dependent SS316 yield and tensile strength data. ${ }^{35,38}$

Young's moduli for SS304 are compared in Figure 3-7. As shown in this figure, all of the data exhibit a decrease in Young's Modulus as temperatures increase. With the exception of Cheng et al.'s data, Young's Modulus data also appear to be consistent with relatively little scatter. Cheng et al.'s data ${ }^{36}$ were obtained from specimens formed into hot-rolled bars and solution heat treated at $1150{ }^{\circ} \mathrm{C}$ for $1 \mathrm{~h}$ before machining and Byun et al.'s data ${ }^{38}$ were obtained from specimens annealed at $1050{ }^{\circ} \mathrm{C}$ for $30 \mathrm{~min}$ after machining. Data differences are attributed to differences in material composition, specimen fabrication history, and test uncertainties. 


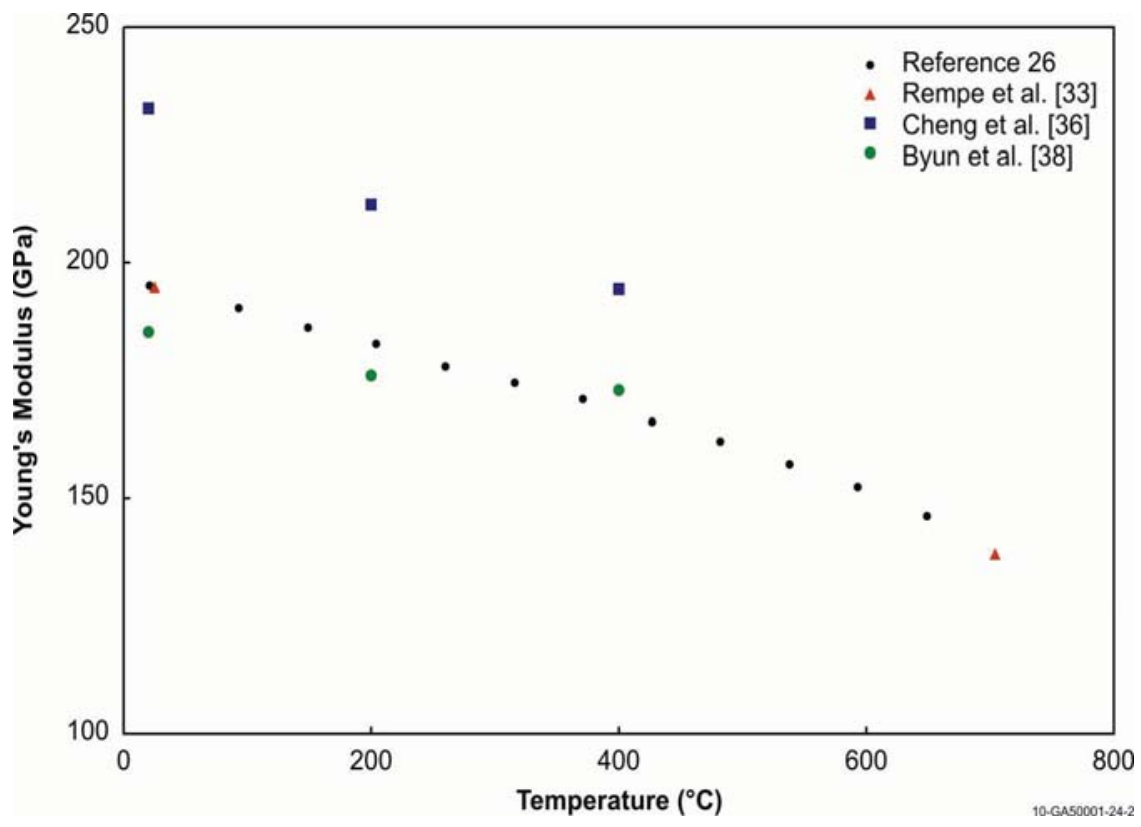

Figure 3-7. Temperature-dependent Young's modulus for SS304. ${ }^{26,33,36,38}$

Figure 3-8 compares engineering stress-strain curves for selected SS316 and SS304 austenitic stainless steels. ${ }^{38,39}$ These steels showed temperature dependencies relative to strength and ductility. Specifically, the strength decreased as temperature increased. Contrary to most other metals, the ductility did not decline systematically with decreasing temperature; rather, it peaked between $-100^{\circ} \mathrm{C}$ and room temperature $\left(20^{\circ} \mathrm{C}\right)$. Except for the $20 \%$ cold-worked specimens tested at room temperature or higher, tensile specimens showed high uniform elongations and relatively small necking elongations. (Hereafter, engineering strain will be expressed in percent [\%] to distinguish it from the true strain expressed as a fraction.)

As shown in Figure 3-9, stainless steel yield strength (YS) and ultimate tensile strength (UTS) decrease with increasing temperature. ${ }^{38}$ (Data shown were from specimens annealed at $1050{ }^{\circ} \mathrm{C}$ for $30 \mathrm{~min}$ after machining from a $1-\mathrm{mm}$ thick sheet that was $20 \%$ cold-rolled.) In the annealed steels, the yield strengths at $-150{ }^{\circ} \mathrm{C}$ were in the range $430-570 \mathrm{MPa}$, or 4-6 times those at $400{ }^{\circ} \mathrm{C}$. In the cold-worked stainless steel, however, the YS temperature dependence was much smaller; the YS at $-150{ }^{\circ} \mathrm{C}$ is $1040 \mathrm{MPa}$, less than 2 times that at $400^{\circ} \mathrm{C}$. The UTS displayed less significant temperature dependence than YS. For all tested materials, UTSs at $-150^{\circ} \mathrm{C}$ were in the range $1000-1400 \mathrm{MPa}$, whereas those at $400{ }^{\circ} \mathrm{C}$ were 400-610 MPa. Excluding the cold-worked material, the difference in the strength between the test materials was reduced a little at elevated temperatures. Meanwhile, at about $100{ }^{\circ} \mathrm{C}$ or higher, the $20 \%$ cold-worked 316LN stainless steel showed prompt necking at yield, resulting in zero uniform ductility. The other remarkable feature of the temperature dependence is the change in curve shape with test temperature. Above room temperature, except for some of the $20 \%$ cold-worked 316LN specimens showing prompt necking at yield, the engineering stress increased monotonically with engineering strain until necking intervened. At $-50^{\circ} \mathrm{C}$ or below, however, the austenitic steels showed two-stage hardening behavior; the initial parabolic hardening stage, where strain-hardening rate decreased with strain, ending at an engineering strain between 3 and 20\%, and an increase-decrease cycle of strain-hardening rate in a second hardening stage. Among the test materials, the annealed 316 steel displayed the weakest temperature dependence in the curve shape. 


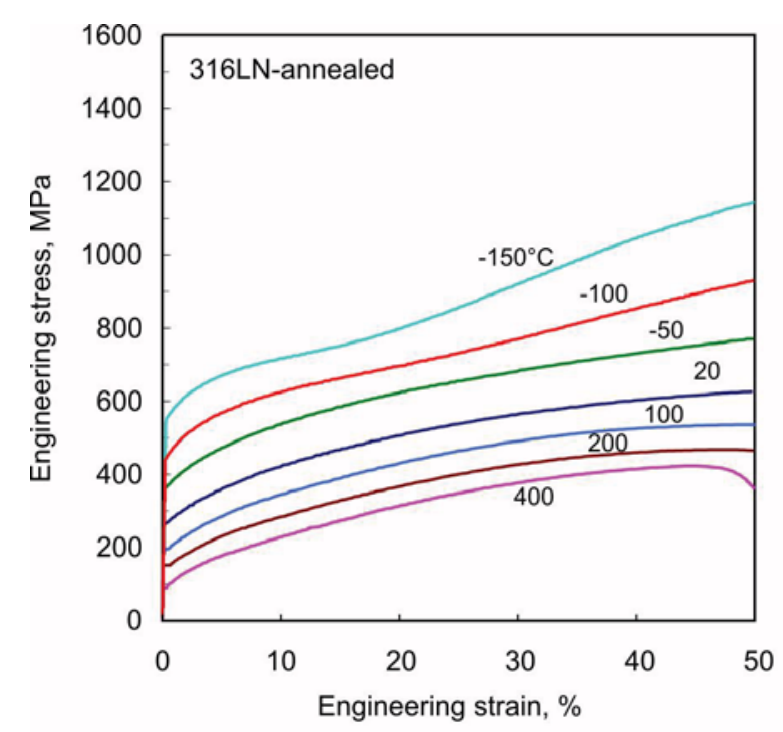

(a)

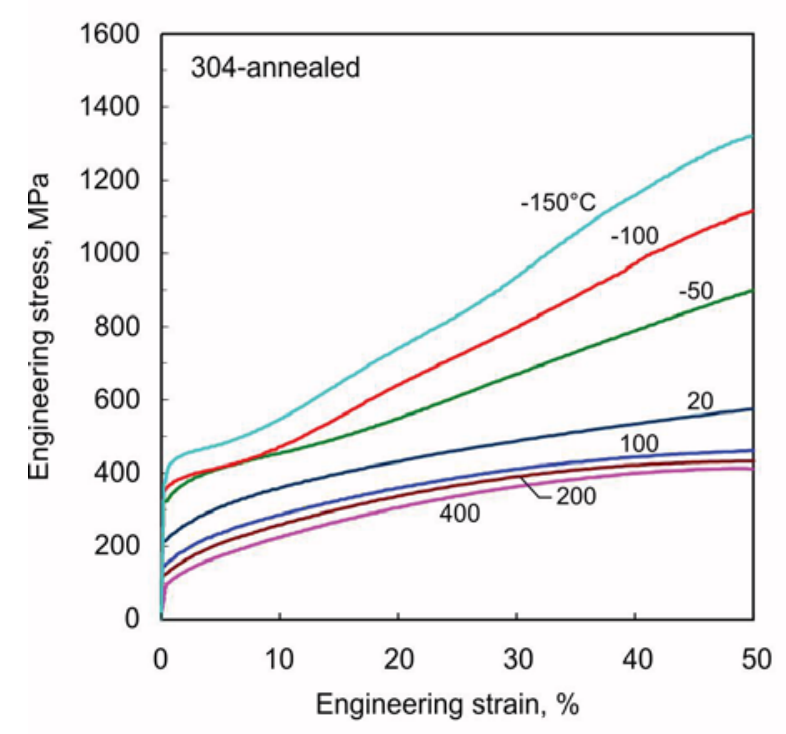

(c)

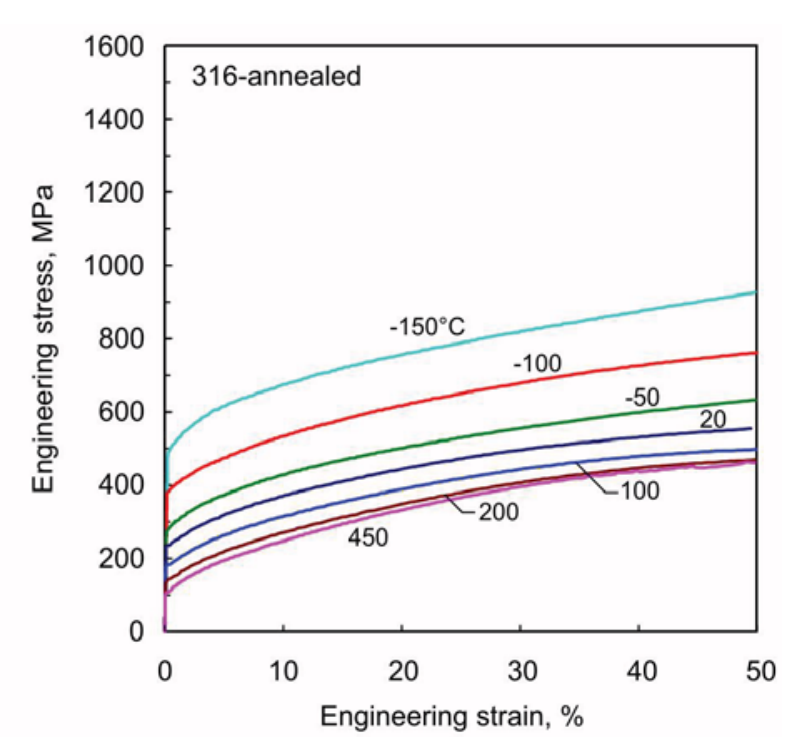

(b)

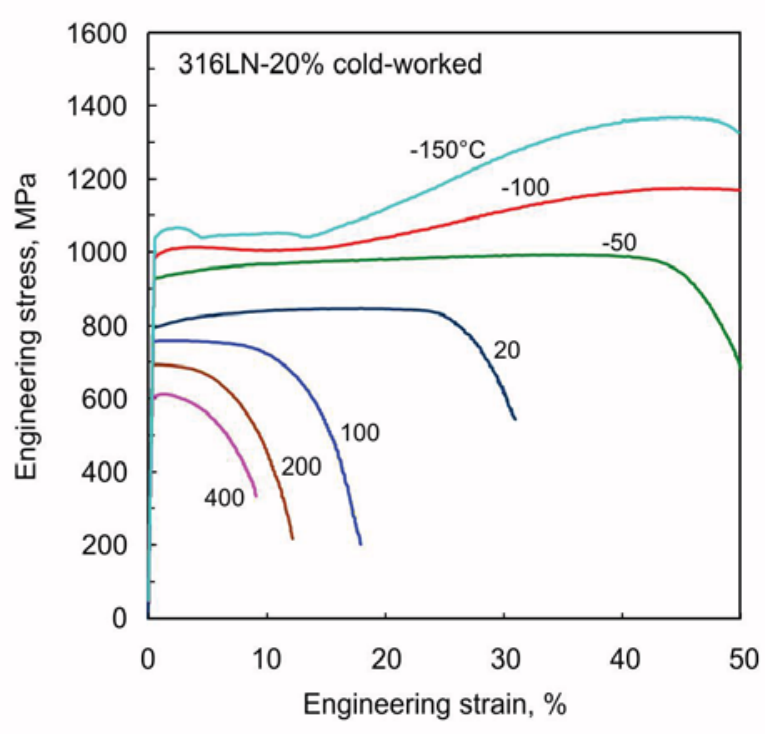

(d)

Figure 3-8. Temperature-dependent engineering stress - strain curves for (a) annealed 316LN, (b) annealed 316, (c) annealed 304, and (d) $20 \%$ cold-worked $316 \mathrm{LN}^{38,39}$

Figure $3-10^{36}$ compares temperature-dependent SS 304 stress-strain data with a proposed bilinear kinematic hardening model. The material used in this work is SS304 stainless steel. Its chemical composition (in wt \%) is $\mathrm{C}, 0.03 \%$; Ni, $9.8 \%$; $\mathrm{Cr}, 18.0 \%$; Mn, $1.7 \%$;, $\mathrm{S}<0.05 \%$; with the remainder, Fe. The hotrolled bar of the material was first treated by solution heat treatment at $1150{ }^{\circ} \mathrm{C}$ for 1 hour, and then machined into round and solid bar specimens for uniaxial test and tubular specimens for multi-axial tests. ${ }^{37}$ In this figure, there are no material data available for the temperature range $700-1400{ }^{\circ} \mathrm{C}$, for which linear interpolation method was used to obtain model parameters. It is seen that the tensile stress-strain curves decrease at higher temperatures. Likewise, the temperature increases, the yield strength and flow stress of the material decreases. 


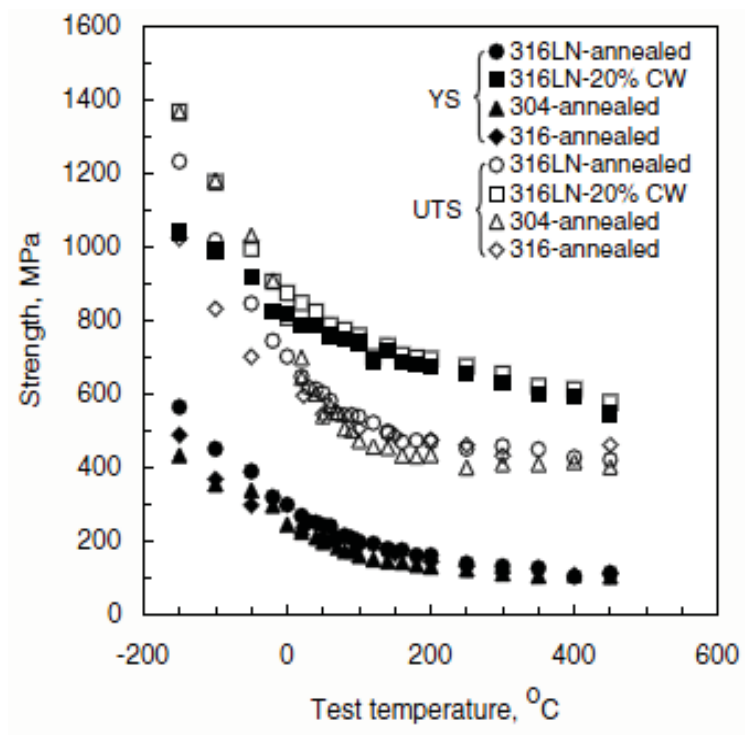

Figure 3-9. Temperature-dependent yield and ultimate tensile strength for stainless steels.

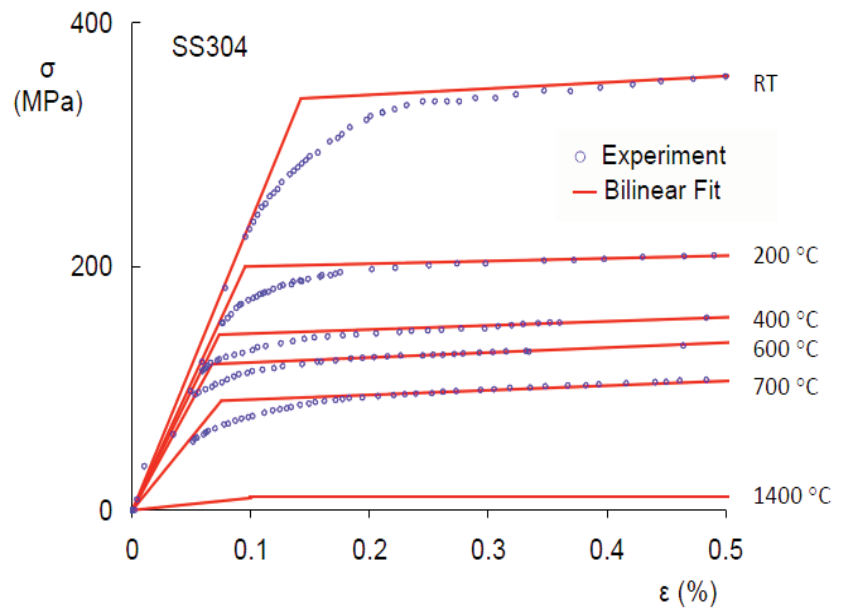

Figure 3-10. Temperature-dependent SS304 stress-strain data and the corresponding bilinear fit.

The temperature-dependent engineering stress-strain curves for unirradiated 304 stainless steels (SS304) found in the literature are compared in Figure 3-11.35,36,38 The temperature dependencies of true strain-hardening and plastic-instability properties are investigated for austenitic stainless steels; including annealed 304, 316, 316LN, and 20\% cold-worked 316LN (cold-worked samples were machined from a sheet that was $20 \%$ cold-rolled from a 1 -mm thick sheet.), at test temperatures from -150 to $450{ }^{\circ} \mathrm{C} .{ }^{38}$ The chemical compositions and thermo-mechanical histories of the materials are listed in Reference 38. The gauge section dimensions of sub-sized tensile specimens are $7.62 \mathrm{~mm}$ long, $1.5 \mathrm{~mm}$ wide and $0.75 \mathrm{~mm}$ thick. The temperature dependence of deformation and failure behaviors in these stainless steels in terms of equivalent true stress-true strain curves is analyzed, ${ }^{39}$ and the irradiation dose dependencies of strain hardening behavior during unstable deformation and fracture properties are studies based on the calculated true stress strain curves. ${ }^{40}$ 


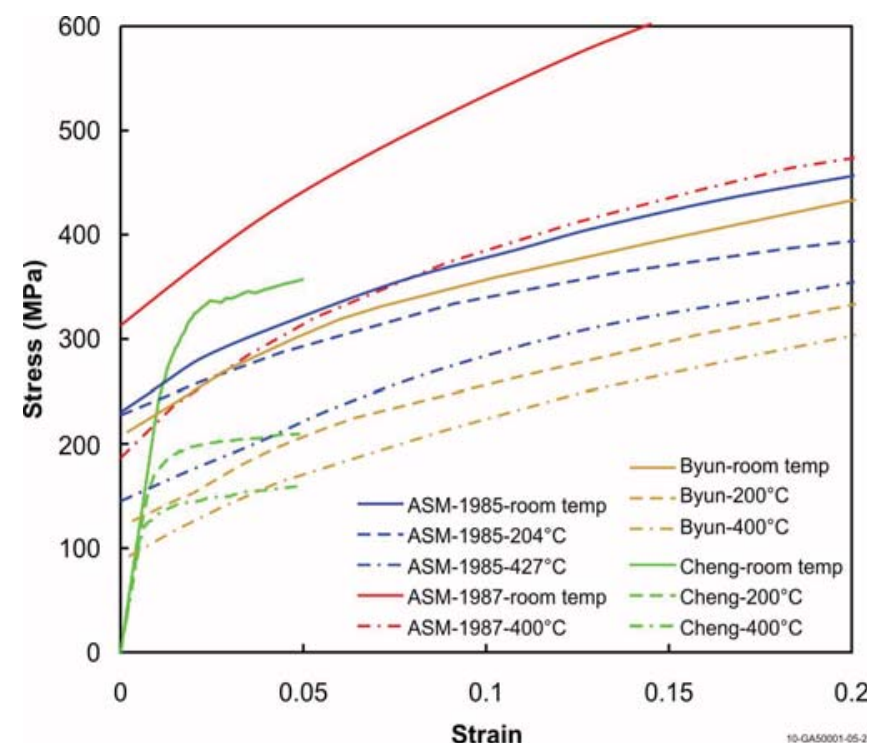

Figure 3-11. Temperature-dependent engineering stress-strain curves for 304 stainless steel.

\subsubsection{Inconel}

Inconel alloys are generally used in nuclear power reactors as spacer grids for fuel assemblies, for springs for safety rod accelerators, and other in-core components. There are limited data on mechanical properties as a function of temperature in the literatures although Inconel alloys, such as 600,718 , and X750 , are widely used in many fields of industry. Figure 3-12 compares typical yield and ultimate stress values and elongation of Inconel as a function of temperature recommended by their vendor. ${ }^{22}$ As the temperature increases, the yield strength and the tensile strength of Inconel alloys decrease. Tensile properties for temperatures up to $1373 \mathrm{~K}$, and creep data from 1005 to $1366 \mathrm{~K}$ for Inconel 600 are summarized in References 33 and 41. Figure 3-13 plots temperature-dependent ultimate strengths and compares it with data provided by the vendor. Figure 3-14 compares Young's Modulus of Inconel 600, 718 and X-750 as a function of temperature. ${ }^{2,23}$ Table 3-6 gives heat treatment conditions of Inconel 600, 718, and X-750 for data plotted in Figure 3-14.

Table 3-6. Heat treatment for Inconel alloy data plotted in Figure 3-14.

\begin{tabular}{|c|c|}
\hline Inconel & Condition \\
\hline 600 & $870^{\circ} \mathrm{C}\left(1600^{\circ} \mathrm{F}\right)$ for $1 \mathrm{hr}$ and air cooling \\
\hline 718 & $\begin{array}{l}1 \mathrm{hr} @ 982^{\circ} \mathrm{C}\left(1800^{\circ} \mathrm{F}\right) \text {, air cool }+8 \mathrm{hrs} @ 718^{\circ} \mathrm{C}\left(1325^{\circ} \mathrm{F}\right) \text {, furnace cool @ } 56^{\circ} \mathrm{C} / \mathrm{hr} \text { to } 621^{\circ} \mathrm{C} \\
\left(100^{\circ} \mathrm{F} / \mathrm{hr} \text { to } 1150^{\circ} \mathrm{F}\right) \text {, hold for } 8 \mathrm{hr} \text { and air cool }\end{array}$ \\
\hline $\mathrm{X}-750$ & $\begin{array}{l}1149^{\circ} \mathrm{C}\left(2100^{\circ} \mathrm{F}\right), 2 \text { to } 4 \mathrm{hr} \text {, air cool, intermediate age @ } 843^{\circ} \mathrm{C}\left(1550^{\circ} \mathrm{F}\right), 24 \mathrm{hr} \text {, air cool, final } \\
\text { age @ } 704{ }^{\circ} \mathrm{C}\left(1300{ }^{\circ} \mathrm{F}\right), 20 \mathrm{hr} \text {, air cool }\end{array}$ \\
\hline
\end{tabular}




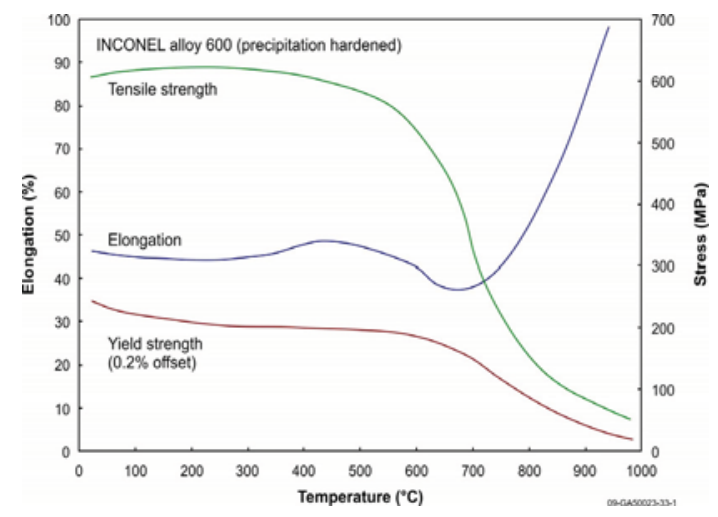

(a)

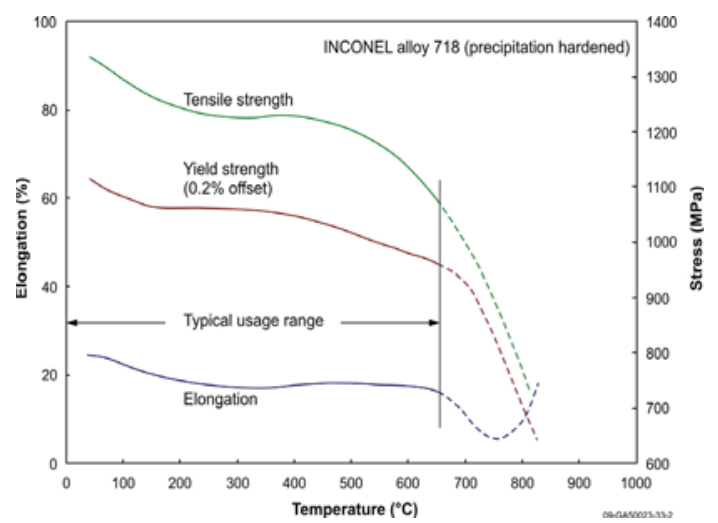

(b)

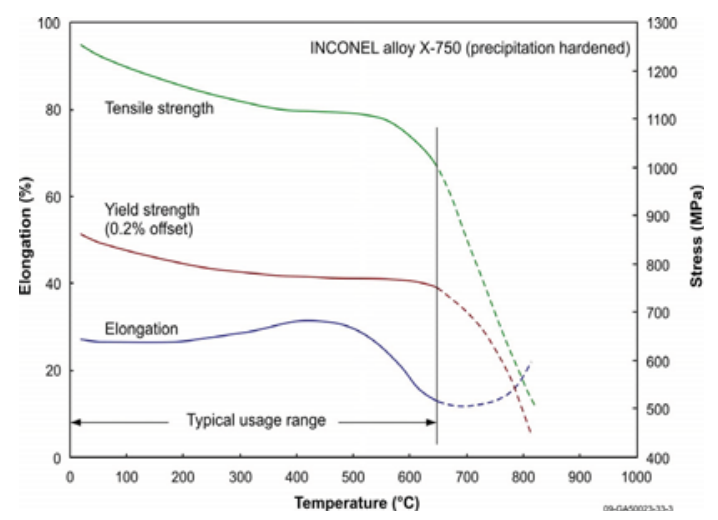

(c)

Figure 3-12. Mechanical properties of (a) Inconel 600, (b) Inconel 718 and (c) Inconel X-750.

\subsubsection{Nitronic Alloys}

Nitronic alloys, such as Nitronic 50 and 60, are produced by Electralloy under license from Armco, Inc. Room temperature yield strengths for these materials are nearly twice that of Types of 304 and 316 stainless steels. Figure 3-15 compares Nitronic 50 yield strength, tensile strength, and elongation as a function of annealing temperature. ${ }^{24}$ This figure shows there are some discrepancies of strength depending on the condition of heat treatment. That is, the higher the temperature of heat treatment (at either $1066{ }^{\circ} \mathrm{C}$ or $1121{ }^{\circ} \mathrm{C}$ ), the lower the yield strength and the tensile strength. Figure 3-16 shows data illustrating the temperature-dependent Young's Modulus of Nitronic 50.

Nitronic 50 has very good mechanical properties at both elevated and sub-zero temperature. It also has corrosion resistance greater than that provided by stainless steel Types 316, 316L. In addition, High Strength (HS) Nitronic 50 has a yield strength about three or four times that of Type 316. Generally, Nitronic 50 is supplied with annealing at $1066{ }^{\circ} \mathrm{C}$ and water quenching because this treatment provides a higher level of mechanical properties along with excellent corrosion resistance. 


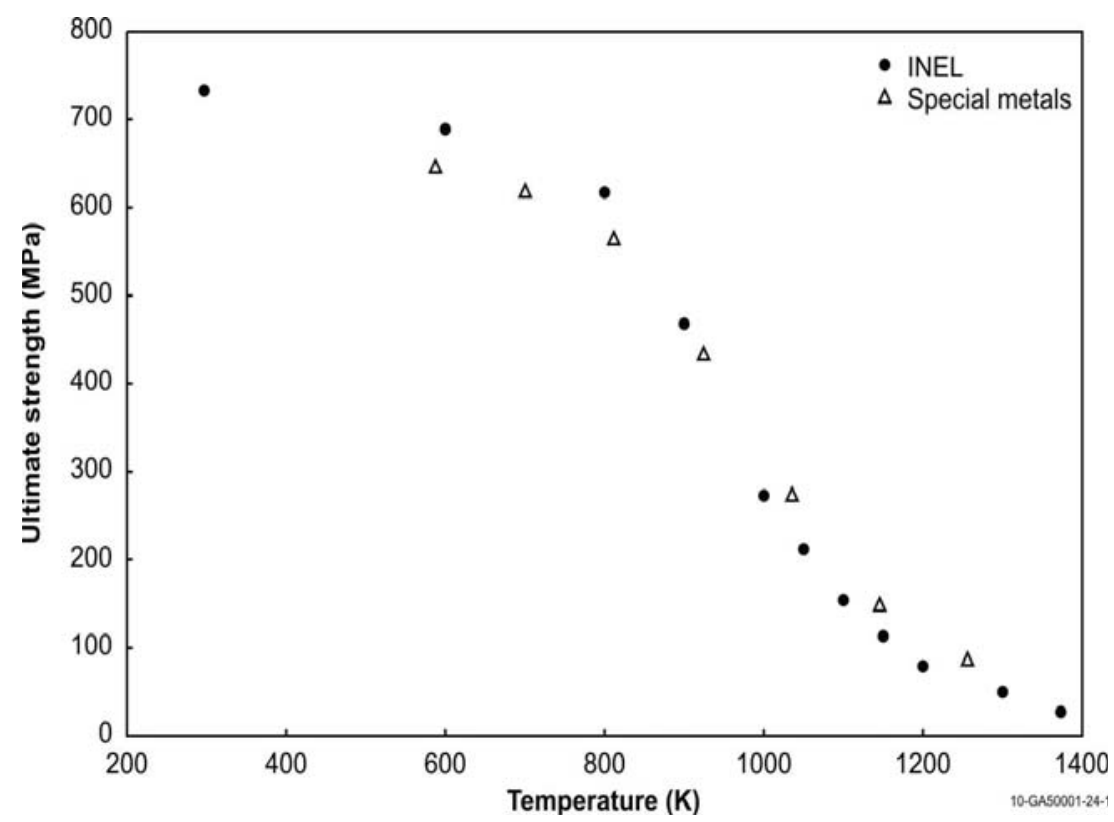

Figure 3-13. Inconel 600 ultimate strength-INL test results compared with Special Metals data. ${ }^{33}$

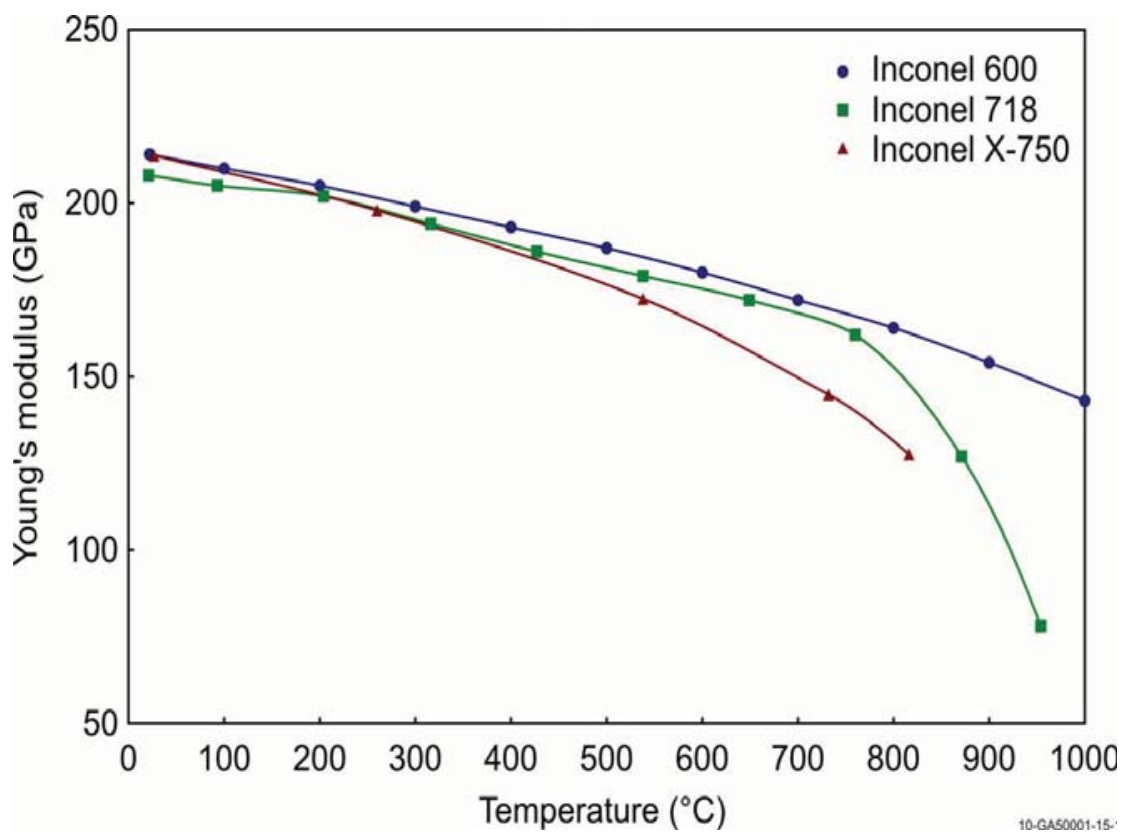

Figure 3-14. Young's Modulus of Inconel 600, 718 and X-750 as a function of temperature 


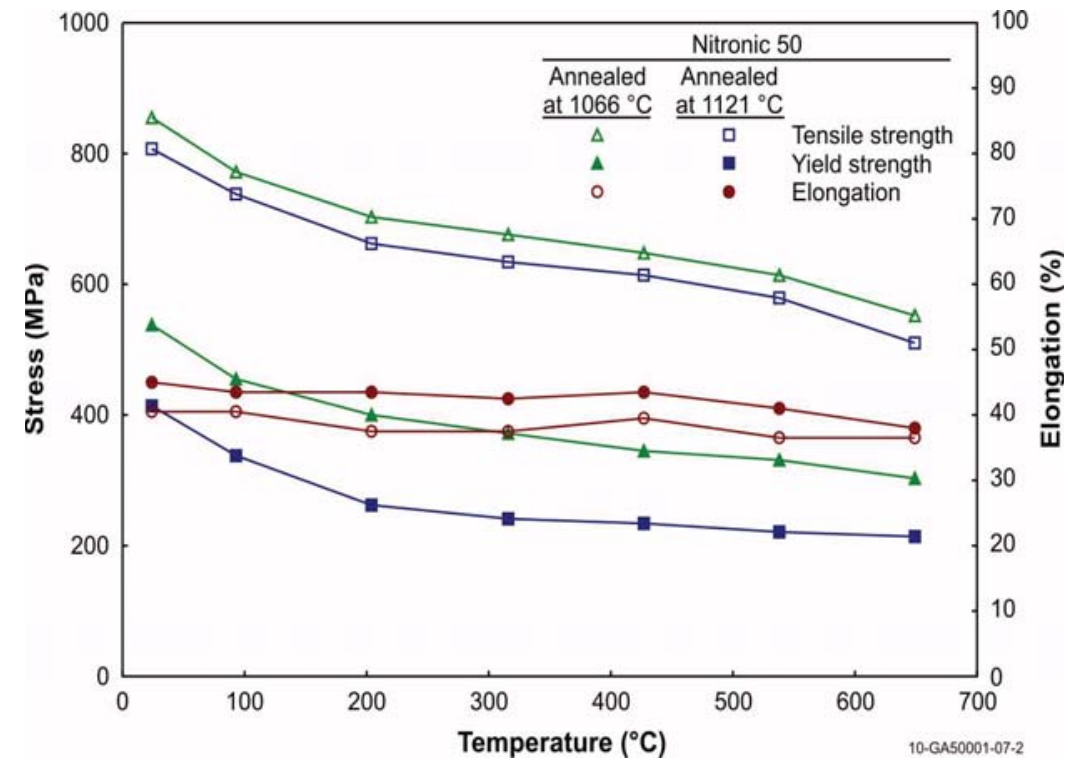

Figure 3-15. Yield strength, tensile strength and elongation of Nitronic 50 as a function of temperature.

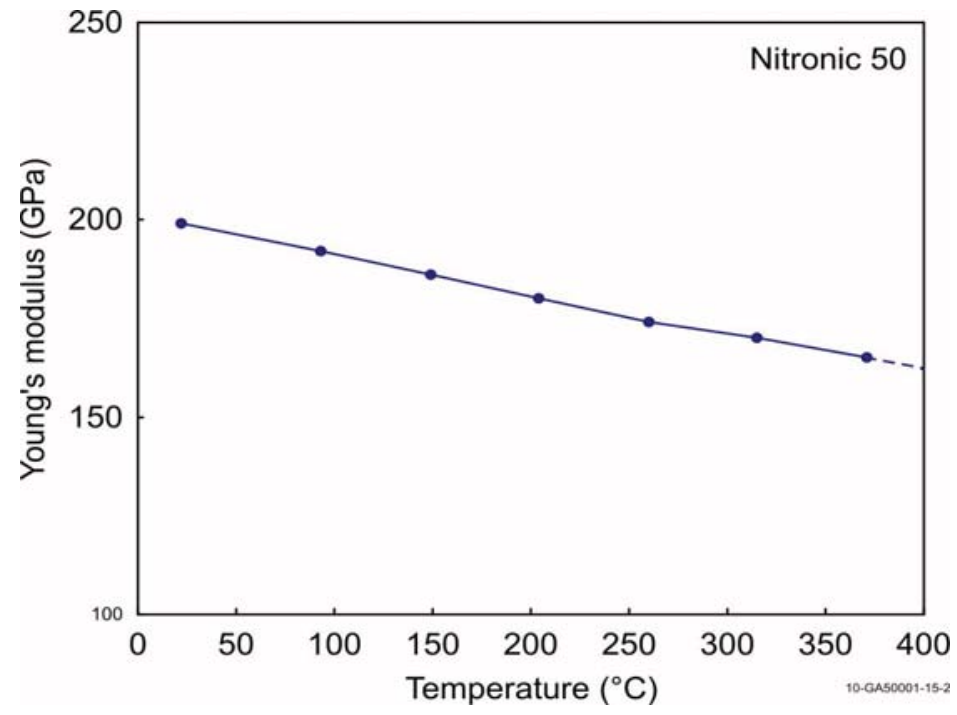

Figure 3-16. Young's Modulus of Nitronic 50 as a function of temperature.

\subsection{Summary}

The study of irradiation creep is an important concern for the core structures and the RPV of LWRs operating in the US with respect to life time extension. Most components of PWRs and BWRs are located in very harsh environments. These materials include low alloy steel, carbon steel, stainless steel, Inconel, etc. Existing data reviewed in this section for unirradiated materials illustrate the need for material-specific tests for stainless steel. Comparisons of data in the literature illustrate that there are large variations in 
parameters such as Young's Modulus, Yield Strength, and Ultimate Strength at room and elevated temperatures. Data were even more limited data for materials such as Inconel and Nitronic.

Stainless steels can be hardened by cold working, but not by heat treatment. Heat-treated stainless steels have excellent corrosion resistance, unusually good formability, and increase in strength as a result of cold work. Inconel alloys (600, 718 and X-750), nickel-chromium alloys, have good oxidation/corrosion resistance, and higher strength than that of stainless steels. Inconel 718 and X-750 have been precipitatehardened adding some elements, such as iron, niobium, molybdenum, aluminum and titanium, etc. Nitronic 50 (XM-19) is a type of austenitic stainless steels with enhanced corrosion resistance and approximately twice the yield strength at room temperature. 
INL/EXT-10-17779 


\section{IRRADIATED COMPARISON DATA}

As noted previously, the reactor vessel and its internal components are subjected to damage from highenergy neutron radiation. Large property and dimensional changes can occur in these materials due to radiation damage associated with radiation-induced segregation, precipitation hardening, embrittlement, and dimensional changes. The induced damage may impact the materials performance over an extended service period in LWRs, as discussed in Reference 19. The effects of irradiation on creep properties of various materials has been investigated by in-pile or/and post-irradiated creep test conducted using several methods; including MTRs, fission reactors, cyclotron or other setups. ${ }^{42-48}$ Irradiation creep has been extensively investigated to provide data that can be used for component analysis.

This section provides results from a review of irradiated data found in the literature for stainless steel, Inconel, and Nitronic materials. Available data for each material are presented in this section.

\subsection{Stainless Steel}

Irradiation creep of materials, in particular stainless steel, is an important concern in nuclear reactor structures, especially of fast breeder reactors and fusion reactors. ${ }^{13,15,49-55}$ Most irradiation creep studies on austenitic stainless steels focused on Type 316. Irradiation creep results of stainless steels are summarized in this section.

According to Reference 15, irradiation creep elongation was measured on stainless steel alloys (AMCR steels, 315 CE-reference steels, US-316 and US-PCA steels) of the irradiation temperature between 300 and $500{ }^{\circ} \mathrm{C}$ and stresses between 25 and $300 \mathrm{MPa}$ in the HFR at Petten. Table 4-1 shows the compositions of steel alloys tested in this investigation.

Table 4-1. The main compositions of steels (wt\%).

\begin{tabular}{|c|c|c|c|c|c|c|}
\hline Designation & $\mathbf{C}$ & $\mathbf{M n}$ & $\mathbf{N i}$ & $\mathbf{C r}$ & $\mathbf{S i}$ & $\mathbf{T i}$ \\
\hline AMCR-0033 & 0.105 & 17.50 & - & 10.12 & 0.555 & - \\
\hline AMCR-7758 & 0.062 & 28.6 & - & 10.0 & 0.87 & 0.87 \\
\hline AMCR-7763 & 0.10 & 19.4 & - & 10.2 & 0.94 & 0.85 \\
\hline CE-316 & 0.0024 & 1.81 & 12.32 & 17.44 & 0.46 & - \\
\hline US-316 & 0.06 & 2.0 & $10-14$ & $16-18$ & 1.0 & - \\
\hline US-PCA & 0.06 & $1.5-2.25$ & $15-17$ & $13-15$ & $0.4-0.6$ & $0.2-0.4$ \\
\hline
\end{tabular}

As indicated in this table, the AMCR steels contained larger amounts of chromium and smaller amounts of manganese than SS304 or SS316. However, results suggest that the AMCR and US steels would experience similar changes in the low dose region. As noted in Section 2.5, two kinds of irradiation creep facilities for uniaxial stresses were used at the HFR. One was the Trieste facility, in which 49 specimens could be irradiated at a time at various stresses and temperature, and the other the Crisp facility, in which the creep elongation of only three specimens could be measured at a time in situ during irradiation. 
The neutron flux density in the irradiation position in the HFR at Petten was $2 \times 10^{18} \mathrm{~m}^{-2} \mathrm{~s}^{-1}$ corresponding to a displacement rate of $1.7 \times 10^{-7} \mathrm{dpa} \mathrm{s}^{-1}$. After one or more reactor cycles, the irradiation rigs were removed. After a cooling down period of about two months, the lengths of the specimens were measured in a hot cell by means of a photoelectric incremental linear measuring system.

In the Trieste facility, dimensional changes as small as $\pm 1.5 \mu \mathrm{m}$ could be measured. This precision is much higher than that obtained in the Crisp facility in which the elongation changes were obtained in-situ at temperature during irradiation. The irradiation temperature of each measuring point could be determined with a precision of $\pm 10^{\circ} \mathrm{C}$ and the applied stresses with a precision of $\pm 15 \mathrm{MPa}$.

The length changes of five specimens of AMCR-0033 annealed at $400{ }^{\circ} \mathrm{C}$ prior to irradiation are plotted versus the neutron dose in Figure 4-1. The total length changes of the materials annealed at $400{ }^{\circ} \mathrm{C}$ after the solution anneal are much smaller than those of AMCR-7763. This was attributed to: (i) the solution annealed state could not be maintained on cooling the large bars of the AMCR-0033 alloys from which the specimens were cut, and (ii) the volume change due to carbide formation in AMCR-0033, which does not contain titanium, is much smaller than that in AMCR-7763. It appears inconsistent that the length decreases with increasing irradiation temperature as shown in Figure 4-1. It is known that this feature is connected with $\alpha$-ferrite formation, which increases with increasing irradiation temperature. It is also puzzling that creep elongation and creep rate are smaller for $75 \mathrm{MPa}$ than for $50 \mathrm{MPa}$ at the lower irradiation temperature (see Figure 4-1a.). This phenomenon has been frequently observed and is attributed to stressassisted formation of $\alpha$-ferrite. It was also found that $\alpha$-ferrite is formed without irradiation if nucleation sites are provided. ${ }^{15}$

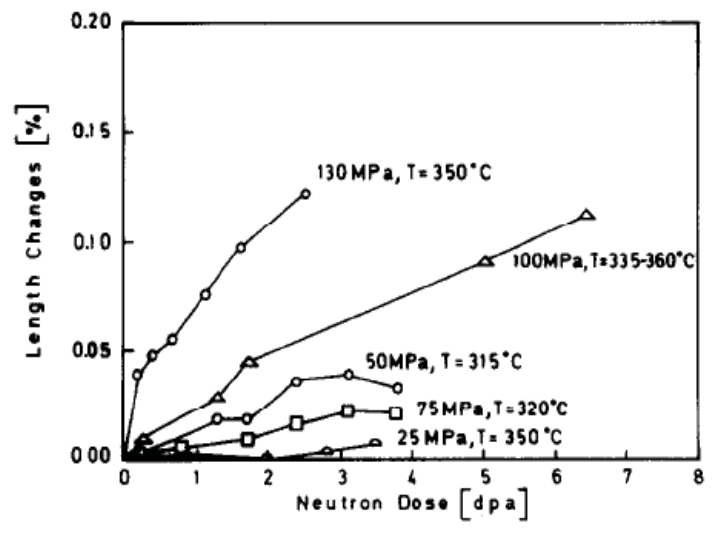

(a)

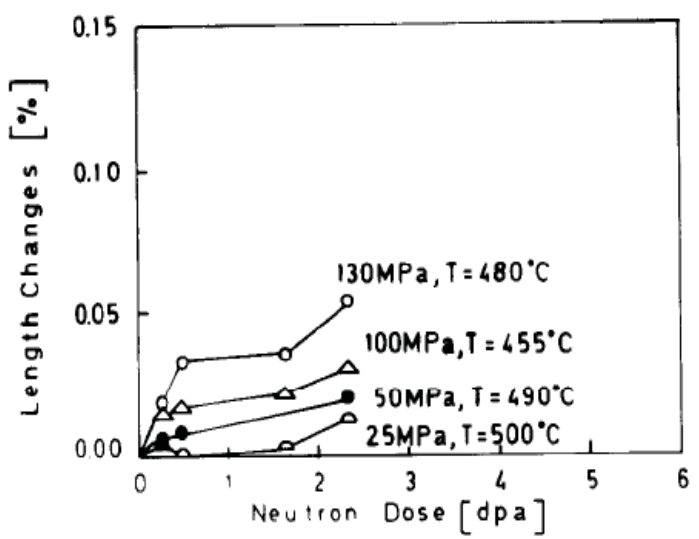

(b)

Figure 4-1. The length changes of specimen of AMCR- 0033 annealed at $400^{\circ} \mathrm{C}$ are plotted versus the neutron dose.

As mentioned in Reference 15, at the beginning of irradiation, a type of "primary" creep stage was observed for doses up to 3-5 dpa. The "primary" creep strain decreased in cold-worked steel materials with decreasing stress and decreasing irradiation temperature. Negative creep strains, depending on the pretreatment of the materials, are possible. The "primary" creep strain is mainly attributed to volume changes 
due to the formation of radiation-induced phases, e.g., to the formation of $\alpha$-ferrite below about $400{ }^{\circ} \mathrm{C}$ and of carbides below about $700{ }^{\circ} \mathrm{C}$, rather than irradiation creep. The "secondary" creep, which occurs after primary creep at doses larger than 3 to $5 \mathrm{dpa}$, is primarily attributed to irradiation creep. The irradiation creep rate is almost independent of the irradiation temperature $\left(Q_{i r r}=0.132 \mathrm{eV}\right)$ and linearly dependent on the stress.

\subsubsection{SS304}

Most irradiation creep experiments on stainless steels have emphasized the influence of concomitant swelling in some fast breeder reactors, fusion reactors and spallation neutron devices. The test data were used to evaluate the creep behavior at high dose (or high swelling) for breeder reactor application because of the relatively high swelling behavior of SA 304L relative to $20 \% \mathrm{CW} 316 \mathrm{SS}$. Usually, the low dose data are not analyzed in detail. Solution-annealed (SA) 304L stainless steel irradiation creep test data have previously been reported and analyzed. ${ }^{49}$ Irradiation tests on annealed 304L stainless steel, helium pressurized tubes varying from 0 to $188 \mathrm{MPa}$ of hoop stress, were performed in EBR-II at a temperature of $390{ }^{\circ} \mathrm{C}$ to a maximum dose of $93.3 \mathrm{dpa}$. The low fluence data are applicable to LWRs, where swelling is significantly reduced relative to other reactors. In the case of PWRs, the service behavior of baffle-former bolts and split pins are dependent upon irradiation creep. Hence, irradiation creep behavior at low doses needs to be carefully evaluated for application to light water reactors. These irradiation tests were performed using a 'cook and look' approach, where samples are irradiated in-situ for a period of time, removed from the reactor, measured in a hot cell, and then returned to the reactor. Results were used to evaluate irradiation creep behavior.

From the end of the 1970s, studies on the irradiation characteristics of Type 304 have mainly focused on the evaluation of swelling-induced irradiation at lower fluence levels (30-45 dpa). ${ }^{53,54}$ Recently, detailed evaluations on the swelling independent steady state creep rate coefficient were completed on annealed 304L stainless steel. ${ }^{55}$ The irradiated data of annealed 304L stainless steel used for the swelling evaluation were obtained from Reference 49 . The results show that the swelling $\left(\Delta \mathrm{V} / \mathrm{V}_{\mathrm{o}}\right)$ - independent steady state irradiation creep coefficient is equal to $0.380 \times 10^{-6} / \mathrm{MPa}$-dpa. Figures $4-2$ shows measured $\Delta \mathrm{D} / \mathrm{D}_{\mathrm{o}}$ versus dose in the high dose region for unstressed capsules (P-19 and P-21), the capsules with hoop stresses of $69 \mathrm{MPa}$ (P-32, P-39 and P-49) and the capsules with hoop stresses of $188 \mathrm{MPa}$ (P-38 and P-48). Figure 4-3 also shows measured $\Delta \mathrm{D} / \mathrm{D}_{\mathrm{o}}$ versus dose in the low dose region for unstressed capsules and the capsules with hoop stresses of 69 and $188 \mathrm{MPa}$ and presents an enlarged view of the low dose region and the least square fits. The low dose region is in the range of $0-17 \mathrm{dpa}$, and the high dose region is 17-89 dpa (the average of the maximum dose for all of the capsules). It is shown that in all cases, the 0 dpa intercept of the least square fit is negative. This is a result of not considering the irradiation strain accumulated during the first irradiation cycle and therefore the strain does not start at zero. The adjustment of the $\Delta \mathrm{D} / \mathrm{D}_{\mathrm{o}}$ values by the low dose intercept of the least square fit assumed that all of the $\Delta \mathrm{D} / \mathrm{D}_{\mathrm{o}}$ strain was due to swelling and irradiation creep. This assumption was considered to be approximate for the unstressed data; and in the case of the stressed data, reasonable for the following reasons. There are two possible effects that would result in deviations from the strain values initiating from zero. The effects are (1) second phase precipitation/densification and (2) transient irradiation creep. The negative value for the low dose intercept, shown in Figure 4-3, could be partly due to second phase precipitation rather than swelling during the first irradiation period. On the other hand, stress increases the negativity of the strain intercept at zero dose in the case of the stressed samples. For the stressed (69 and $188 \mathrm{MPa}$ ), the low dose intercepts are greater than for second phase precipitation/densification. Meanwhile, Reference 56 has shown that austenitic creep coefficient appear to be relatively independent of variables such as cold work, temperature and com- 
position. This can be seen that the effects of cold-working and composition on the creep coefficient appear to be relatively insignificant.

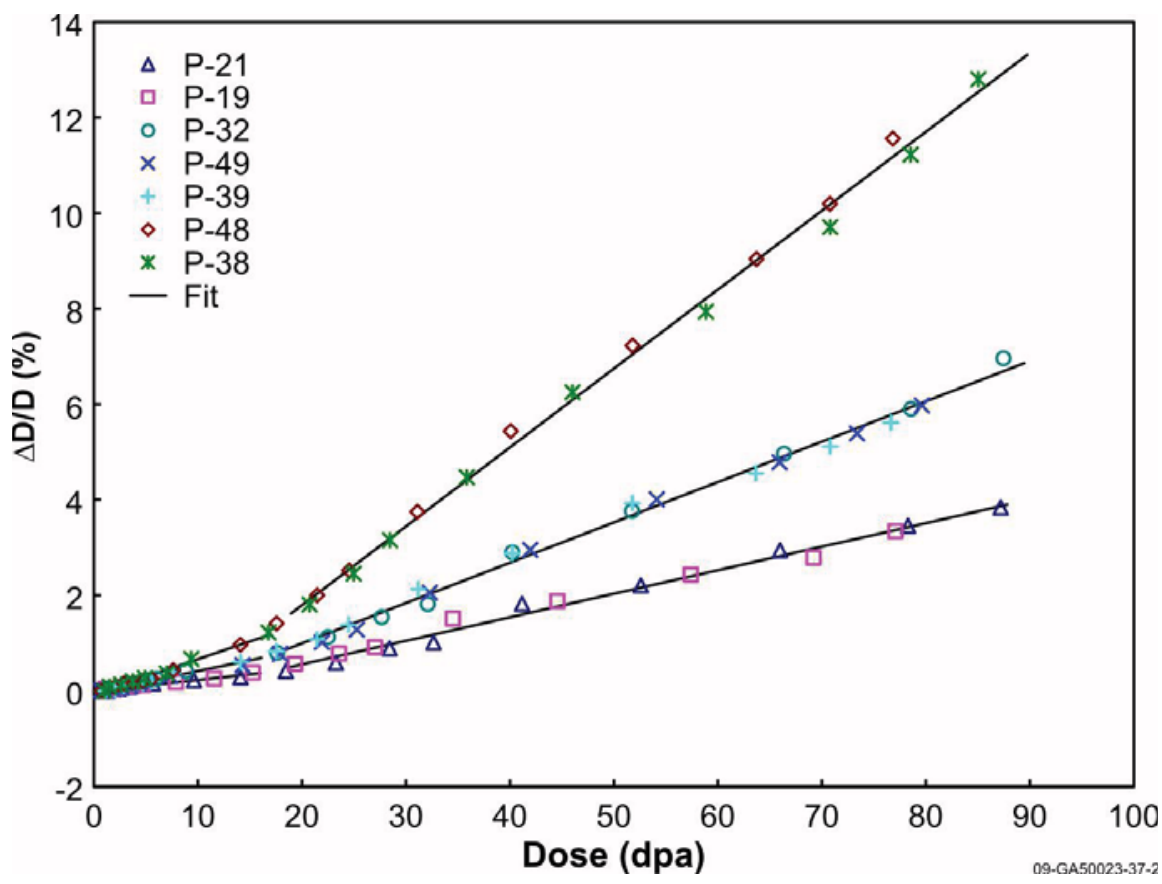

Figure 4-2. Measured $\Delta \mathrm{D} / \mathrm{D}_{\mathrm{O}}$ versus dose for the unstressed capsules (P-19, P-21), the capsules with a hoop stress of $69 \mathrm{MPa}(\mathrm{P}-32, \mathrm{P}-39, \mathrm{P}-49)$, and the capsules with a hoop stress of $188 \mathrm{MPa}$ (P-38, P-48).

\subsubsection{SS316}

Numerical calculations for radiation-induced creep and stress relaxation were performed to predict radiation-induced deformation of an Inconel X-750 bolt in an LWR core and of a 316 stainless steel blanket in experimental fusion reactors. ${ }^{50}$

Figure 4-4 shows some engineering stress-strain curves for irradiated 316 SS and EC316LN SS to analyze irradiation dose dependence. ${ }^{40}$ As shown in this figure, most engineering stress-strain curves are impacted by irradiation, exhibiting increases in strength and decreases in elongation. The one exception being $316 \mathrm{SS}$ tested at $288^{\circ} \mathrm{C}$, for which radiation effects were minimal. The chemical composition and thermo-mechanical treatment of the test materials and the irradiation and test conditions are summarized in Reference 40. There were two types of small-sized flat specimens for 316 SS and EC316LN SS, whose gage section dimensions are $8 \mathrm{~mm} \times 1.5 \mathrm{~mm} \times 0.25 \mathrm{~mm}$ and $5 \mathrm{~mm} \times 1.2 \mathrm{~mm} \times 0.25 \mathrm{~mm}$, respectively.

Figure 4-5 shows the calculated stress dependence of creep strain at 60 and $300{ }^{\circ} \mathrm{C}$ for the accumulated displacement of $2 \mathrm{dpa}$. In this figure, 'SA' and 'CW' designate 'solution annealed' and 'cold worked', respectively. At $60{ }^{\circ} \mathrm{C}$, the stress dependence is little stronger than that of $300{ }^{\circ} \mathrm{C}$ but still very weak. This low dependence on stress is believed to cause a very significant stress relaxation, as reported in Reference 57. Although the accumulated creep strain after $2 \times 10^{6} \mathrm{~s}$ of continuous irradiation at $60{ }^{\circ} \mathrm{C}$ is more than that of $300{ }^{\circ} \mathrm{C}$, the accumulated creep strain after $2 \times 10^{7} \mathrm{~s}$ of continuous irradiation at $300{ }^{\circ} \mathrm{C}$ is 


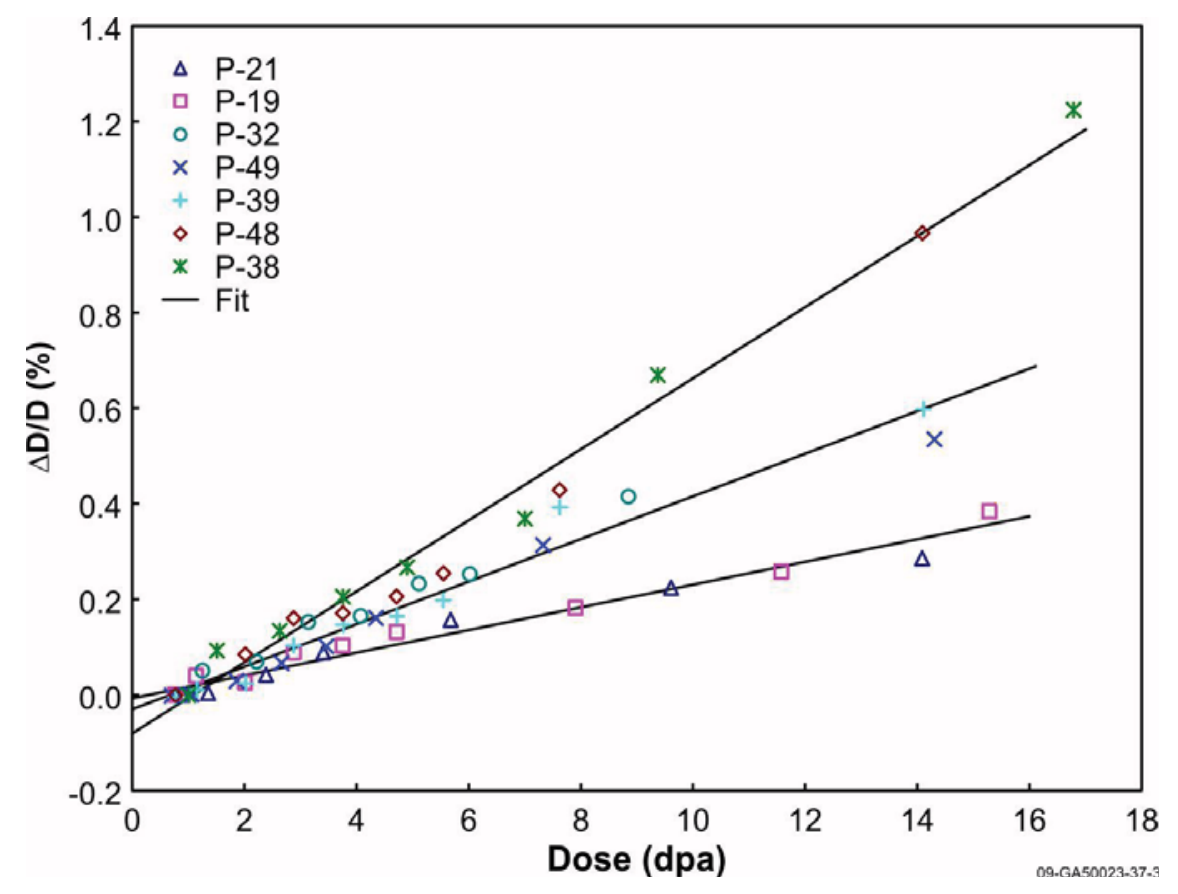

Figure 4-3. Measured $\Delta \mathrm{D} / \mathrm{D}_{\mathrm{o}}$ versus dose for the unstressed capsules (P-19, $\left.\mathrm{P}-21\right)$, the capsules with a hoop stress of $69 \mathrm{MPa}(\mathrm{P}-32, \mathrm{P}-39, \mathrm{P}-49)$, and the capsules with a hoop stress of $188 \mathrm{MPa}(\mathrm{P}-38, \mathrm{P}-48)$ in the low dose region.

more than that of $60{ }^{\circ} \mathrm{C}$. The accumulated creep strain at $300{ }^{\circ} \mathrm{C}, 1 \times 10^{-6} \mathrm{dpa} / \mathrm{s}$, is more than $1 \%$, while that at $60^{\circ} \mathrm{C}, 1 \times 10^{-8} \mathrm{dpa} / \mathrm{s}$, is much smaller (although large enough to cause significant radiation-induced stress relaxation).

\subsection{Inconel}

Nickel-base alloys as Inconel 600, 718 and X-750 has been successfully used in fission reactors for grid spacers for fuel elements and for springs for safety rod accelerators, etc. Alloy X-750 of Inconel is used to repair hardware of boiling water reactor (BWR) core shrouds. However, very few data are found in the literature on the dimensional stability of Inconel alloys under neutron irradiation. Several neutron irradiation studies were carried out on commercial Ni-base alloys, including Alloys 600, 625, 702, 718, 800, 706, PE16, Hastelloy X, and Rene 41, in the 1958-1974 time frame. ${ }^{58}$ Proton irradiations were completed to investigate effects of irradiation on the microstructure of Inconel 600 alloy. ${ }^{59,60}$ In addition, tensile properties of Inconel 718 have been investigated after neutron irradiation to $0.0006-1.2 \mathrm{dpa}$ at $60-100{ }^{\circ} \mathrm{C}$ in the High Flux Isotope Reactor (HFIR) at Oak Ridge National Laboratory (ORNL), as well as SA 316LN stainless steel are also included for comparison. ${ }^{61}$ In this section, available irradiation creep results for Inconel alloys are summarized.

Figures 4-6 and 4-7 show the engineering tensile test curves and true stress-true strain curves of precipitation-hardened Inconel 718 (PH IN718) and solution-annealed Inconel 718 (SA IN718), respectively. ${ }^{61}$ The chemical composition of the alloy (Inconel 718 ) was, in $\mathrm{wt} \%, 18.3 \mathrm{Fe}, 18.13 \mathrm{Cr}, 5.07 \mathrm{Nb}$, 

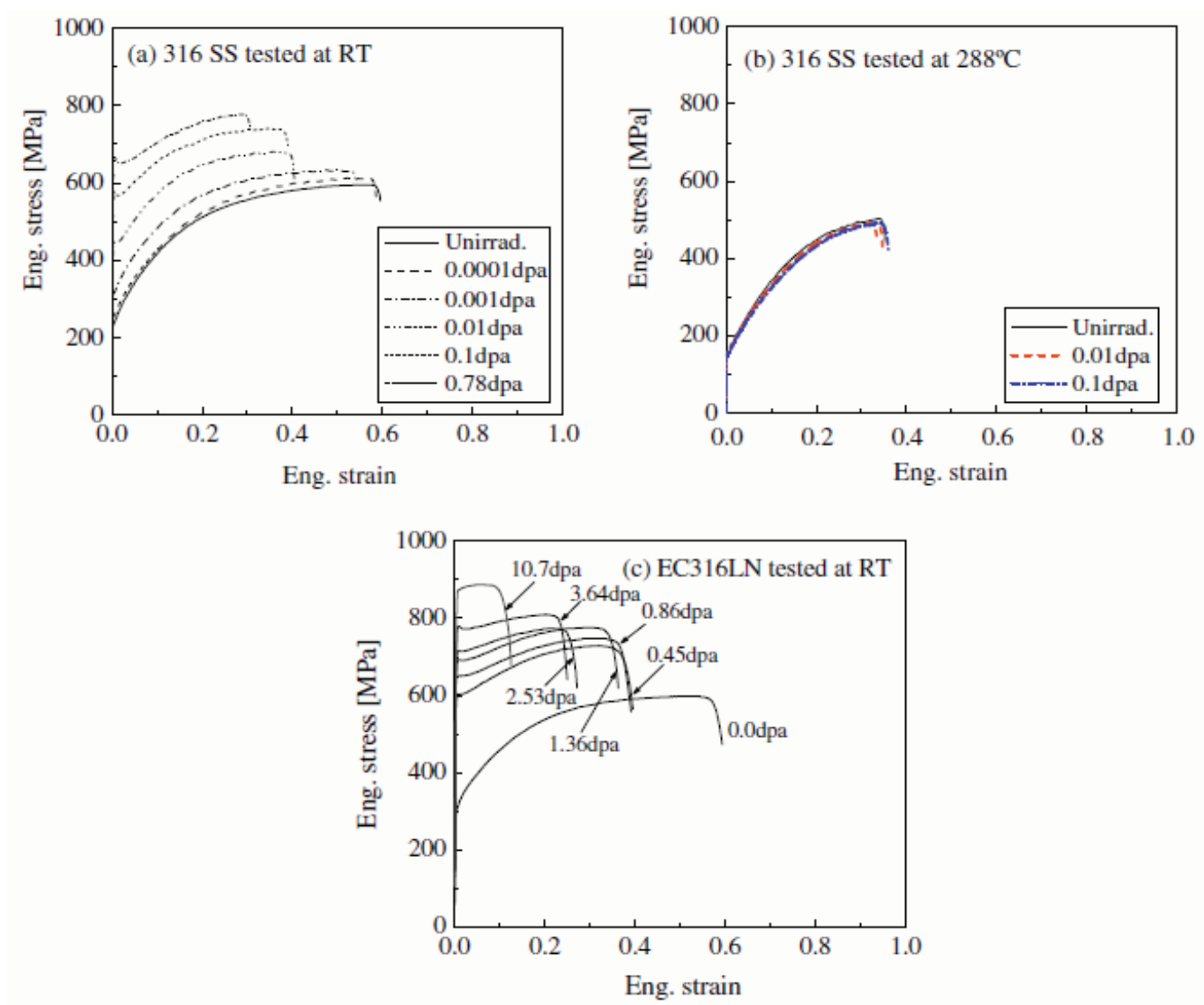

Figure 4-4. Engineering stress-strain curves for irradiated austenitic stainless steels.

3.0Mo, $1.1 \mathrm{Ti}, 0.54 \mathrm{Al}, 0.4 \mathrm{Co}, 0.21 \mathrm{Mn}, 0.13 \mathrm{Si}, 0.05 \mathrm{C}$ with the balance Ni. Flat tensile specimens of nominal gage section dimensions of $0.76 \mathrm{~mm}$ thick, $1.5 \mathrm{~mm}$ wide, and $7.6 \mathrm{~mm}$ long were cut from sheet material in the rolling direction. Machining and sanding operations were completed before the specimens were heat-treated. All specimens were solution-annealed in a vacuum at $1065{ }^{\circ} \mathrm{C}$ for $30 \mathrm{~min}$. Then, some SA specimens were aged, or precipitation hardened, at $750^{\circ} \mathrm{C}$ for $10 \mathrm{~h}$ followed by $20 \mathrm{~h}$ at $650{ }^{\circ} \mathrm{C}$ to form $\gamma^{\prime}$ and $\gamma$ ' precipitates in the austenitic matrix. As shown in Figure 4-6, the engineering stresses of the PH IN718 are high and are not strongly affected by irradiation. Elongation reduces with increasing dose. In the dose range $0-0.054 \mathrm{dpa}$, the material retained positive strain-hardening rate until plastic strain reached $9 \%$ or more. At higher doses, the specimens showed short strain hardening in early deformation but started to deform in an unstable mode at small plastic strains of about $1.5 \%$. The SA IN718 is much weaker than the PH IN718, and it shows larger fractional increase in radiation-induced strengthening. Small yield drops and/or short plateaus are present at yield in the stress-strain curves after irradiation. Unlike the PH IN718, the SA IN718 retained high elongation after irradiation; the uniform elongation was more than $20 \%$ at the highest dose of $1.2 \mathrm{dpa}$. Figure 4-7 presents the true stress $(\sigma)$-true strain $(\varepsilon)$ curves in the uniform deformation range calculated from the engineering stress-strain curves in Figure 4-6. The slopes of the curves, strain-hardening rate $(\mathrm{d} \sigma / \mathrm{d} \varepsilon)$, decreased as dose increased. After yield, or yield plateau, for the annealed and irradiated specimens, the stress-strain curves showed positive strain hardening until a plastic instability occurred at the uniform deformation limit, which corresponds to the ultimate load. 


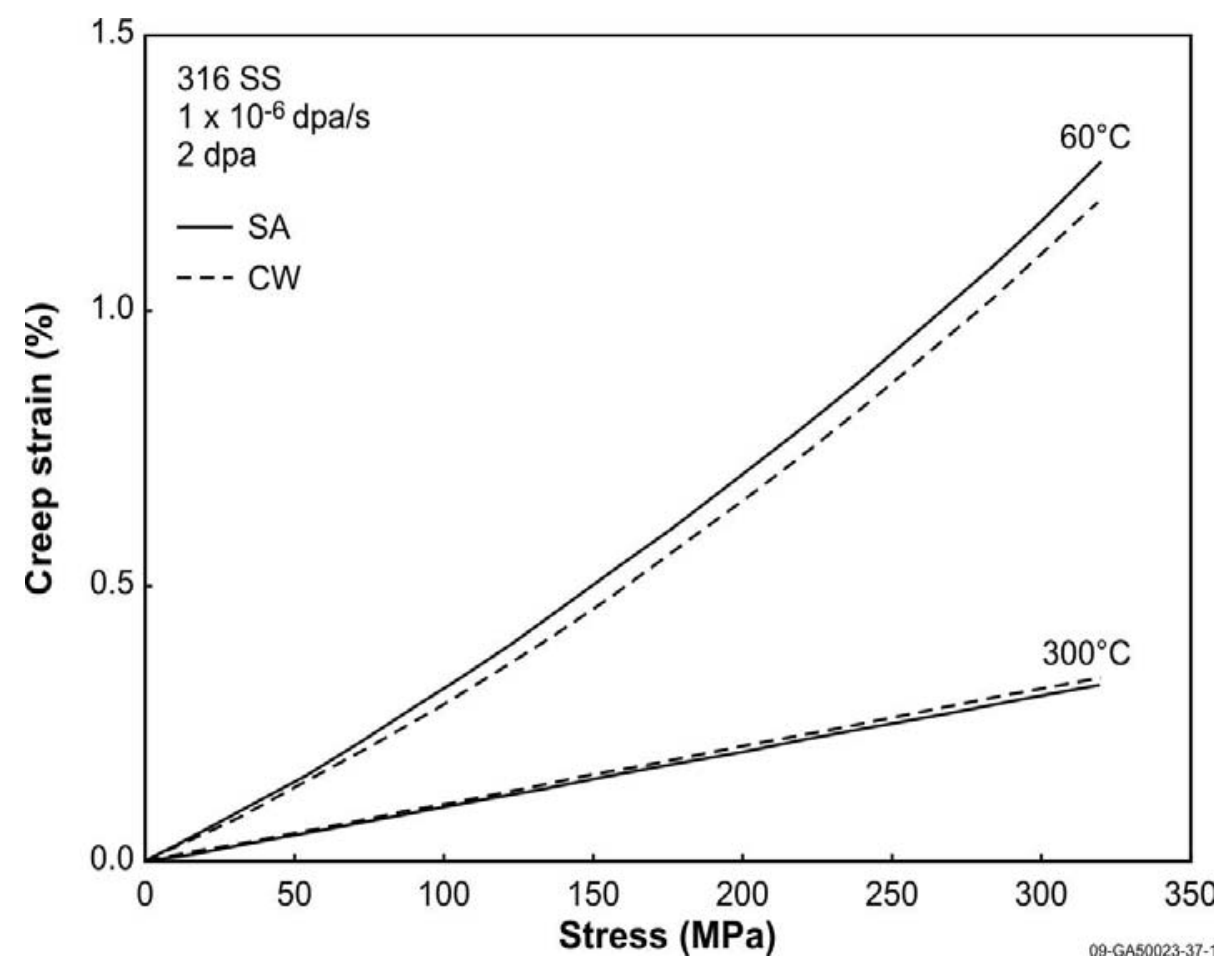

Figure 4-5. Calculated stress dependence of irradiation creep strain of SS316 at 2 dpa for $60{ }^{\circ} \mathrm{C}$ and $300{ }^{\circ} \mathrm{C}$.

As summarized in Reference 61:

(1) In the SA IN718, an almost threefold increase in yield strength was found at $1.2 \mathrm{dpa}$; and the material retained a strong strain-hardening capability and a high uniform ductility of more than $20 \%$. However, the originally much stronger PH IN718 displayed little radiation-induced hardening in yield strength and significant softening in ultimate tensile strength.

(2) The strain-hardening behavior of the SA IN718 was shown to be similar to that of SA 316LN austenitic stainless steel and their average strain-hardening rate decreased slightly with dose. The IN718 in PH condition displayed much higher strain-hardening rates than in SA condition; however, it experienced larger deterioration of strain-hardening capability after irradiation.

Figure 4-8 shows the temperature dependence of hardening for Alloy 718 in a solution treated (ST) condition. ${ }^{58}$ For a dose of $20 \mathrm{dpa}$, hardening persisted up to $600^{\circ} \mathrm{C}$; then decreased with increasing irradiation temperature, becoming negligible at $735^{\circ} \mathrm{C}$. Ductility values were strongly reduced by irradiation with a ductility decrease at $550 \sim 625^{\circ} \mathrm{C}$ in tests carried out at the irradiation temperature. In this range, failures occurred at maximum load with total and uniform strains of 1 2\%. An even more severe level of embrittlement was encountered when testing was carried out at temperatures above the irradiation temperature $\left(\mathrm{T}_{\mathrm{i}}\right)$, in order to simulate possible off-normal temperature excursions in a fuel pin. Under these conditions, failure occurred soon after yielding with uniform and total strains in the range $0.1 \sim 0.2 \%$. 

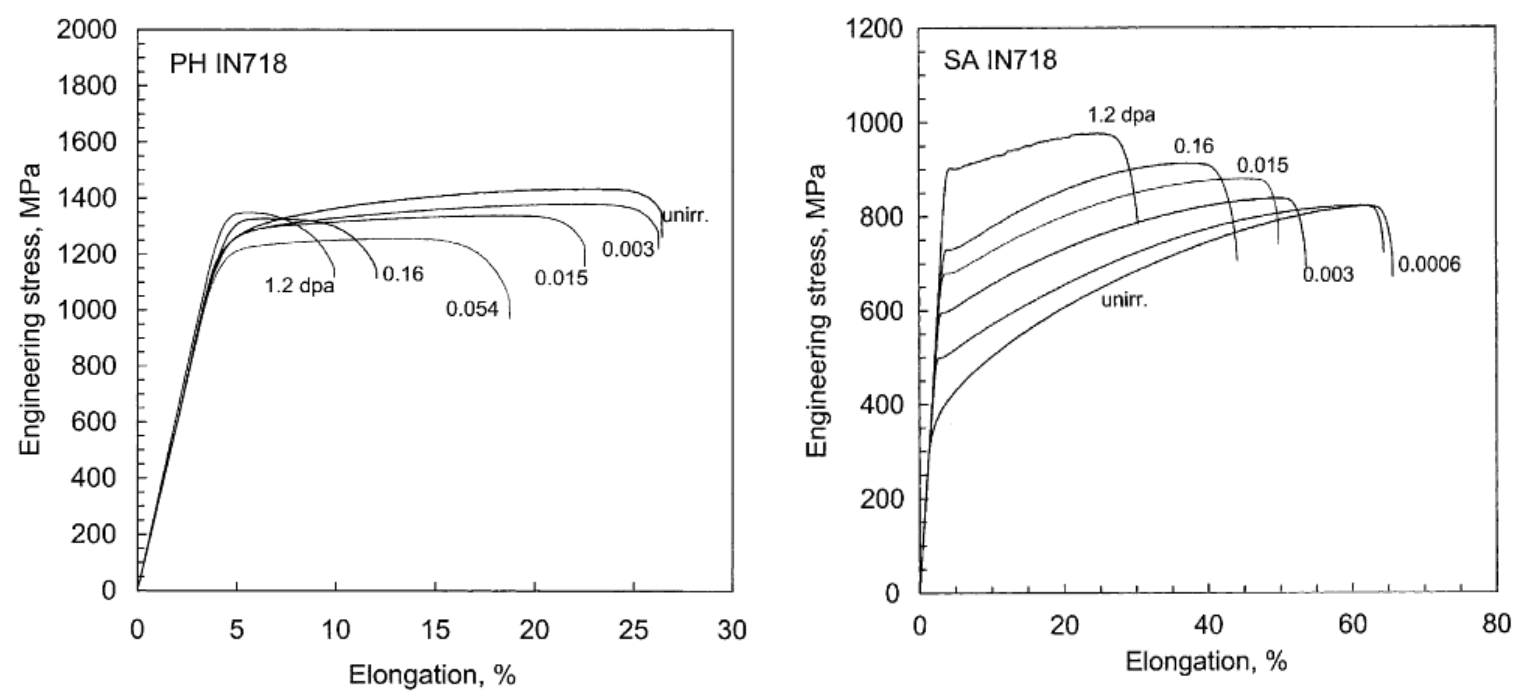

Figure 4-6. Engineering stress-strain curves of precipitation-hardened Inconel 718 (PH IN718) and solution-annealed Inconel 718 (SA IN718) at various doses.

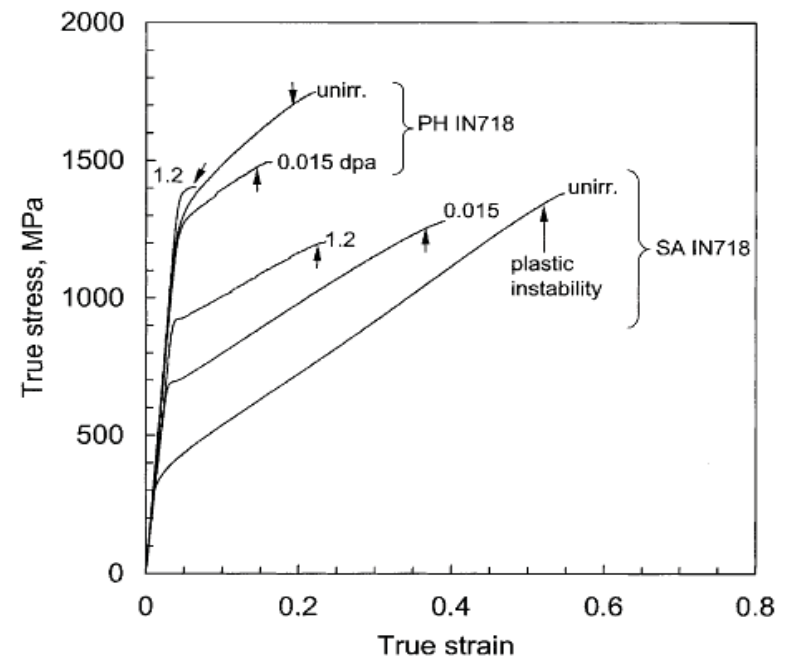

Figure 4-7. True stress-true strain curves of precipitation-hardened Inconel 718 (PH IN718) and Solution-annealed Inconel 718 (SA IN718).

$\mathrm{SCK} \cdot \mathrm{CEN}$ conducted irradiation creep test of Inconel 718 exposed to 0.3 and $0.5 \mathrm{dpa}$ at $300{ }^{\circ} \mathrm{C}$ in BR2 to obtain data for loading conditions typical of the actual operation conditions of the bolts in ITER. ${ }^{42}$ In these tests, specimens were irradiated, and creep data were obtained during PIE. The pressurized tube specimens were prestressed to about $80 \%$ of the yield strength. Irradiation-induced creep deformation is then used to determine the equivalent stress relaxation ratio. Two test geometries were selected for irradiation: the tensile round specimen to determine the tensile properties, and the pressurized tube for the creep 


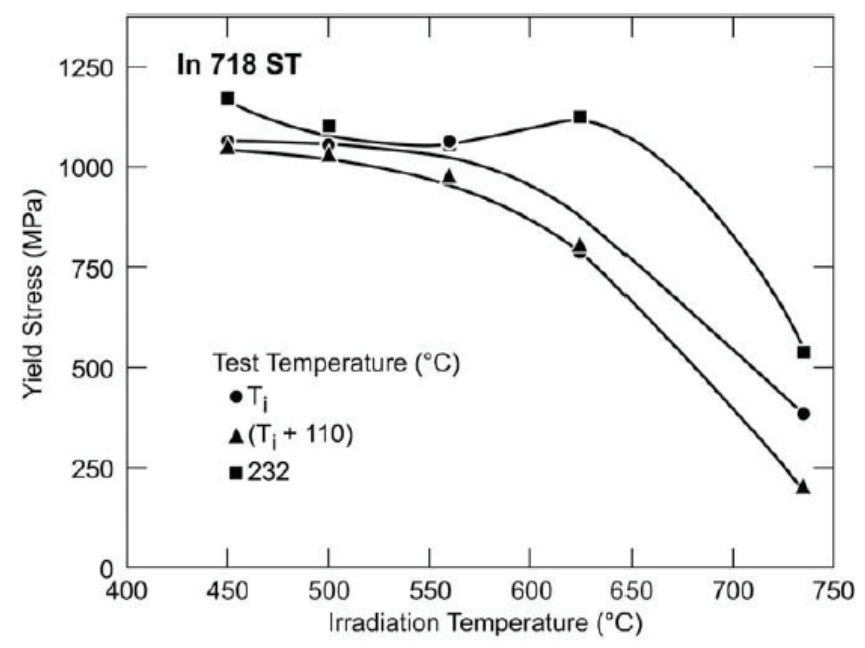

Figure 4-8. Yield stress versus irradiation temperature, $T_{i}$, for Alloy 718 in the solution treated condition, irradiated $\sim 20$ dpa and tested at three different temperatures.

experiments. The specimen geometry and size are selected to fit within available space in the irradiation rig. The tensile specimen is such that the gauge length is cylindrical with a nominal length of $18 \mathrm{~mm}$ and $3 \mathrm{~mm}$ diameter. Tubing with $6.0 \mathrm{~mm}$ OD (outer diameter) and $5.4 \mathrm{~mm}$ ID (inner diameter) was used to manufacture the specimens (see Figure 4-9). The tubes were laser welded and pressurized to operate at hoop stresses close to $1000 \mathrm{MPa}$ at the nominal irradiation temperature $\left(\mathrm{T}=300{ }^{\circ} \mathrm{C}\right)$. The laser welding parameters were optimized to allow high pressures without failure. As shown on Figure 4-9, one end cap had a capillary hole to allow specimen pressurization. The tubes are filled with argon at liquid nitrogen temperature. The volume or weight of argon introduced in the tube is such that after sealing the capsule and heating to the operating temperature, the desired pressure (or stress) was reached.

The irradiation rig is schematically shown in Figure 4-10. Based on the flux distribution of the BR2 reactor, the specimen arrangement is chosen such that two irradiation levels are reached, i.e. $\sim 100 \%$ and $\sim 65 \%$ of the maximum fluence. A third position located outside the active zone is used for the reference specimens. Five Fe-neutron flux monitors were incorporated in each of the three irradiation needles containing the specimens (see Figure 4-10). The specimens were irradiated for 2 cycles in the BR2 reactor, i.e., cycles $3 / 99$ and 5/99. The average cumulated fast neutron $(\mathrm{E}>1 \mathrm{MeV})$ after two cycles, calculated from the power delivered from the surrounding fuel elements, is estimated to be $3.52 \times 10^{20} \mathrm{n} / \mathrm{cm}^{2}$ at the mid plane level (maximum flux location). The specimens were irradiated in the Callisto loop in a pressurized flowing water at $310 \pm 10^{\circ} \mathrm{C}$ and 155 bar. The temperature of the water is continuously monitored.

The measured creep strain is plotted as a function of neutron fluence in Figure 4-11. Within the investigated range, the effective strain varies linearly with the neutron fluence. Figure 4-12 shows how the effective creep strain varies with the applied effective stress and neutron exposure. The differences between the various dose levels are the most significant at the highest applied stress ( 880 MPa). At the two other stress levels, an average $0.1 \%$ creep deformation is measured at 0.3 and $0.5 \mathrm{dpa}$. However, it should be kept in mind that the initial specimen diameter was assumed to be constant (5.995) for all samples within a $90 \%$ confidence band of $\pm 2.6 \mu \mathrm{m}$, and therefore, the creep strain is known with a $\pm 0.05 \%$ accuracy (see Figure 4-12). It also is found that the stress level does not affect the stress relaxation ratio. 

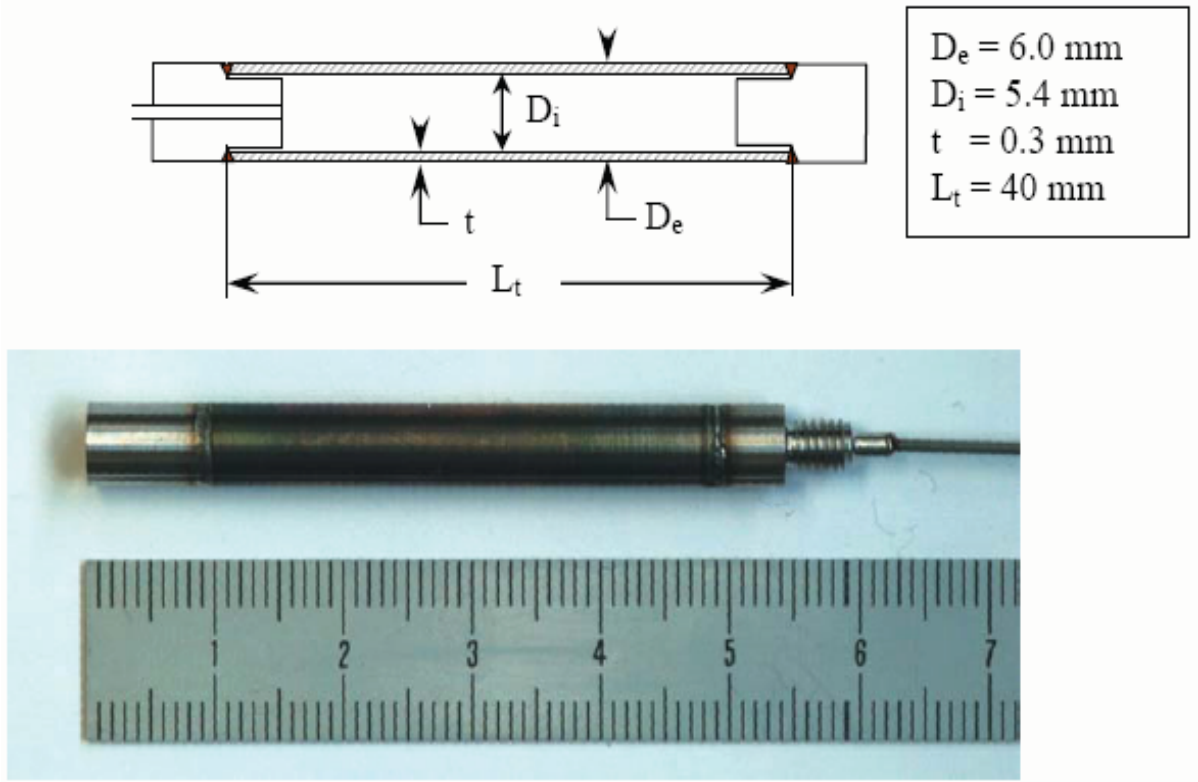

Figure 4-9. Creep test tube geometry

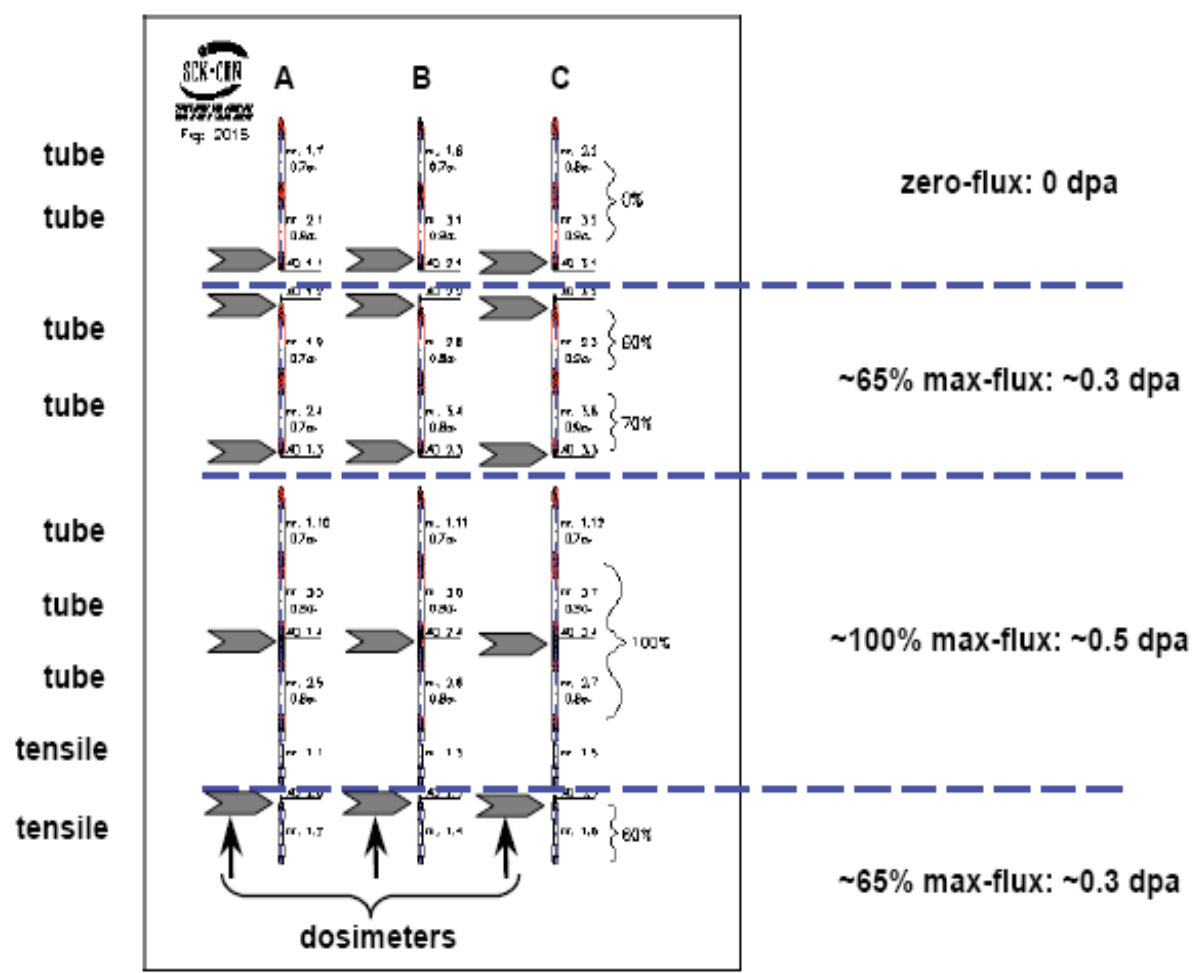

Figure 4-10. Irradiation rig showing the location of the specimens and dosimeters. 
Moreover, thermal creep is negligible at $300{ }^{\circ} \mathrm{C}$ for $1000 \mathrm{~h}$. At $0.5 \mathrm{dpa}$, the strain relaxation ratio is about $40 \% \pm 10 \%$. The results obtained on the pressurized tubes are in very good agreement with available published data, ${ }^{62-68}$ mainly obtained on bent beams.

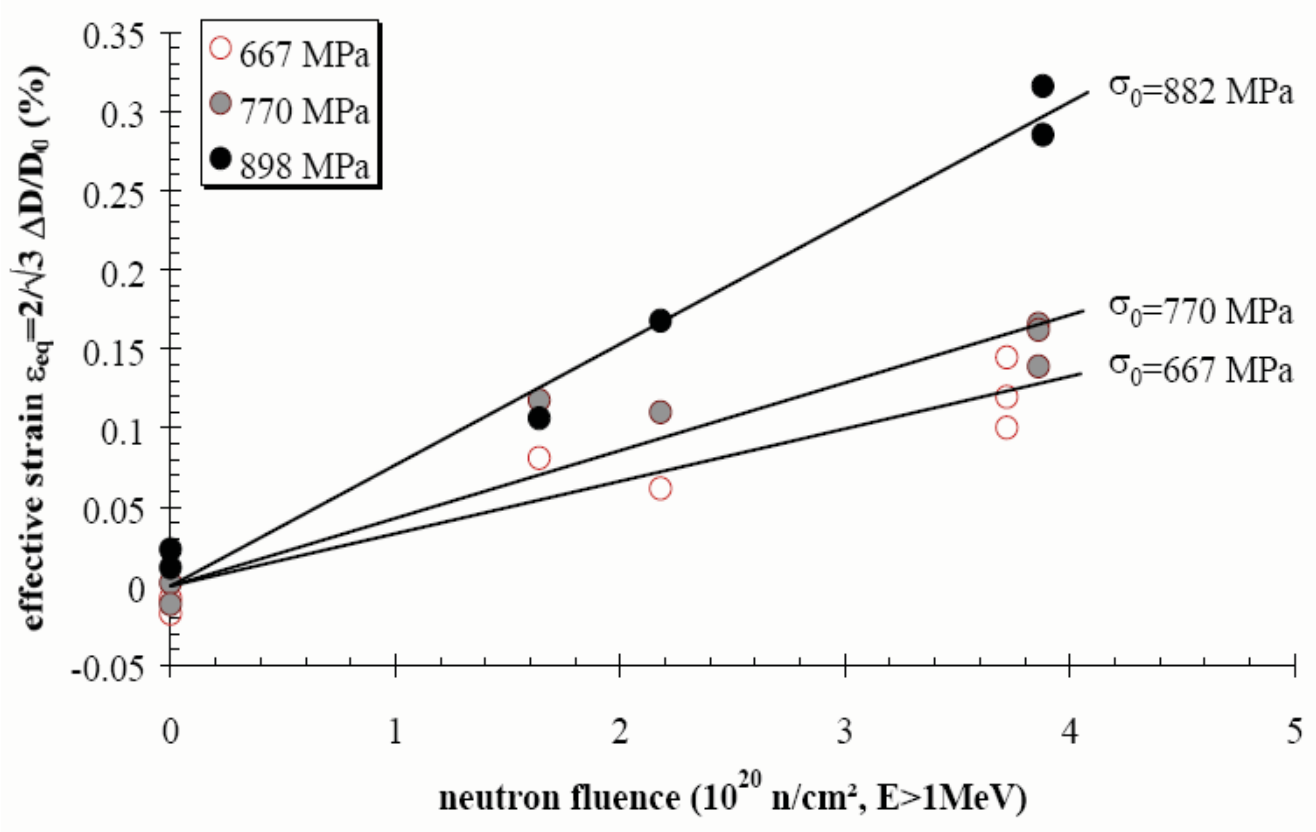

Figure 4-11. Creep strain as a function of neutron fluence.

According to the Reference 50, the irradiation creep rate of Inconel X-750 is almost linear in stress below about $200 \mathrm{MPa}$. This low stress dependence cause significant stress relaxation, which is similar to that of stainless steel 316 described in Section 3.2.1.

\subsection{Nitronic}

High strength and excellent corrosion resistance were reasons Nitronic 50 (XM-19) was chosen for a new prototype vessel for nuclear waste calcination. It is used in the scrubber tower which clean the hot gases coming off the calciner; the unit that drives off volatile material. Nitronic 50 is also used in repair hardware of BWR core shrouds. However, no data were found in the literature on the dimensional stability of Nitronic 50 under neutron irradiation.

\subsection{Summary}

Existing data found for irradiated material illustrate that the strength of material degrades during irradiation, especially at high temperatures. Irradiation data indicate that at temperatures above $400{ }^{\circ} \mathrm{C}$ and/or at high doses up to a maximum dose of $93.3 \mathrm{dpa}$, austenitic stainless steels (SS304 and SS316) have low 


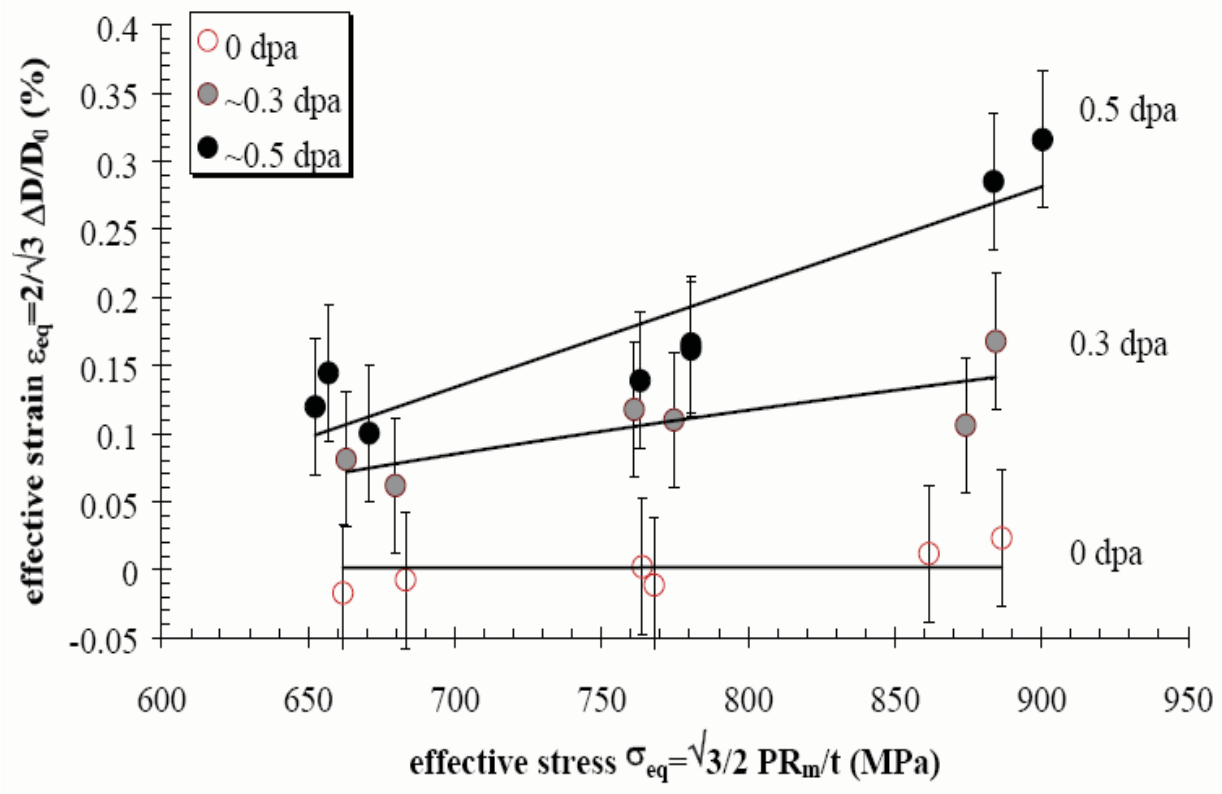

Figure 4-12. Creep strain as a function of applied stress and neutron dose.

resistance to irradiation-induced swelling and creep. However, at lower temperatures, they may have much better resistance to irradiation-induced embrittlement effects as compared to ferritic/martensitic (FM) steels. However, very few data are found in the literature on the dimensional stability of Inconel alloys under neutron irradiation. No data were found in the literature on the dimensional stability of Nitronic 50 under neutron irradiation.

In summary, available information indicate that key insights can be gained from obtaining real-time irradiation creep data obtained at LWR operating conditions. 


\section{CREEP TEST RIG DESIGN AND EVALUATION APPROACH}

An instrumented creep test rig is being developed to perform creep tests of specimens in LWR (Light Water Reactor) coolant conditions in the ATR. As discussed in this section, this creep test rig is initially evaluated in an autoclave at INL's HTTL (High Temperature Test Laboratory). Results from this autoclave evaluation will be used to finalize a design for use in an ATR PWR loop. This section provides details about the test rig design, analyses completed to evaluate the effects of gamma heating in the ATR, and the current autoclave evaluation approach.

\subsection{Design}

Figure 5-1 shows the INL creep test rig design. Major components include a tensile specimen, a bellows, an LVDT fabricated by IFE/HRP, and fixturing to connect these components. IFE/HRP welded the LVDT, bellows, and connecting fixturing in this test rig using e-beam and seal welding techniques. A schematic that shows the positioning of the creep test rig in the HTTL autoclave is shown in Figure 5-2. Figure 5-3 contains a photo of the test rig, the tensile specimen, and the autoclave fixturing. Figure 5-4 shows the test rig inserted in into the autoclave fixturing with the standoffs used to position the fixture in the autoclave. Table 5-1 provides additional information about each of the components in this test rig. More detailed dimensions and material information can be found in Reference 69.

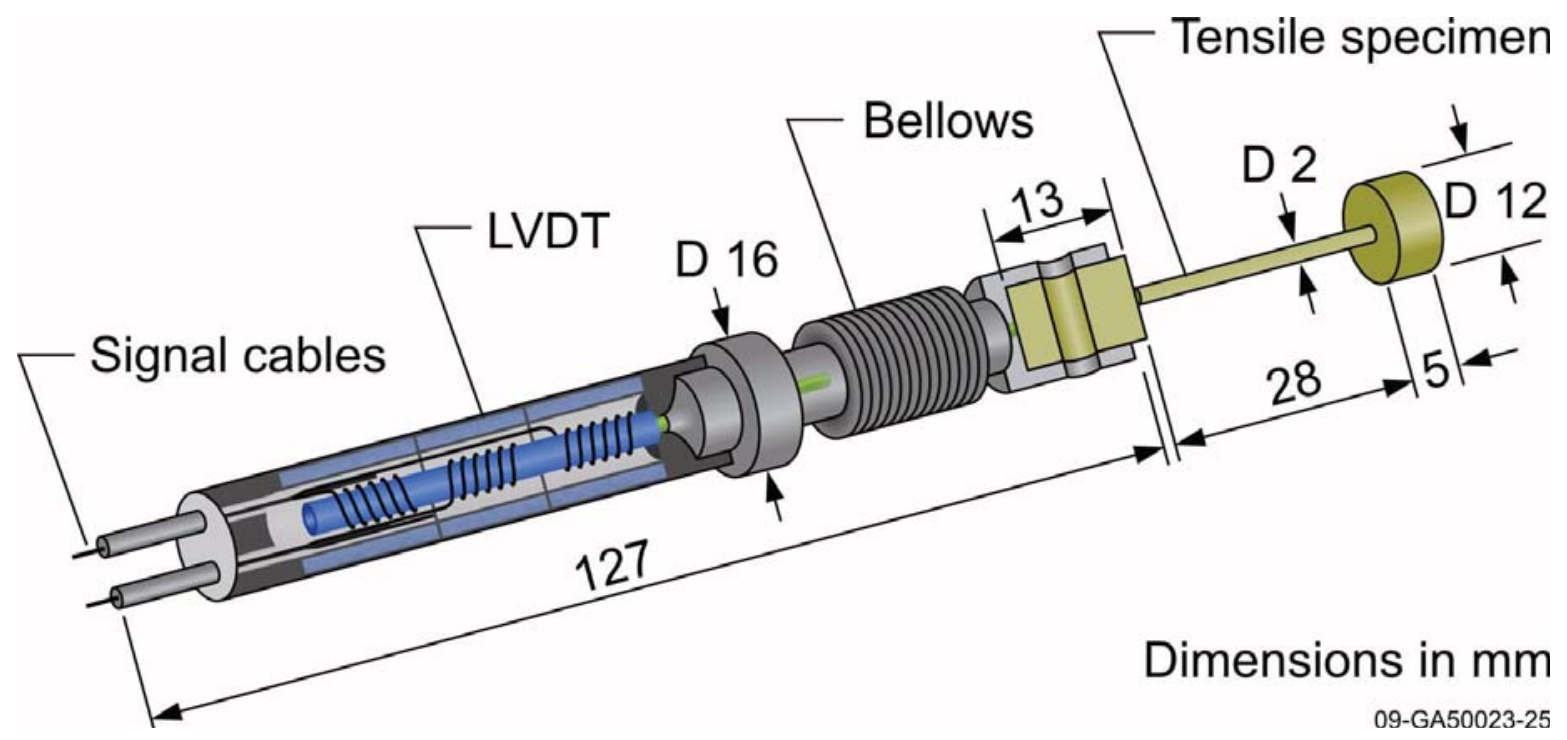

Figure 5-1. Creep test rig design. 


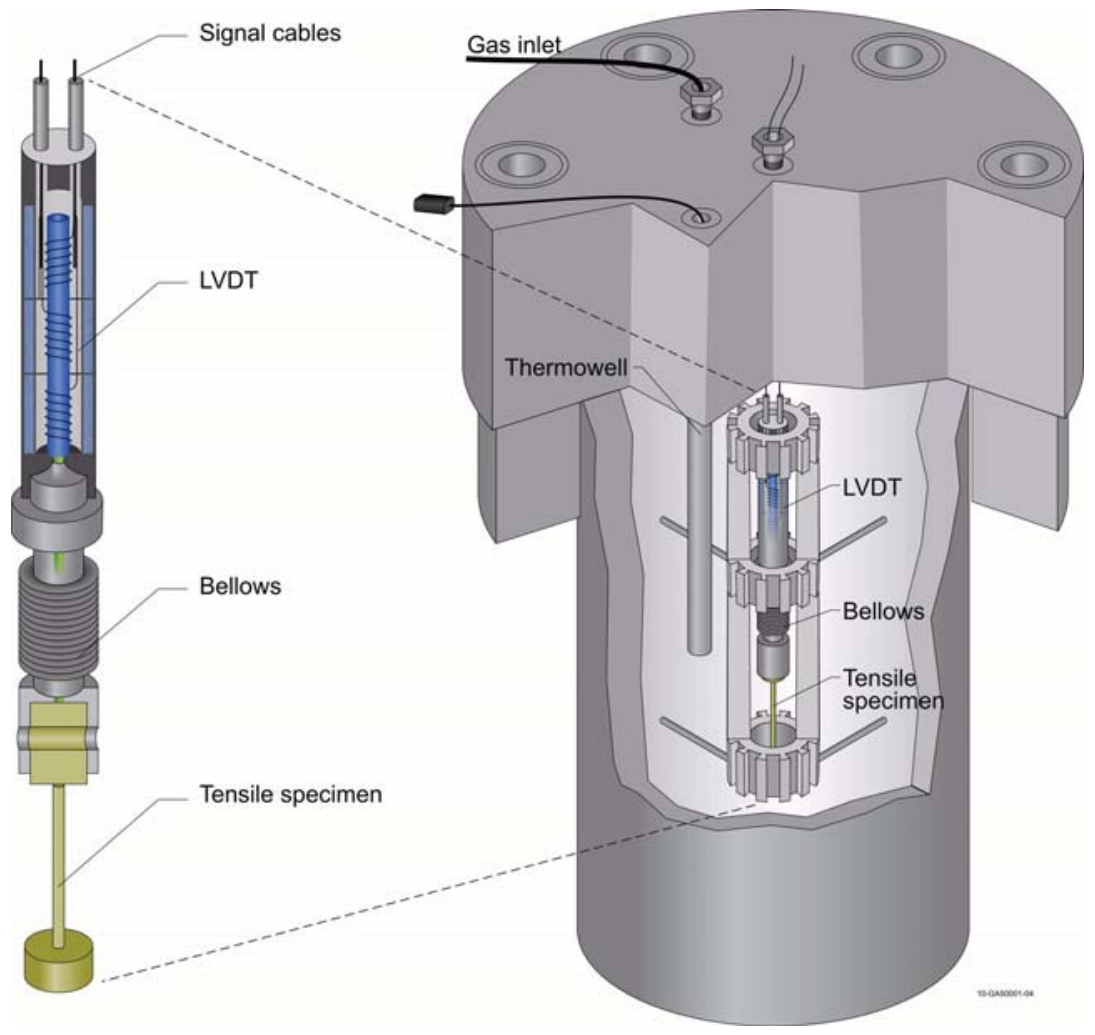

Figure 5-2. Schematic of test rig positioned in autoclave for testing.

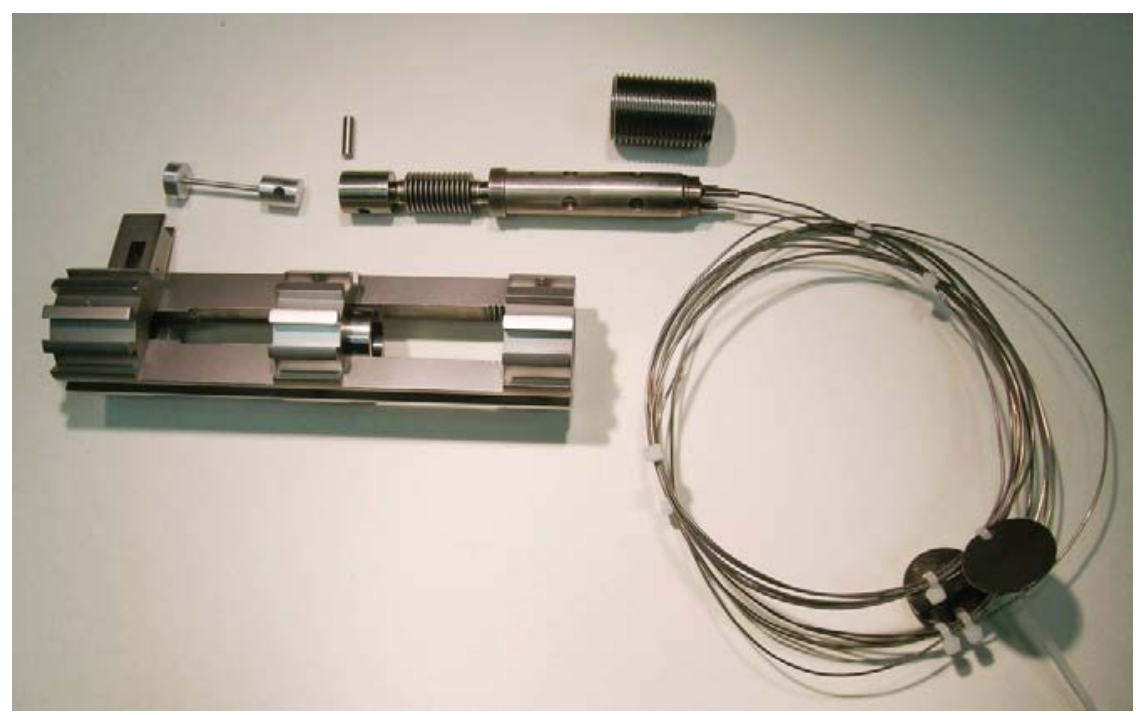

Figure 5-3. Photo of creep test rig assembly, tensile specimen and autoclave fixturing. 


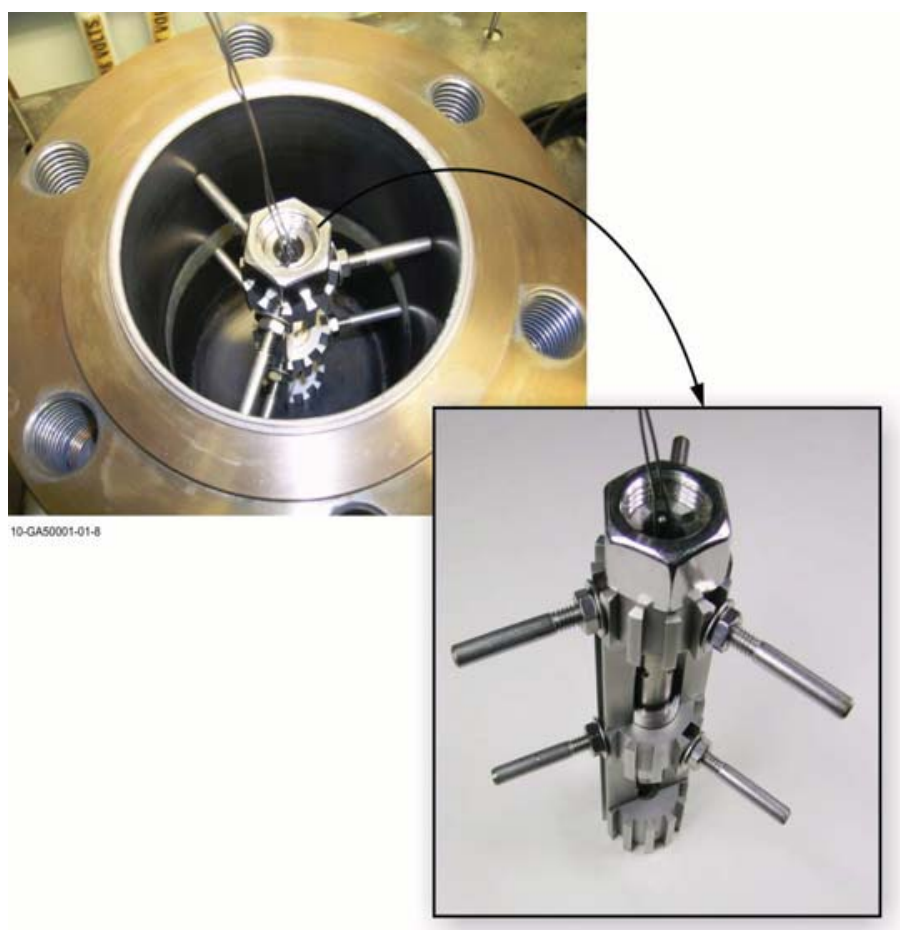

Figure 5-4. Test rig inserted into fixture with positioning stand-offs used in the autoclave.

Table 5-1. Summary description of components in creep test rig.

\begin{tabular}{|l|l|l|l|}
\hline \multicolumn{1}{|c|}{ Component } & Manufacturer & \multicolumn{1}{c|}{ Model Number } & \multicolumn{1}{c|}{ Material } \\
\hline Bellows & Miniflex & $\begin{array}{l}\text { I718-320-110-790 Rev: } \\
-- \text { C }\end{array}$ & Inconel 718, unaged \\
\hline LVDT & IFE/HRP & Type 5 & Inconel 600; Core - AISI 403 \\
\hline Connecting Fixturing & IFE/HRP & NA $^{\text {a }}$ & Inconel 600 \\
\hline Tensile Specimen & INL & NA & SS304, Inconel 600, etc. \\
\hline
\end{tabular}

a. Although no model number is applicable, detailed IFE/HRP specifications can be found in Reference 69.

An unaged Inconel 718 bellows, manufactured by Miniflex, was selected because of its superior mechanical properties (e.g., yield strength, ductility, and radiation resistance) although bellows could be fabricated from other materials (e.g., Inconel 625, Inconel X-750 or stainless steel). Table 5-2 summarizes specifications provided by the vendor for this bellows. 
Table 5-2. Bellows specifications for creep test rig.

\begin{tabular}{c|c}
\hline Bellows part number & I718-320-110-790 \\
\hline Convolution Inner Diameter, $D_{i}$ cm (inches) & $0.719(0.283)$ \\
Convolution Outer Diameter; $D_{o}$; cm (inches) & $1.295(0.510)$ \\
Wall Thickness, cm (inches) & $0.02794(0.011)$ \\
Neck OD / Neck ID, cm (inches) & $0.818 / 0.762(0.322 / 0.300)$ \\
Neck Length, cm (inches) & $0.376(0.148)$ \\
Convolution Free Length, cm (inches) & $2.134(0.84)$ \\
Maximum Deflection (compression), cm (inches) & $0.361(0.146)$ \\
Spring Rate, SR; kg $/$ cm $\left(\right.$ lbs $/$ inch) $_{\text {External Effective Area, cm }{ }^{2}(\mathrm{sq} . \text { inch) }}^{\mathrm{a}}$ & $14.1(790)$ \\
[ External Effective Area - Sample Area, cm ${ }^{2}(\mathrm{sq}$. inch) $]$ & $0.794(0.123) / 0.810^{\mathrm{a}}(0.125)^{\mathrm{a}}$ \\
Squirm Rating, MPa (psig) & $\left.0.763(0.118) 0.778^{\mathrm{a}}(0.120)^{\mathrm{a}}\right]$ \\
Burst Rating, MPa (psig) & $26.2(3800)$ \\
Number of convolutions & $55.2(8000)$ \\
\hline
\end{tabular}

a. Per the vendor recommendations, the external effective area is calculated using:

$A_{\text {ext-eff }}=\pi\left(\frac{D_{o}+D_{i}+2 t}{4}\right)^{2}$

\subsection{ABAQUS Evaluations for Gamma Heating Effects}

Calculations to quantify the possible effects of gamma heating during creep test rig irradiation in the ATR have been completed. These calculations focussed on LVDT temperatures primarily because of potential Curie point effects/limitations. (For purposes of this analysis, the Curie point limitation was assumed to be $633 \mathrm{~K}$, which is consistent with the IFE/HRP estimate.) Details associated with the calculations are described below.

\subsubsection{Model}

Abaqus (Version 6.8-2) ${ }^{70}$ was used to model selected key components of the creep test rig as shown in Figure 5-5. This model accounts for steady-state radial heat transfer based on the indicated nodalization of a two-dimensional slice through the LVDT in the creep test rig. Corresponding model dimensions and materials are listed in Table 5-3. Gamma heating was assumed to develop only in metallic materials. As indicated, it was necessary to estimate some dimensions in the absence of drawings and a reluctance to attempt destructive evaluation. A description of pertinent modeling details, progressing from the sleeve toward the core, is provided below. (Note that axial heat transfer is ignored in this model.)

Although a fixture partially surrounds key components of the creep test rig, gamma heating contributions from the fixture to the outer surface of the sleeve were ignored because cooling water flow will effectively cool the fixture. Consequently, there was no need to include any part of the fixture in this model. 


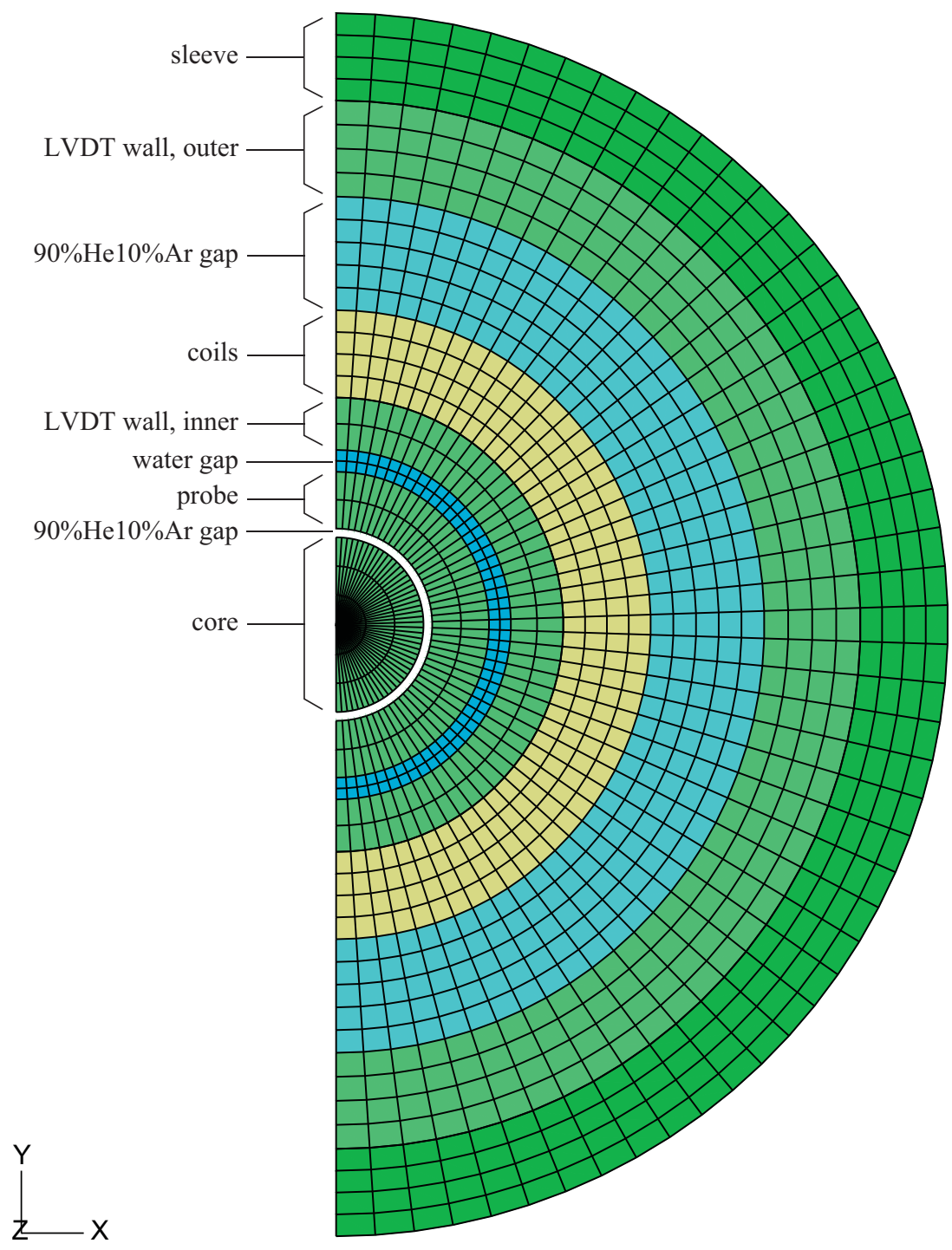

Figure 5-5. Abaqus model of a radial cross-section through key components of the creep test rig.

The outer boundary of the creep test rig (and all exterior surfaces of the fixture) are exposed to water at $568 \mathrm{~K}$ flowing at a rate of $0.00126 \mathrm{~m}^{3} / \mathrm{s}^{71}$ A forced convective coefficient of $7950 \mathrm{~W} / \mathrm{m}^{2}-\mathrm{K}$ was calculated as a constant boundary condition for this surface.

The sleeve appears to have an interference fit onto the outer wall of the LVDT body. In addition, numerous holes in the sleeve are expected to allow cooling water to flood into gaps if any exist between the sleeve and the body. For these reasons, a contact conductance sufficient to virtually eliminate sleeveto-body thermal resistance was used in all calculations.

A gap exists between the inside surface of the LVDT outer wall and the LVDT coils. This gap is filled with $\mathrm{Al}_{2} \mathrm{O}_{3}$ powder in an atmosphere of $90 \% \mathrm{He} 10 \% \mathrm{Ar}$. IFE/HRP originally added the $\mathrm{Al}_{2} \mathrm{O}_{3}$ powder to the gap as a way to improve heat transfer. However, their testing has indicated that the effective conductiv- 
Table 5-3. Abaqus model dimensions.

\begin{tabular}{|c|c|c|c|c|}
\hline Component & Material & $\mathrm{ID}(\mathrm{m})$ & $\mathrm{OD}(\mathrm{m})$ & Comments \\
\hline Sleeve & Inconel 600 & 0.012 & 0.014 & \\
\hline LVDT wall, outer & Inconel 600 & 0.0098 & 0.012 & \\
\hline Outer wall-to-coil gap & $90 \% \mathrm{He} 10 \% \mathrm{Ar}$ & 0.0072 & 0.0098 & ID estimated \\
\hline Coils & Inconel $600^{\mathrm{a}}$ & 0.0052 & 0.0072 & Assumed material; estimated OD \\
\hline LVDT wall, inner & Inconel 600 & 0.004 & 0.0052 & \\
\hline Inner wall-to-probe gap & Water & 0.0035 & 0.004 & \\
\hline Probe & Inconel 600 & 0.0022 & 0.0035 & \\
\hline Probe-to-core gap & $90 \% \mathrm{He} 10 \% \mathrm{Ar}$ & 0.002 & 0.0022 & \\
\hline Core & Iron & $\mathrm{na}^{\mathrm{b}}$ & 0.002 & \\
\hline
\end{tabular}

a. Selected as a way to produce a conservative estimate of gamma heating.

b. Not applicable (na) because the core is a solid cylinder.

ity of the gap is dominated by the conductivity of the inert gas mixture. For that reason, heat transfer through the gap was modeled based on the conductivity of $90 \% \mathrm{He} 10 \% \mathrm{Ar}$. Associated thermal conductivities are provided in Section 5.2.2. Note that the presence of $\mathrm{Al}_{2} \mathrm{O}_{3}$ powder was assumed to preclude any radiation heat transfer in this gap.

LVDT coils are wound onto the outer surface of the LVDT inner wall after the inner wall has been plasma spray coated with an electrically-insulating ceramic material. In this analysis, the coils were treated as a block of Inconel 600 as a way to conservatively bound gamma heating of that region of the model. A layer of $\mathrm{Al}_{2} \mathrm{O}_{3}(0.02 \mathrm{~mm}$ thick $)$ was assumed to be the insulating material. Corresponding thermal conductivies and resulting conductances for this insulator are provided in Section 5.2.2.

Holes are provided to allow cooling water penetration into and out of the annulus between the inner surface of the LVDT body and the outer surface of the probe. However, the holes are small so convective conditions are expected to be negligble. For that reason, conduction through a water-filled gap was assumed. Corresponding thermal conductivities are listed in Section 5.2.2.

Finally, there is a gap between the probe and the LVDT core, which is needed to permit movement of the core relative to the coils. It was assumed that this gap is filled a mixture of $90 \% \mathrm{He}$ and $10 \% \mathrm{Ar}$, thereby supporting heat transfer via radiation and conduction. Properties used in calculating this heat transfer are provided in the following section.

\subsubsection{Properties}

Creep test rig modeling required both thermal and gamma heating properties as discussed below.

\subsubsection{Thermal}

Required properties included thermal conductivities for all materials listed in Table 5-3 and the corresponding conductance values for coil-to-body contact and for the probe-to-core He/Ar gap. Those proper- 
ties are provided in Tables 5-4 and 5-5, respectively. Radiation emissivities and view factors also used in the probe-to-core He/Ar gap are listed in Table 5-6.

Table 5-4. Thermal conductivies used in modeling key components of the creep test rig.

\begin{tabular}{|c|c|c|c|c|c|}
\hline \multirow{2}{*}{ Temperature $(\mathrm{K})$} & \multicolumn{5}{|c|}{ Thermal Conductivities (W/m-K) for } \\
\hline & $90 \% \mathrm{He} 10 \% \mathrm{Ar}^{\mathrm{a}}$ & Water $^{b}$ & Inconel $600^{c}$ & $\mathrm{Al}_{2} \mathrm{O}_{3}{ }^{\mathrm{d}}$ & Iron $^{\mathrm{e}}$ \\
\hline 300 & 0.119 & & & 36. & \\
\hline 350 & 0.133 & & & 30.7 & \\
\hline 373 & & & 11.9 & & 57. \\
\hline 394 & & 0.695 & & & \\
\hline 400 & 0.146 & & & 26.4 & \\
\hline 422 & & 0.695 & & & \\
\hline 450 & 0.159 & 0.687 & & & \\
\hline 473 & & & 13.6 & & 52. \\
\hline 478 & & 0.672 & & & \\
\hline 500 & 0.172 & & & 20.2 & \\
\hline 505 & & 0.649 & & & \\
\hline 533 & & 0.618 & & & \\
\hline 550 & 0.184 & & & & \\
\hline 561 & & 0.577 & & & \\
\hline 573 & & & 15.2 & & 48. \\
\hline 589 & & 0.522 & & & \\
\hline 600 & 0.197 & & & 15.8 & \\
\hline 650 & 0.209 & & & & \\
\hline 673 & & & 16.9 & & 45. \\
\hline 700 & 0.221 & & & 12.6 & \\
\hline 750 & 0.233 & & & & \\
\hline 773 & & & 18.5 & & \\
\hline 800 & 0.244 & & & 10.4 & \\
\hline 873 & & & 20.2 & & 36. \\
\hline
\end{tabular}
a. Reference 72 .
b. Reference 73 .
c. Reference 74 .
d. Reference 75 .
e. Reference 76 . 
Table 5-5. Conductance values used in modeling key components of the creep test rig.

\begin{tabular}{c|c|c}
\hline \multirow{2}{*}{ Temperature $(\mathrm{K})$} & \multicolumn{2}{|c}{ Conductance $\left(\mathrm{W} / \mathrm{m}^{2}-\mathrm{K}\right)$ for } \\
\cline { 2 - 3 } & Coils-to-Inner LVDT Wall Contact & Probe-to-Core He/Ar Gap \\
\hline 300 & 360000 & \\
350 & 307000 & \\
400 & 264000 & 337. \\
450 & & 371. \\
\hline 500 & 202000 & 404. \\
550 & & 436. \\
600 & 158000 & 466. \\
650 & & 495. \\
700 & 126000 & 523. \\
750 & & 551. \\
800 & 104000 & 578. \\
\hline & & 603. \\
\hline
\end{tabular}

Table 5-6. Radiation properties used in creep test rig He/Ar gaps.

\begin{tabular}{c|c|c|c|c}
\hline \multirow{2}{*}{ Model Location } & \multicolumn{2}{|c|}{ Emissivities $^{\text {a }}$} & \multicolumn{2}{c}{ View Factors $^{*}$} \\
\cline { 2 - 5 } & A & B & A to B & B to A \\
\hline Probe (A)-to-Core (B) He/Ar Gap & 0.59 & 0.77 & 0.83 & 1 \\
\hline
\end{tabular}

a. At $633 \mathrm{~K}$, where Inconel 600 values were taken from Reference 77 and AISI 403 values were taken from Reference 78.

\subsubsection{Gamma Heating}

Gamma heat rates for Inconel 600 and iron (representative of AISI 403 used in the LVDT core) are shown in Figure 5-6. ${ }^{79}$ These rates are consistent with projected powers for Cycle 143B, with a center lobe power of $27.6 \mathrm{MW}$.

\subsubsection{Results}

The Abaqus model was used to calculate temperatures as a function of the position of the creep test rig relative to the ATR core midplane. This approach was necessary to determine a position that could be acceptable without exceeding the LVDT Curie temperature (of $633 \mathrm{~K}$ ). Results shown in Figure 5-7 indicate that the coil temperatures will exceed the Curie point unless the LVDT is positioned at least $76.7 \mathrm{~cm}$ above the core midplane. Corresponding temperature contours for the creep test rig and the coil portion of that rig are shown in Figures 5-8 and 5-9, respectively. From Figure 5-9, note that the coil temperature profile is relatively flat. In other words, coil temperatures are nearly uniform radially at or very near $633 \mathrm{~K}$. 


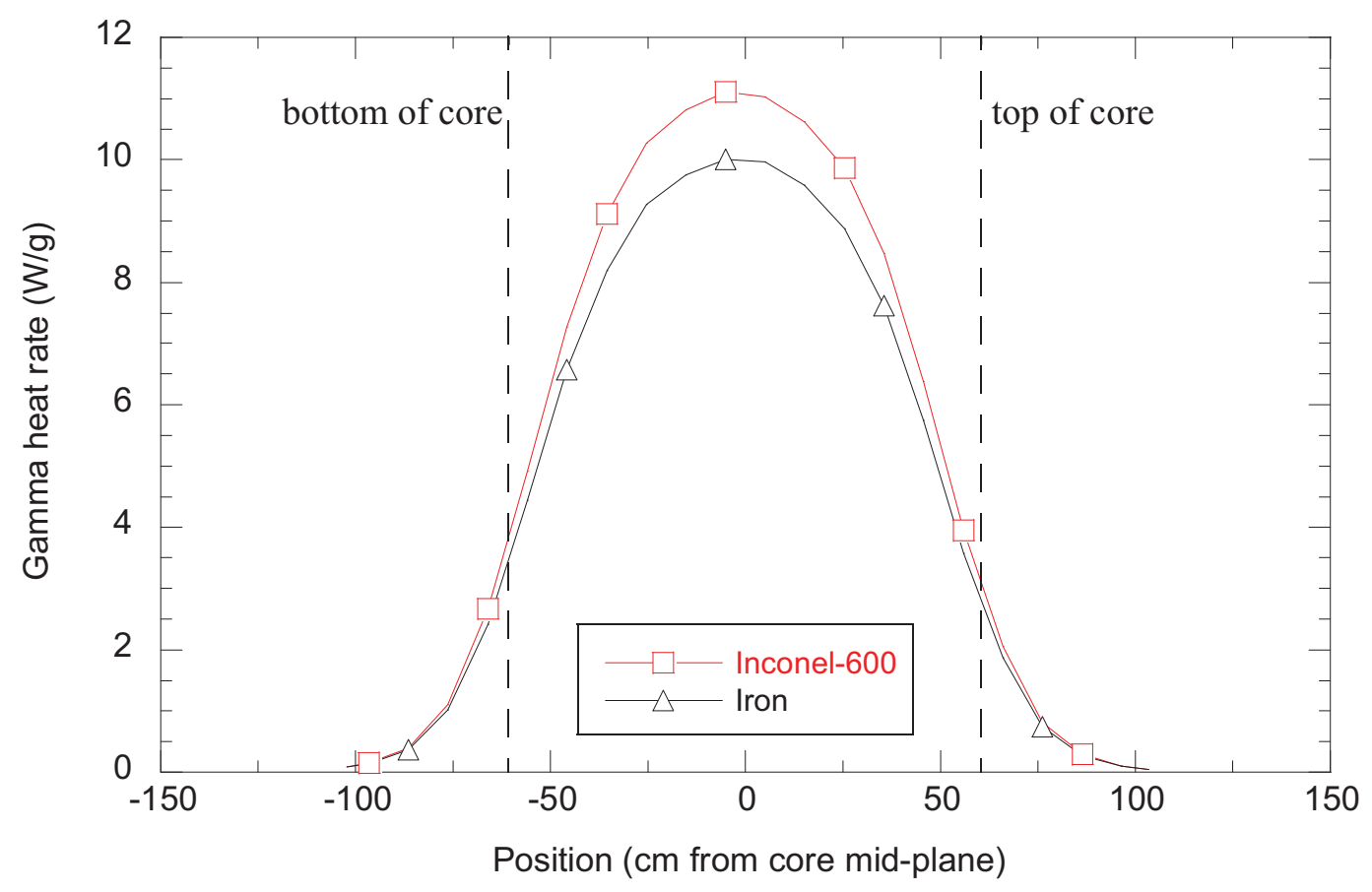

Figure 5-6. Inconel 600 and iron gamma heat rates (as projected for Cycle 143B).

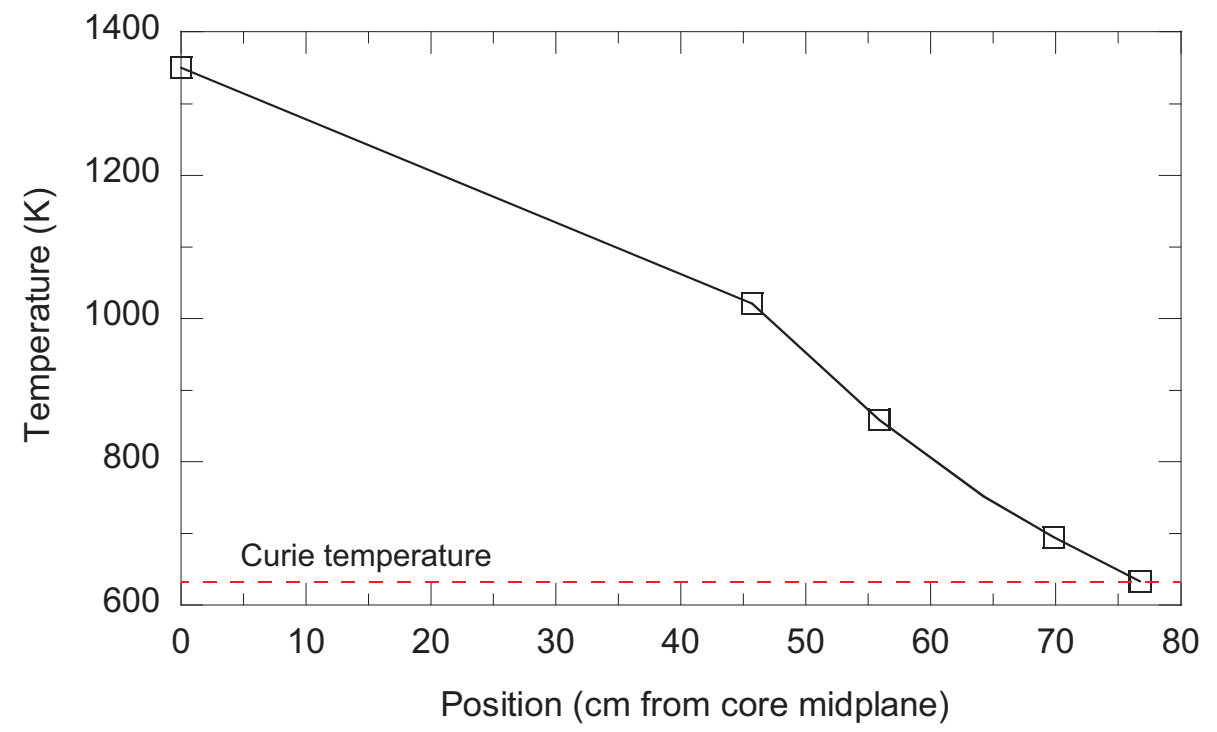

Figure 5-7. Maximum LVDT coil temperature as a function of position relative to the core midplane. 

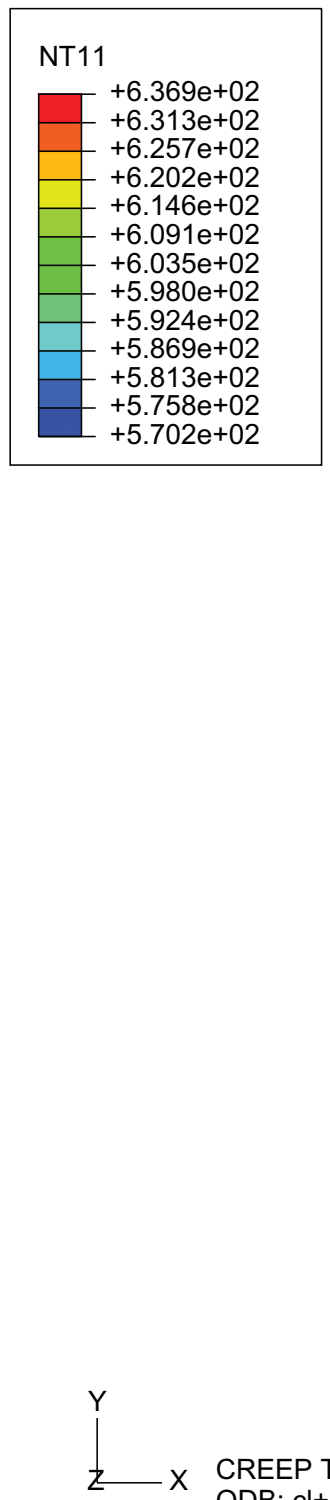

CREEP TEST RIG GAMMA HEATING ANALYSIS, CYLINDRICAL COORDINATES ODB: cl+30-creeprig.odb Abaqus/Standard Version 6.8-2 Fri Apr 30 15:16:27 MDT 2010

Figure 5-8. Temperature contours (in K) for key components of the creep test rig irradiated $76.7 \mathrm{~cm}$ above the ATR core midplane during Cycle 143B (with a projected center lobe power of 27.6 MW).

\subsubsection{Conclusions}

Results from this analysis indicate that the LVDT within the creep test rig must be positioned at least $76.7 \mathrm{~cm}$ above the core midplane in order to keep coil temperatures at or below $633 \mathrm{~K}$. This assumes deployment of the creep test rig during Cycle 143B (with a center lobe power of 27.6 MW). Alternately, the LVDT position can be established for any other test at locations where Inconel 600 and stainless steel gamma heat rates are 0.79 and $0.72 \mathrm{~W} / \mathrm{g}$, respectively (or less). 

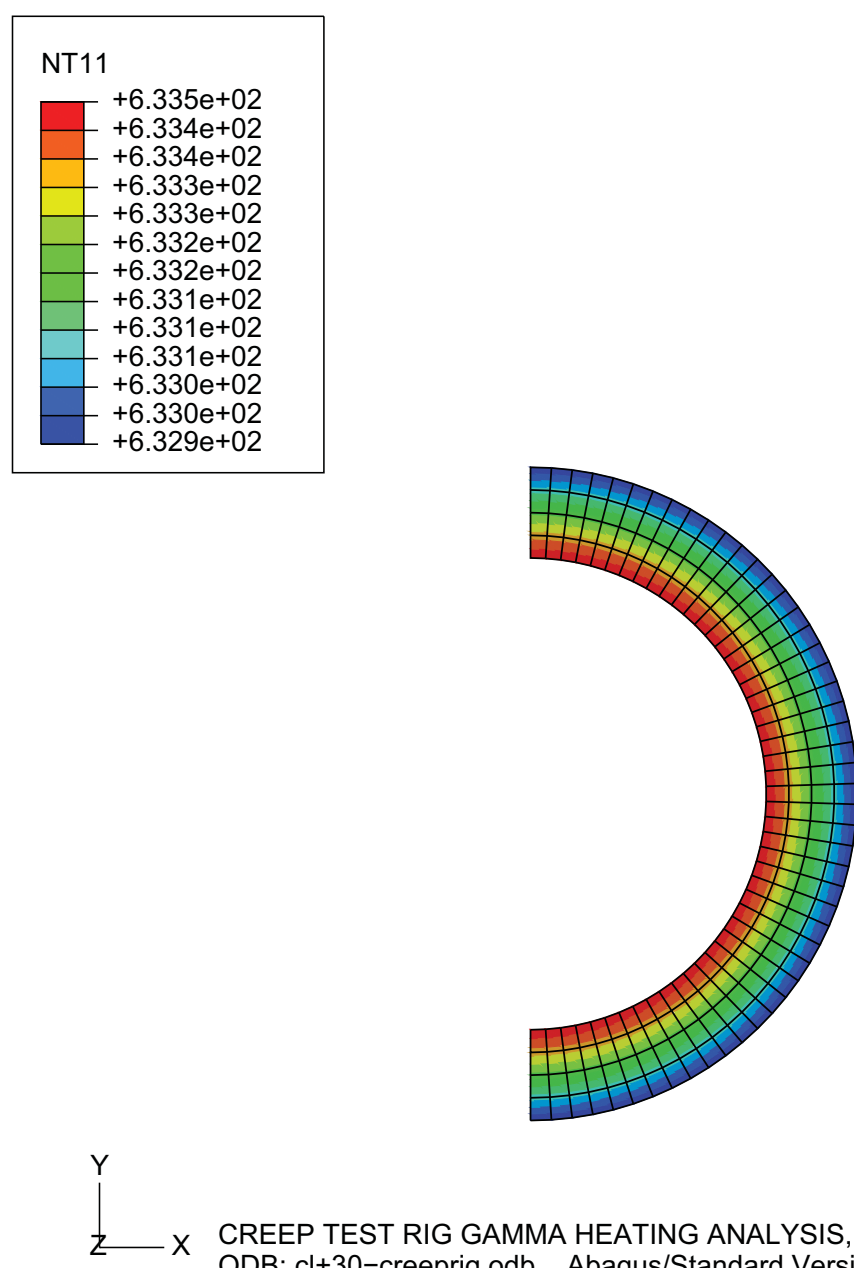

CREEP TEST RIG GAMMA HEATING ANALYSIS, CYLINDRICAL COORDINATES ODB: $\mathrm{cl}+30$-creeprig.odb Abaqus/Standard Version 6.8-2 Fri Apr 30 15:16:27 MDT 2010

Figure 5-9. Temperature contours (in K) for the LVDT coil irradiated $76.7 \mathrm{~cm}$ above the ATR core midplane during Cycle 143B (with a projected center lobe power of 27.6 MW).

\subsection{Autoclave and Associated Equipment}

Figure 5-10 shows the autoclave and supporting equipment layout for tests conducted at the HTTL. Table 5-7 lists specific equipment included in this setup.

Table 5-7. Autoclave and supporting equipment information

\begin{tabular}{|l|l|l|}
\hline \multicolumn{1}{|c|}{ Component } & \multicolumn{1}{c|}{ Vendor } & \multicolumn{1}{c|}{ Model Number/Specification } \\
\hline Autoclave & Autoclave Engineers & Drawing No 40C-0116 \\
\hline Pressure Relief Valve & Farris Engineering & 27CA23H-M20 / Set pressure 2800 psig \\
\hline Vent Valve & Autoclave Engineers & 10 V4081TG \\
\hline Pressure Gauge & Autoclave Engineers & P-0481-CG \\
\hline Pump & Milton Roy & XT1177SRNNM1NNNN \\
\hline
\end{tabular}


Table 5-7. Autoclave and supporting equipment information

\begin{tabular}{|l|l|l|}
\hline \multicolumn{1}{|c|}{ Component } & \multicolumn{1}{|c|}{ Vendor } & \multicolumn{1}{c|}{ Model Number/Specification } \\
\hline Block Valve & Autoclave Engineers & 2B4S15L4HT \\
\hline Back-Pressure Regulator & Haskel & 27741-1 S/N V809-36 \\
\hline Power Controller & Autoclave Engineers & CT-1000 \\
\hline Pulse Dampener & Pulse Guard & PIG 61 B44X75 \\
\hline
\end{tabular}

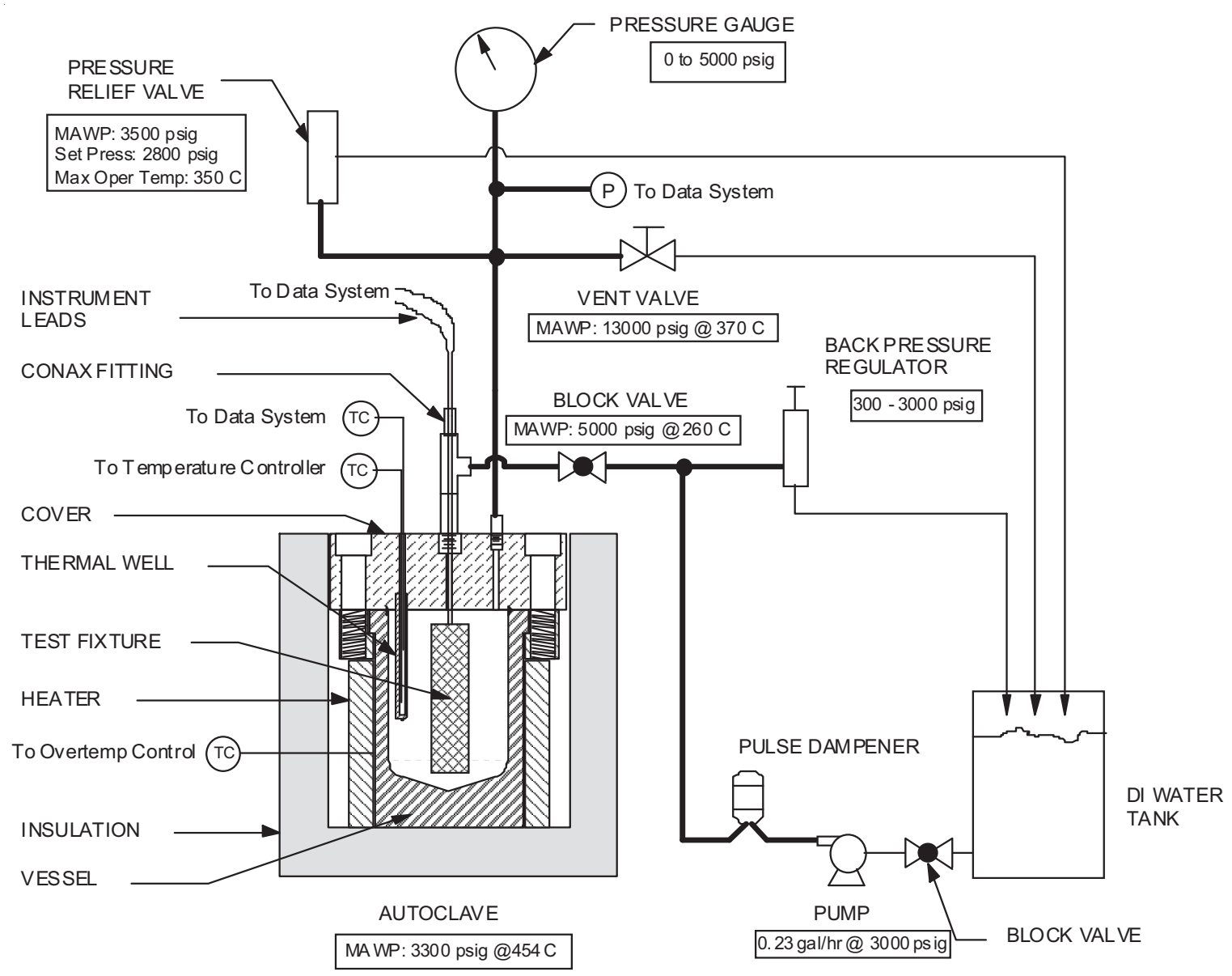

Figure 5-10. Autoclave and supporting equipment layout.

The autoclave was designed by and procured from Autoclave Engineers for operation at a Maximum Allowable Working Pressure (MAWP) of $22.75 \mathrm{MPa}(3300 \mathrm{psi})$ at $454{ }^{\circ} \mathrm{C}\left(850^{\circ} \mathrm{F}\right)$. A pressure relief valve currently set at $19.31 \mathrm{MPa}(2800 \mathrm{psi})$ prevents over pressurization of the autoclave.

The heater is controlled by a proportional-integral-derivative (PID) controller which uses the thermocouple inserted into the thermowell to detect and control temperature. An over temperature thermocouple is located between the heater and the vessel body and will shut off the heater if the vessel temperature exceeds the user specified high temperature limit. The subcooled water pressure is maintained by the high pressure pump, which will run throughout each experiment. The system pressure is controlled by the back pressure regulator which is manually set for the specific experiment. The vent valve is used to manually 
vent the air as the system fills and also to vent air that is released from solution as the water heats up. Instrument leads from the device being tested exit the autoclave through an appropriately configured Conax fitting. A data acquisition system records data from the instrument, the temperature from a second thermocouple inserted into the thermowell, and the pressure from the pressure transducer installed in the system tubing.

\subsection{Proposed Test Procedure}

The test rig is evaluated at anticipated ATR PWR loop conditions. The loop operating conditions will be simulated in a laboratory setting using an autoclave. Proposed coolant conditions for autoclave testing are listed in Table 5-8.

Table 5-8. Experimental parameters for autoclave coolant.

\begin{tabular}{|l|c|}
\hline Coolant & Pressurized $\mathrm{H}_{2} \mathrm{O}$ \\
\hline Temperature $\left({ }^{\circ} \mathrm{C}\right)$ & $280-350$ \\
\hline System pressure $\mathrm{MPa}(\mathrm{psi})$ & $15.51-15.86(2250-2300)$ \\
\hline $\begin{array}{r}\text { Coolant chemistry } \\
\mathrm{pH}\left(\text { at } 25^{\circ} \mathrm{C}\right)\end{array}$ & $4.2-10.5$ \\
\hline
\end{tabular}

Autoclave test objectives that have been defined include:

- Checkout of test rig design and verification that it can withstand PWR coolant temperatures and pressures

- Verification of signal processing equipment

- Calibration of test rig design using samples with known creep behavior

- Provide insights related to the final creep test rig design that will be inserted into an ATR PWR loop.

In general, testing consists of the following steps:

- Place fixture in the autoclave

- Fill autoclave with cold water, test water chemistry and adjust, as needed, to insure that the $\mathrm{pH}$ is within the values specified in Table 5-8

- Secure lid on autoclave and assemble tubing

- Using the pump, pressurize the autoclave to the pressure level established by the back-pressure regulator

- Determine LVDT initial reference point.

With the pump running, the autoclave is vented through the vent valve until it is liquid solid. Heat up of the autoclave is then initiated. The autoclave is manually vented periodically during heat up to remove any air that may come out of solution. Several degrees of subcooling are maintained in the autoclave. The pump operates continuously throughout the test period to make up for any fluid loss. The back pressure regulator maintains the pressure constant throughout the test period and can be used to adjust the system pressure if so desired. During testing, coolant may be periodically sampled to allow the $\mathrm{pH}$ to be recorded. LVDT signals from an IFE/HRP signal processing unit and autoclave temperature and pressure is monitored using LabView based software on a PC. 
The LVDT signal processing system provided by IFE/HRP excites the primary coil with $400-1000 \mathrm{~Hz}$, 20-50 mA constant current. With this constant current system, the input voltage to the LVDT is directly proportional to the wire/coil resistance of the LVDT. At room temperature, a typical resistance is $\sim 90 \mathrm{ohm}$ for the primary coil and $16 \mathrm{~m}$ of cable. At temperature, typical values are $200 \mathrm{ohm}$ at $350{ }^{\circ} \mathrm{C} .200 \mathrm{ohms}$ at $50 \mathrm{~mA}$ equals to a voltage of $10 \mathrm{VAC}$. The secondary voltages that are transmitted back to the data acquisition system are very low, typically less than 1 VAC (but the output from the electronics unit is higher due to the electronic gain in the unit). Note that the input signal to the LVDT is sinusoidal, and the output signal is VDC.

Autoclave tests are typically conducted at these conditions for long durations. In addition, several test cycles are completed to verify that this test rig can withstand several pressure/temperature cycles. After testing, the autoclave is disassembled; and components visually inspected to assess what, if any, damage occurred during testing. Specimen elongation is measured and compared with data obtained during load frame tensile testing.

\subsection{Tensile Specimen}

Tensile specimen size is selected based on anticipated loads during creep testing at LWR pressures. Using Equations (5-1) through (5-3), the force that will be exerted on the specimen, $F_{\text {spec }}$, is estimated by subtracting the force required to compress the bellows, $F_{\text {bellows }}$, from the total force applied to the bellows, $F_{\text {total }}$.

$$
\begin{aligned}
& F_{\text {spec }}=F_{\text {total }}-F_{\text {bellows }} \\
& F_{\text {bellows }}=S R \times d \\
& F_{\text {total }}=P_{\text {system }} \times A_{\text {ext-eff }}
\end{aligned}
$$

where

$$
\begin{array}{ll}
S R= & \text { Bellows spring rate, } \mathrm{N} / \mathrm{m}\left(\mathrm{lb}_{\mathrm{f}} / \mathrm{in}\right) \\
d= & \text { Sample elongation, } \mathrm{m}(\mathrm{in}) \\
A_{\text {ext-eff }} & \text { External effective area, } \mathrm{m}^{2}\left(\mathrm{in}^{2}\right) \\
P_{\text {system }}= & \text { System pressure, } \mathrm{N} / \mathrm{m}\left(\mathrm{lb}_{\mathrm{f}} / \mathrm{in}\right)
\end{array}
$$

For the bellows $S R$ (e.g., $790 \mathrm{lb}_{\mathrm{f}} / \mathrm{in}$ ) and anticipated maximum sample elongation in these creep tests, $d_{\max }$, (e.g., $10^{-6}$ inch), the force to compress the bellows is negligible compared to the total force applied to the bellows at system pressure (e.g., $\left.F_{\text {bellows }}<<F_{\text {total }}\right)$. Using the effective bellow area $\left(0.841 \mathrm{~cm}^{2} / 0.130 \mathrm{in}^{2}\right.$ from Table 5-2) and a representative PWR pressure (2250 psi from Table 5-8), the peak force exerted on the specimen is $1,305.4 \mathrm{~N}$ or $293 \mathrm{psi}$ ).

Applying Equation (5-4), an appropriate specimen radius, $r_{\text {spec }}$, can be selected to obtained the desired range of stress loads (90-350 MPa) for this PWR pressure. 


$$
\sigma_{\text {spec }}=\frac{F_{\text {spec }}}{\pi r_{\text {spec }}^{2}}
$$

Figure 5-11 plots estimated stress as a function of specimen radius for samples tested at $2250 \mathrm{psig}$. As shown in this figure, the desired range of stress loads (90-350 MPa) can be obtained if the specimen radius ranges from approximately 1.1 to $2.2 \mathrm{~mm}$.

The test rig is evaluated using several types of specimen materials, including SS304, Inconel 600, and SS316. As noted in Section 5.4, elongation measurements are compared with data presented in Section 3. Results are then used to 'calibrate' the stress applied by the test rig to tensile specimens and adjust, if necessary, data inferred from the LVDT.

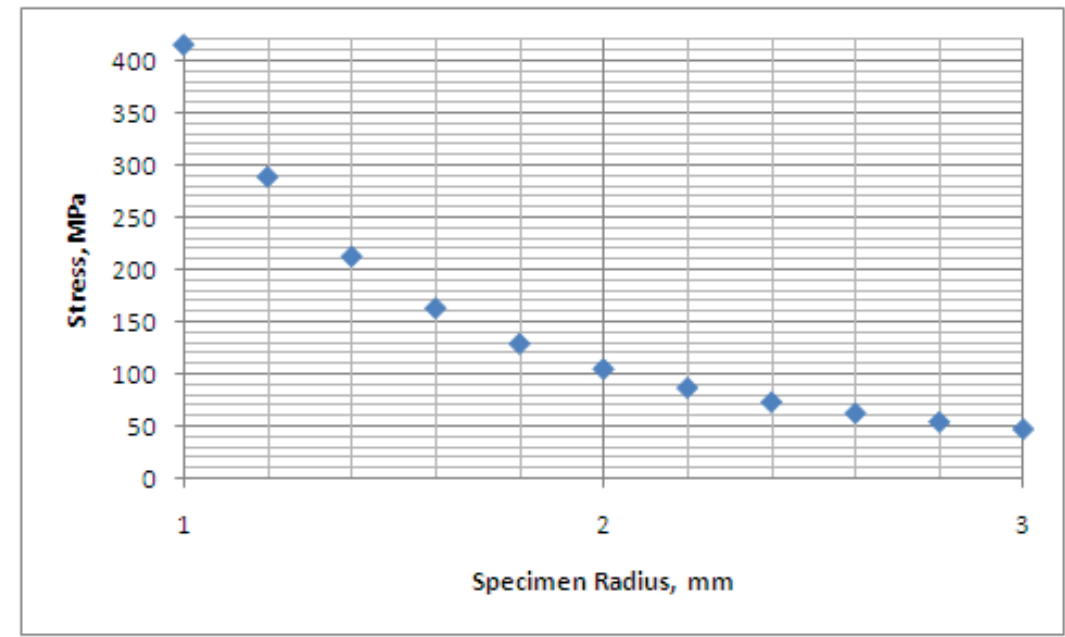

Figure 5-11. Estimated stress for candidate specimen sizes assuming 2250 psi test pressure. 
INL/EXT-10-17779 


\section{RESULTS}

A creep test rig was developed as a prototype of a device that will ultimately be used to perform specimen tests in PWR coolant conditions in the ATR. As previously discussed, initial testing of this prototype was performed in an autoclave at INL's HTTL. As discussed in Section 5, objectives of the autoclave testing include:

- Creep test rig checkout and verification that it can withstand PWR coolant conditions.

- Verification that signal processing equipment operates properly.

- Calibration of the creep test rig using samples with known creep behavior.

- Provide insights to finalize the design for creep test rig evaluations in an ATR PWR loop.

Initial results are described below.

\subsection{Initial Autoclave Testing}

To address the first two objectives, a SS304 specimen, with a gauge diameter of $2 \mathrm{~mm}$ and a gauge length of $28 \mathrm{~mm}$, was loaded into the creep test rig and the whole assembly was placed inside the autoclave. Instrument indications for temperature, pressure, and the LVDT output voltage were noted while the autoclave temperature and pressure remained at normal conditions. All indications were consistent with the autoclave conditions. The autoclave temperature and pressure were then gradually increased and ultimately stabilized at $\sim 300{ }^{\circ} \mathrm{C}$ and $\sim 15.5 \mathrm{MPa}$. The corresponding instrument indications for temperature, pressure, and the LVDT output voltage were again noted. Those indications were also consistent with the autoclave conditions. Furthermore, changes in the instrument indications, relative to readings under normal conditions, were reasonable. Finally, the autoclave temperature and pressure were allowed to return to normal conditions. When the system stabilized, instrument indications returned to those consistent with normal conditions.

This sequence provided indications that the creep test rig functions as designed and that the creep test rig can withstand PWR coolant conditions. In addition, instrument indications for temperature, pressure, and LVDT output voltage indicate that signal processing equipment operates properly. It should be noted that simple observations, like those just described, were made during the course of completing all autoclave testing. Those observations confirmed satisfactory performance of the creep test rig and associated instrumentation relative to the first two objectives.

Although evaluation of creep behavior remains an ultimate goal, initial testing in the elastic region was pursued to address the latter two test objectives. Specifically, room temperature measurements were made using two SS304 specimens (with a gauge diameter of $2 \mathrm{~mm}$ and a gauge length of $28 \mathrm{~mm}$ ). In these tests, the autoclave pressure was gradually increased from atmospheric pressure to pressures producing a stress level below the SS304 yield strength (assumed to be $\sim 200 \mathrm{MPa}$ ). Limiting the stress to a level below the yield strength ensures that the sample remains in the elastic region, allowing the possibility of its reuse. In addition, this approach ensures that the sample will remain intact, which also precludes concerns regarding possible adverse affects on the creep test rig that might accompany specimen failure.

Because initial testing was limited to the elastic region, Young's Modulus comparisons were completed to assess the response characteristics of the creep test rig. To that end, stress / strain data for the 
SS304 specimen corresponding with the previously described pressure ramp is shown in Figure 6-1. The slope of that stress / strain curve, which is Young's Modulus for the SS304 specimen, was estimated to be $206 \mathrm{GPa}$ (as indicated).

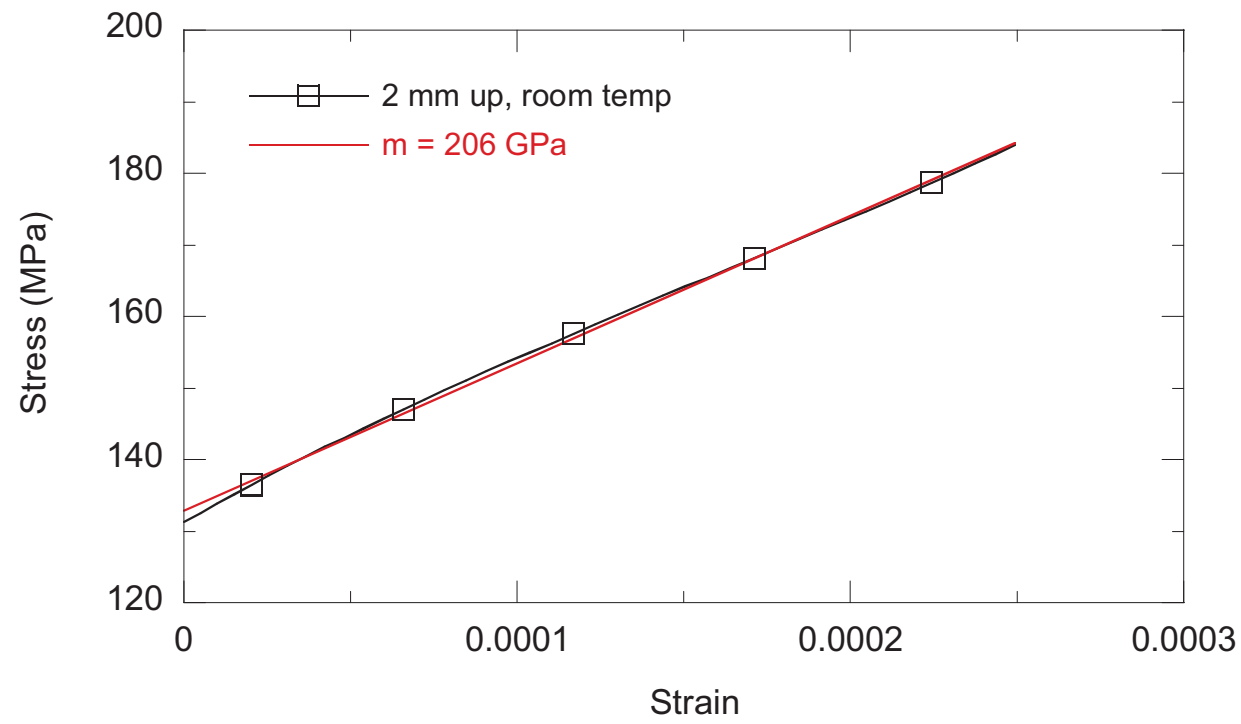

Figure 6-1. Creep test rig results for a $2 \mathrm{~mm}$ diameter / $28 \mathrm{~mm}$ long SS304 specimen.

SS304 specimens were also subjected to tensile testing in a load frame as a way to validate the creep test rig results (shown in Figure 6-1). The load frame results are shown in Figure 6-2. In addition to the load frame stress / strain results, the slope of the stress / strain data (or Young's Modulus) was estimated to be $200 \mathrm{GPa}$ as indicated in the figure. Clearly, Young's Modulus as estimated through use of the creep test rig is in close agreement with Young's Modulus as estimated through load frame testing. Consequently, these results provide some indication that the creep test rig can be used to measure elongation of a specimen in the elastic region. Further testing is needed to confirm these findings. 


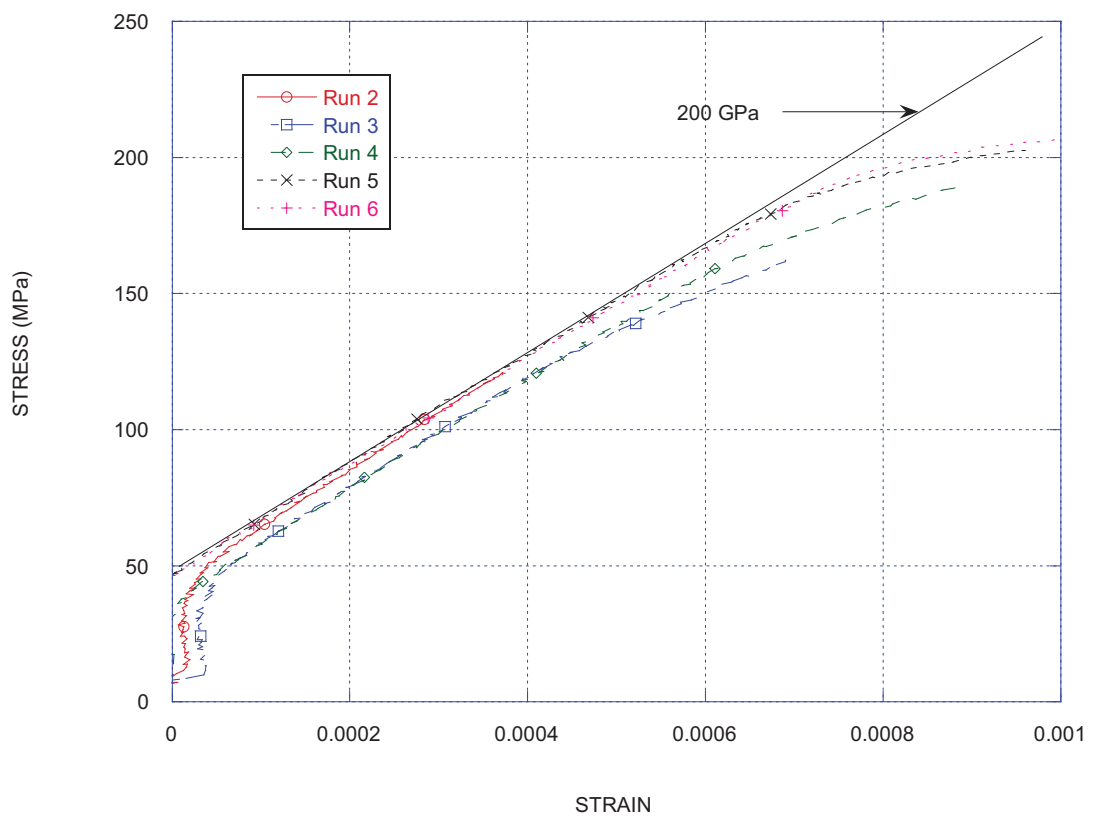

Figure 6-2. Load frame results for a $2 \mathrm{~mm}$ diameter / $28 \mathrm{~mm}$ long SS304 specimens. 
INL/EXT-10-17779 


\section{SUMMARY AND RECOMMENDATIONS FOR ATR PWR LOOP TESTS}

An instrumented creep testing capability is being developed for specimens irradiated in PWR coolant conditions in the ATR at the INL. The test rig is developed such that samples will be subjected to applied loads ranging from 92 to $350 \mathrm{MPa}$ at temperatures between 290 and $370{ }^{\circ} \mathrm{C}$ up to at least $2 \mathrm{dpa}$. Testing at the HTTL confirmed several aspects about the proposed test rig design and the methods for assessing its performance. Specifically, testing confirmed that the test rig could withstand anticipated temperatures and pressures in an ATR PWR loop and that the autoclave and signal processing equipment performed as designed.

Although evaluation of creep behavior remains an ultimate goal, initial testing in the elastic region was initially pursued to assess the performance of the test rig design. Specifically, room temperature measurements were made using two SS304 specimens (with a gauge diameter of $2 \mathrm{~mm}$ and a gauge length of $28 \mathrm{~mm}$ ). Limiting the stress to a level below the yield strength ensures that the sample remains in the elastic region, allowing the possibility of its reuse. In addition, this approach ensures that the sample will remain intact, which also precludes concerns regarding possible adverse affects on the creep test rig that might accompany specimen failure.

Because initial testing was limited to the elastic region, Young's Modulus comparisons were completed to assess the response characteristics of the creep test rig. SS304 specimens were also subjected to tensile testing in a load frame as a way to validate the creep test rig results. Initial results for Young's Modulus, as estimated through use of the creep test rig, is in close agreement with Young's Modulus, as estimated through load frame testing. Consequently, these results provide some indication that the creep test rig can be used to measure elongation of a specimen in the elastic region. However, further testing is needed to confirm these findings. 
INL/EXT-10-17779 


\section{REFERENCES}

1. Rempe, J. L., D. L. Knudson, K. G. Condie, J. E. Daw, and S. C. Taylor, "Instrumentation to Enhance Advanced Test Reactor Irradiations," INL/EXT-08-13985, September 2009.

2. Moilanen, P., S. Tähtinen, B. N. Singh, and P. Jacquet, "In-Situ Investigation of the Mechanical Performance and Life Time of Copper: Final report on design, construction, and calibration of test module for in-reactor tensile tests in BR-2 reactor," VTT Report BTUO 76-031127, October 27, 2004.

3. Singh, N., S. Tähtinen, P. Moilanen, P. Jacquet, and J. Dekeyser, "In-reactor uniaxial tensile testing of pure copper at a constant strain rate at $90^{\circ} \mathrm{C}$," Journal of Nuclear Materials, 320, pp.299-304, 2003.

4. Van Nieuwenhove, R., Solstad, S., In-core fuel performance and material characterization in the Halden reactor, ANIMMA International Conference, 7-10 June 2009, Marseille, France.

5. Solstad, S., Van Nieuwenhove, R., Instrument Capabilities and Developments at the Halden Reactor Project, Sixth American Nuclear Society International Topical Meeting on Nuclear Plant Instrumentation, Control, and Human-Machine Interface Technologies NPIC\&HMIT 2009, Knoxville, Tennessee, April 5-9, 2009, on CD-ROM, American Nuclear Society, LaGrange Park, IL (2009).

6. Wolfgang Wiesenack, Status and outlook for irradiation testing ...from a Halden Reactor perspective ... mostly, Presented at International Conference on the Physics of Reactors "Nuclear Power: A Sustainable Resource” Casino-Kursaal Conference Center, Interlaken, Switzerland, September 14-19, 2008.

7. Wolfgang Wiesenack, Terje Tverberg, The OECD Halden reactor project fuels testing programme: methods, selected results and plans, Nuclear Engineering and Design 207 (2001) 189-197.

8. T.M. Karlsen, Achievements and further plans for the OECD Halden, reactor project materials programme, Nuclear Engineering and Design 207 (2001) 199-206.

9. Villard, J-F., "State-of-the-art and improvement of online measurements in present and future French research reactors," presentation at the Idaho National Laboratory, September 2009.

10. Bennett, P.; Karlsen, T, In-core corrosion monitoring in the Halden test reactor, Energy Materials: Materials Science and Engineering for Energy Systems, Volume 3, Number 2, June 2008, pp. 8190(10).

11. Fridtjov Øwre and Margaret McGrath, Present Status and Future Plans of the Halden Reactor, presented at 12th IGORR, Beijing, China, 28-31 October 2009.

12. Knudson, D. L., J. L. Rempe, and J. E. Daw, "Evaluation of Candidate Linear Variable Displacement Transducers for High Temperature Irradiations in the Advanced Test Reactor," INL/EXT-09-16972, Idaho National Laboratory, September 2009.

13. Y. Kurata, Y. Itabashi, H. Mimura, T. Kikuchi, H. Amezawa, S. Shimakawa, H. Tsujiand M. Shindo, "In-pile and post-irradiation creep of type 304 stainless steel underdifferent neutron spectra", Journal of Nuclear Materials, 283-287, pp.386-390, 2000. 
14. L.E. Rehn, "Production of freely-migrating defects", Journal of Nuclear Materials, 174, pp.144-150, 1990.

15. Schüle, W. and H. Hausen, "Neutron irradiation creep in stainless steel alloys," Journal of Nuclear Materials, 212-215, pp.388-392, 1994.

16. B. G. Kim, et al., "Status and Perspective of Material Irradiation Tests in the HANARO, paper and presentation from the 1st International Symposium on Materials Testing Reactors, JAEA-Oarai, Japan, July 2008.

17. B. G. Kim, K-N Choo, J. M. Sohn, S. J. Park, Y. K. Kim and Y. J. Kim, "Instrumentations for Materials Irradiation Tests in HANARO," Proceedings of the ANS NPIC HMIT 2009 Topical Meeting on Nuclear Plant Instrumentation, Controls, and Human Machine Interface Technology, Knoxville, TN, April 2009.

18. B.G. Kim, K.N. Choo, Y.K. Kim and J.J. Ha, Irradiation and Instrumentation Technology in HANARO, Presented at 2nd International Symposium on Material Test Reactors, Sep. 28-Oct. 1, 2009, Idaho Falls, Idaho, USA.

19. Allen T. R., and J. T. Busby, "Radiation Damage Concerns for Extended Light Water Reactor Service," Journal of Materials, Vol. 61, No. 7, July 2009.

20. http://www.ssina.com/publicatgions/design.html and Oberg, E., et al., Machinery's Handbook, 25th edition, Industrial Press, Inc., pp.411-412, 1996.

21. Atlas Steels, Specialty Steels Product Reference Manual, Section 9 Appendices.

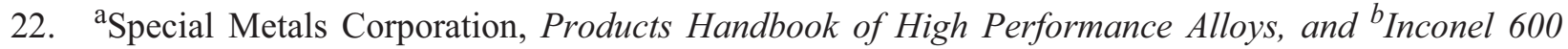
bulletin (from Joy L. Rempe on Feb. 06, 2009).

23. http://www.hightempmetals.com/techdata/hitempInconel718data.php and http://www.hightempmetals.com/techdata/hitempInconelX750data.php

24. http://www.specialtysteelsupply.com/brochure/nitronic-50-technical-data.pdf

25. Touloukian, Y. S., R. K. Kirby, R. E. Taylor, and P. D. Desai, Thermophysical properties of Matter, Vol. 12, Thermal Expansion, Metallic Elements and Alloys, Figure and Table No. 258R, "Provisional Values for Thermal Linear Expansion of Iron + Chromium $+\Sigma X$ X Alloys," IFI/Plenum, New York-Washington, US.

26. http://www.engineeringtoolbox.com/young-modulus-d_773.html

27. Y. Dai, G.W. Egeland, B. Long, Tensile properties of EC316LN irradiated in SINQ to 20 dpa, Journal of Nuclear Materials 377, pp.109-114, 2008.

28. K. Farrell, T.S. Byun, Tensile Properties of Candidate SNS Target Container Material after Proton and Neutron Irradiation in the LANSCE Accelerator, Journal of Nuclear Materials 296, pp.129- 138, 2001. 
29. T.S. Byun, K. Farrell, E.H. Lee, L.K. Mansur, S.A. Maloy, M.R. James, W.R. Johnson, Temperature effects on the mechanical properties of candidateSNS target container materials after proton and neutron irradiation, Journal of Nuclear Materials 303, pp.34-43, 2002.

30. S. Saito, K. Kikuchi, K. Usami, A. Ishikawa, Y. Nishino, M. Kawai, Y. Dai, Tensile properties of austenitic stainless steels irradiated at SINQ target 3, Journal of Nuclear Materials 343, pp.253-261., 2005

31. Boyer, H. E. (editor), Atlas of Stress-Strain Curves, ASM International, Metal Park, OH, p. 291, 1987. (Source: Metals Handbook, Ninth Edition, Vol. 3, Properties and Selection, Stainless Steels, Tool Materials, and Special-Purpose Metals, American Society for Metals, Metal Park OH, p.17, 1978)

32. Boyer, H. E. (editor), Atlas of Stress-Strain Curves, ASM International, Metal Park, OH, p.294, 1987. (Source: Metals Handbook, Ninth Edition, Vol. 8, Mechanical Testing, American Society for Metals, Metal Park, OH, p.35, 1985)

33. Rempe, J. L., S. A. Chávez, G. L. Thinnes, C. M. Allison, G. E. Korth, R. J. Witt, J. J. Sienicki, S. K. Wang, L. A. Sticker, C. H. Heath, and S. D. Snow, "Light Water Reactor Lower Heat Failure Analysis,” NUREG/CR-5642, EGG-2618, Idaho National Engineering Laboratory, October 1993.

34. Metal Handbooks, Ninth Edition, Volume 8, Mechanical Testing, American Society for Metals, Metals Park, OH, 1985, p.34.

35. An International Code 2007 ASME Boiler \& Pressure Vessel Code, Section II, Part D (Customary) Materials, 2007 Ed., pp. 517-524 and pp. 642-654, July 1, 2007.

36. Pei-Yuan Cheng, Influence of Residual Stress and Heat Affected Zone on Fatigue; Failure of Welded Piping Joints, Thesis submitted to the Graduate Faculty of North Carolina State University in partial fulfillment of the requirements for the Degree of Doctor of Philosophy Civil Engineering Raleigh, North Carolina, 2009.

37. Kang et al., Non-proportionally multiaxial ratcheting of cyclic hardening materials at elevated Temperatures: Experiments and simulations, Mechanics of Materials 37, pp. 1101-1118, 2005.

38. T.S. Byun, N. Hashimoto, K. Farrell, Temperature dependence of strain hardening and plastic instability behaviors in austenitic stainless steels, Acta Materialia 52, pp. 3889-3899, 2004.

39. Jin Weon Kim, Thak Sang Byun, Analysis of tensile deformation and failure in austenitic stainless steels: Part I - Temperature dependence, Journal of Nuclear Materials 2396, pp.1-9, 2009.

40. Jin Weon Kim, Thak Sang Byun, Analysis of tensile deformation and failure in austenitic stainless steels: Part II - Irradiation dose dependence, Journal of Nuclear Materials 2396, pp.10-19, 2009

41. S.A. Chavez, G.E. Korth, D.M. Harper, High-temperature tensile and creep data for Inconel 600, 304 stainless steel and SA106B carbon steel, Nuclear Engineering and Design 148, pp.351-363, 1994 
42. Chaouadi, R., M. Scibetta, R. Van Nieuwenhove, B. Smolders, M. Weber, and M. Willekens, "Irradiation Creep Inducing Stress Relaxation of Precipitation Hardened Inconel 718 Exposed to 0.5 dpa at $300^{\circ} \mathrm{C}$," Final Report BLG-843, April 2000.

43. Foster, J. P., K. Bunde, M. L. Grossbeck, and E. R. Gilbert, "Temperature dependence of the $20 \%$ cold worked 316 stainless steel steady state irradiation creep rate," Journal of Nuclear Materials 270, pp.357-367, 1999.

44. Garner, F. A., M. B. Toloczko, and B. H. Sencer, "Comparison of swelling and irradiation creep behavior of fcc-austenitic and bcc-ferritic/martensitic alloys at high neutron exposure," Journal of Nuclear Materials 276, pp.123-142, 2000.

45. Kurata, Y., Y. Itabashi, H. Mimura, T. Kikuchi, H. Amezawa, S. Shimakawa, H. Tsuji, and M. Shindo, "In-pile and post-irradiation creep of type 304 stainless steel under different neutron spectra," Journal of Nuclear Materials 283, pp.386-390, 2000.

46. Foster, J. P., K. Bunde, and D. L. Porter, "Irradiation creep of annealed 304L stainless steel at low dose levels," Journal of Nuclear Materials 317, pp.167-174, 2003.

47. Chung, H. M., and W. H. Cullen, Jr., "Assessment of Void Swelling in Austenitic Stainless Steel Core Internals,” NUREG/CR-6897, ANL-04/28, Argonne National Laboratory, January 2006.

48. Margolin, B. Z., A. G. Gulenko, I. P. Kursevich, and A. A. Buchatskii, "Modeling for Fracture in Materials under Long-term Static Creep Loading and Neutron Irradiation, Part 2, Prediction of Creep Rupture Strength for Austenitic Materials," Strength of Materials, Vol. 38, No. 5, pp. 449-457, 2006.

49. D.L. Porter, G.D. Hudman, and F.A. Garner, Irradiation creep and swelling of annealed Type 304 stainless steel at $\sim 390^{\circ} \mathrm{C}$ and high neutron fluence, Journal of Nuclear Materials 179-181, pp.581584, 1991.

50. Johsei Nakagawa, Calculation of radiation-induced creep and stress relaxation, Journal of Nuclear Materials 225, pp.1-7, 1995.

51. F.A. Garner, M.B. Toloczko, and M.L. Grossbeck, The dependence of irradiation creep in austenitic alloys on displacement rate and helium to dpa ratio, Journal of Nuclear Materials 258-263, pp.17181724, 1998.

52. John Paul Foster, Kermit Bunde, M.L. Grossbeck, and E. Robert Gilbert, Temperature dependence of the $20 \%$ cold worked 310 stainless steel steady state irradiation creep rate, Journal of Nuclear Materials 270, pp.357-367, 1999.

53. J.E. Flinn, CL. McVay and L.C. Walters, In-Reactor Deformation of Solution Annealed Type 304L Sainless Steel, Journal of Nuclear Materials 65, pp.210-223, 1977.

54. G.L. McVay, L.C. Walters and G.D. Hudman, Neutron Irradiation-Induced Creep of Helium Pressurized 304L Stainless Steel Capsules, Journal of Nuclear Materials 79, pp.395-405, 1979.

55. John Paul Foster, Kermit Bunde, and Douglas L. Porter, Irradiation creep of annealed 304L stainless steel at low dose levels, Journal of Nuclear Materials 317, pp.167-174, 2003. 
56. Karl Ehrlich, Irradiation Creep and Interrelation with Swelling in Austenitic Stainless steels, Journal of Nuclear Materials 100, pp.149-166, 1981.

57. Johsei Nakagawa, Calculation of radiation-induced stress relaxation, Journal of Nuclear Materials 212-215, pp.541-545, 1994.

58. A.F. Rowcliffe, L.K. Mansur, D.T. Hoelzer, R.K. Nanstad, Perspectives on radiation effects in nickel-base alloys for applications in advanced reactor, Journal of Nuclear Materials 392, pp.341$352,2009$.

59. Ji-Jung Kai and R.D. Lee, Effects of irradiation on the microstructure of INCONEL 600 alloy, Journal of Nuclear Materials 191-194, pp.717-721, 1992.

60. Ji-Jung Kai and R.D. Lee, Effects of proton irradiation on the microstructural and microchemical evolution of Inconel 600 alloy, Journal of Nuclear Materials 207, pp.286-294, 1993.

61. T.S. Byun, K. Farrell, Tensile properties of Inconel 718 after low temperature neutron irradiation, Journal of Nuclear Materials 318, pp.292-299, 2003.

62. Moen, R. A., K. R. Wheeler, and J. E. Irvin, "Evaluation of Inconel 718 for application in the fast test reactor," Battelle Memorial Institute, Pacific Northwest Laboratory, Richland, BNWL-930, December 1968.

63. Morize, P., J. Baicry, and J. P. Mardon, "Effect of irradiation at $588 \mathrm{~K}$ on mechanical properties and deformation behavior of zirconium alloy strip," Zirconium in the Nuclear Industry: Seventh International Symposium, ASTM STP 939, R. B. Adamson and L. F. P. Van Swam, Eds., ASTM, pp.101119, 1987.

64. Taylor, R. and T. Jeffs, "The effect of irradiation on stress relaxation in Nimonic 80A," Journal of Nuclear Materials, Vol. 19, pp.142-148, 1966.

65. Böhm, H., H. Hauck, W. Leo, and C. Wassilew, "Postirradiation creep rupture properties of austenitic stainless steel and nickel-base alloys," Journal of Nuclear Materials 33, pp.343-346, 1969.

66. Paxton, M. M., B. A. Chin, E. R. Gilbert, and R. E. Nygren, "Comparison of the in-reactor creep of selected ferritic, solid solution strengthened and precipitation hardened commercial alloys," Journal of Nuclear Materials 80, pp.144-151, 1979.

67. Causey, A. R., G. J. C. Carpenter, and S. R. MacEwen, "In-reactor stress relaxation of selected metals and alloys at low temperatures," Journal of Nuclear Materials 90, pp.216-223, 1980.

68. Garzarolli, F., D. Alter, P. Dewes, and J. L. Nelson, "Deformability of austenitic stainless steels and Ni-base alloys in the core of a boiling and a pressurized water reactor," Proceedings of the Third International Symposium on Environmental Degradation of Materials in Nuclear Power Systems, G. T. Theus and J. R. Weeks, Eds., The Metallurgical Society, Inc., pp. 657-664, 1988.

69. IFE/HRP Drawings No. 388591 (INL Test-unit Assembly), No. 388592 (INL Test unit End Plug), No. 388593 (INL Test unit Core Holder), No. 388595 (INL Test unit Bellows Assembly), April 6, 2009. 
70. Abaqus, Version 6.8-2, Build ID 2008_07_21-07.21.56 87172, Dassault Systems Simulia Corporation, Providence, Rhode Island, 2008.

71. Tyler, C., personal communication with D. Knudson, Idaho Falls, Idaho, 2009.

72. Purohit, A., and J. R. Moszynski, "Thermal Conductivity of the Helium-Argon System," ANL-79-3, Argonne National Laboratory, Argonne, Illinois, 1979.

73. CRC Handbook of Tables for Applied Engineering Science, Second Edition, R. E. Bolz and G. L. Tuve, Editors, Cleveland, Ohio, 1976.

74. Touloukian, Y. S., et. al., Themophysical Properties of Matter, Vol. 1, p. 1023, curve 21, IFI/Plenum Publishing, New York, 1970.

75. Touloukian, Y. S., et. al., Themophysical Properties of Matter, Vol. 2, p. 119, IFI/Plenum Publishing, New York, 1970.

76. Holman, J. P., Heat Transfer, Fourth Edition, McGraw-Hill Inc., New York, 1976.

77. Touloukian, Y. S., et. al., Themophysical Properties of Matter, Vol. 7, p. 1354, curve 39, IFI/Plenum Publishing, New York, 1970.

78. Touloukian, Y. S., et. al., Themophysical Properties of Matter, Vol. 7, p. 1228, curve 2, IFI/Plenum Publishing, New York, 1970.

79. Parry, J., personal communication with D. Knudson, Idaho Falls, Idaho, 2009. 